دور الخدمات البلدية في التنمية الاقتصادية المحلية*

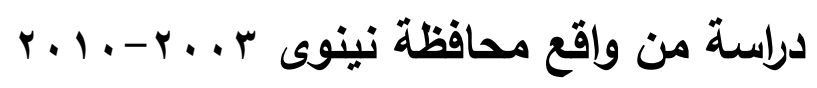

$$
\text { د. دأنوفل قاسم علي الثهوان }
$$

قسم الدراسات الاقتصادية والاجتماعية/ مركز الدراسات الإقليمية/ جامعة الموصل

$$
\text { مستخلص البحث }
$$

تهدف الدراسـة إلى تحليل دور الخدمات البلايسة العامـة في التنميـة الاقتصـادية

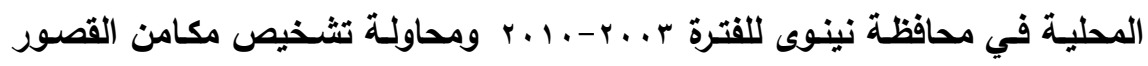

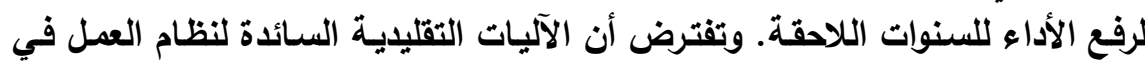

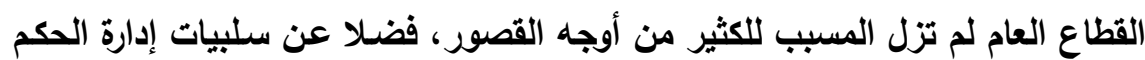

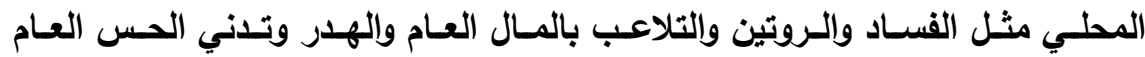

بالمسؤولية والمراقبة والمحاسبة.

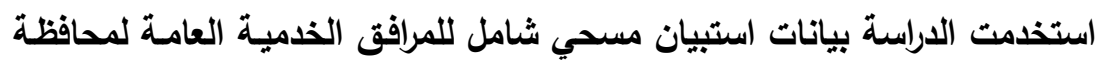

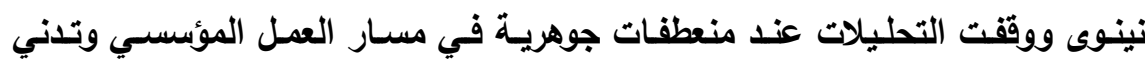

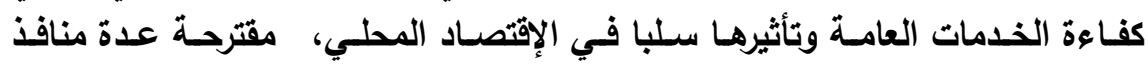
للمعالجات الفورية الملحة والتصحيح للأجل القريب.

كلمات مفتاحية: الخدمات البلاية، القطاع العام، التتمية الإقتصادية، بلايـة الموصل،

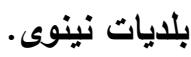

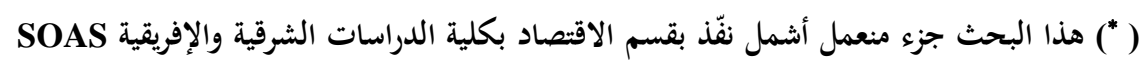

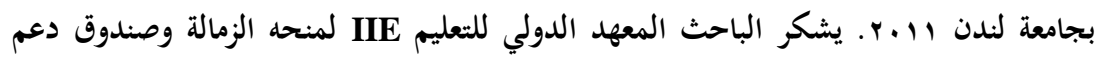

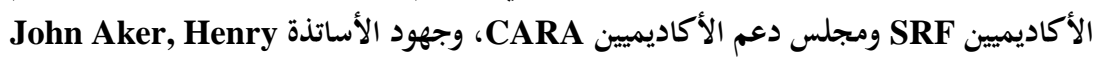
Matheu Graven and Debourah والأساتذة Jeraccy and Kate Robertson عميد الكلية ومعاونته وكذلك Jahnston

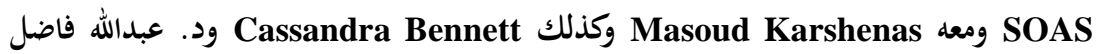

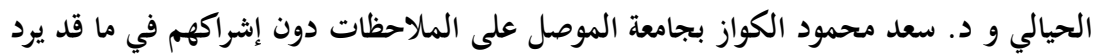
من آراء، وأي خطأ هو من مسؤولية الباحث. 
تدنت معظم مؤشـرات أداء اقتصـاد العـراق بشـكل مستمر طوال العقود

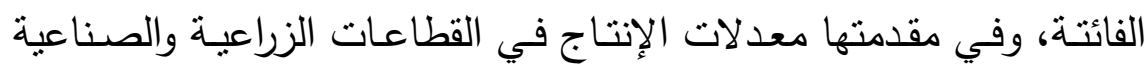
التحويلية والخدماتيـة، بسبب الاعتمـاد على العوائد الريعية والتوجهات غير فيرات

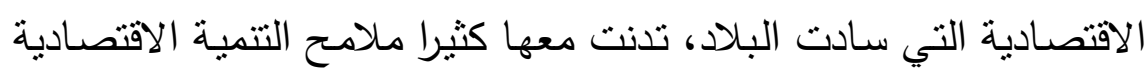
(Alnasrawi 1994)(') والبشرية، حتى باتت بدهية في النشريات الرسمية.

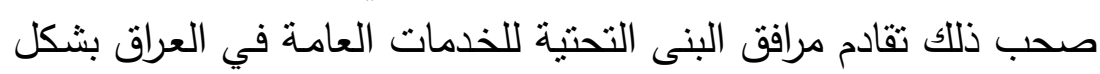

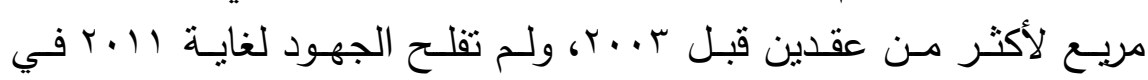

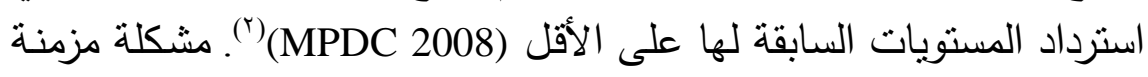

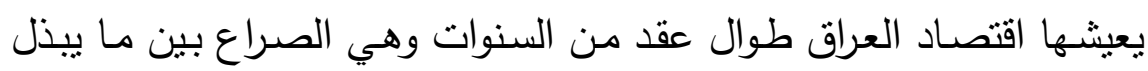

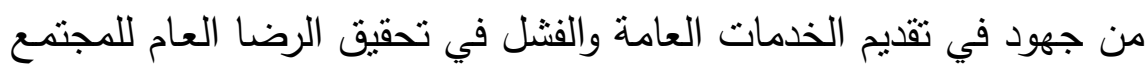

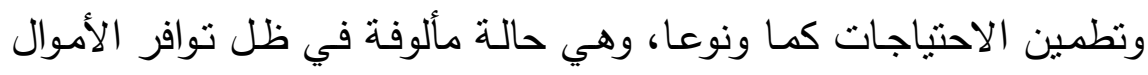

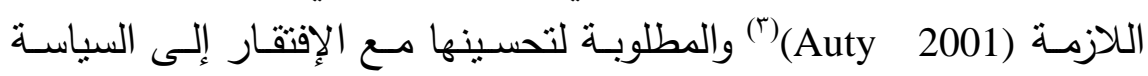

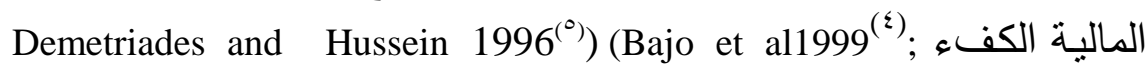
(Ashure2005 .Dlamini1988 $\left.8^{(\vee)}\right)$

الصلة بين نمو الإقتصاد والتأهيل الثامل للبنى التحنية المنتجة للخدمات البلدية العامة في مجالات مياه الثرب وشبكات الصرف الصحي والمجاري

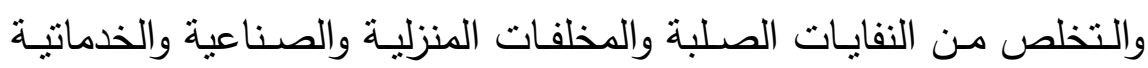

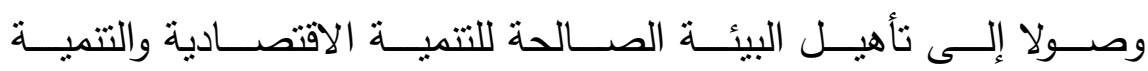
(World Bank 2011

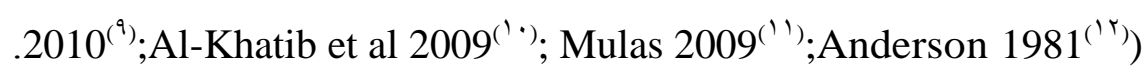
تهـدف الدراسـة إلـى تحليـل دور الخـدمات البلديـة العامـة فـي التتميـة الاقتصادية المحلية في ضوء مناقشة واقع قطاع الخدمات المحلية ومؤشرات

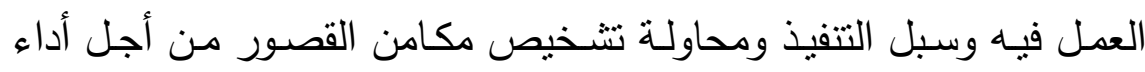




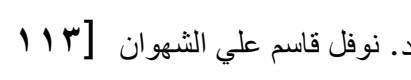
دور الخمات البلدية في التنمية.

كفء ويسهم بفاعلية للسنوات القادمة، من خلال واقع المشكلة وجوانبها في

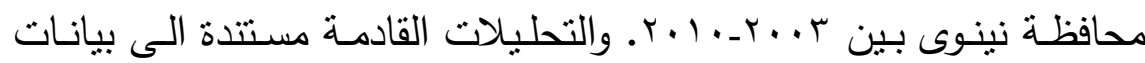
استبيان متفرد لهذه المدة.r'). تفترض المؤشرات الأولية أن الآليات التقليديـة السـائدة لنظـام العمل في

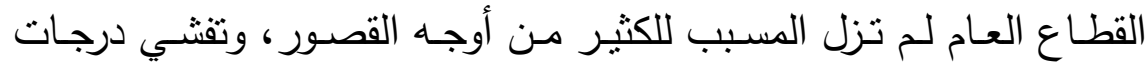
متفاقمة من السلبيات في كل مفاصل الدولة، منل: الروتين والتلاعب بالمال العام والهدر وتدني الحس العام بالمسؤولية والمراقبة والمحاسبة وغيرها من من لـن القيود الأمنية والكفاءة الإدارية والقيادية.

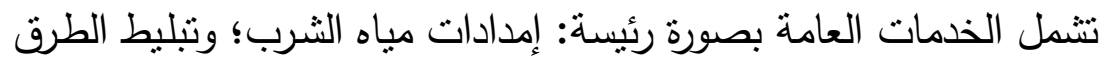

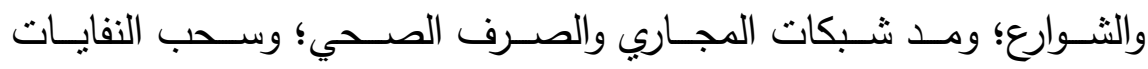

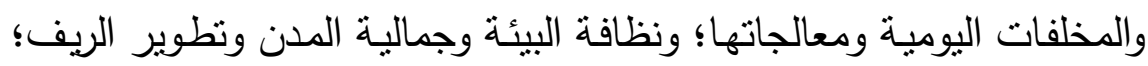

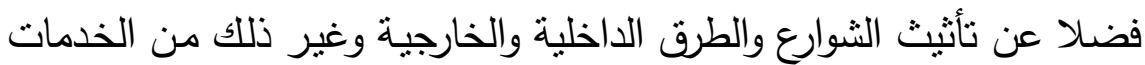

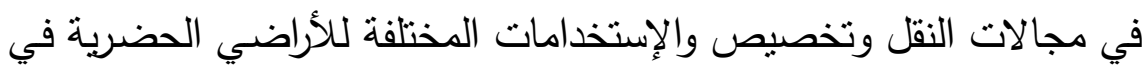

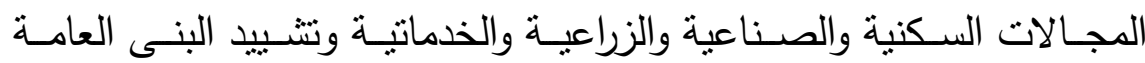

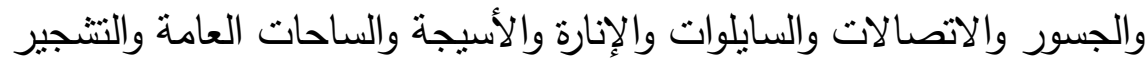

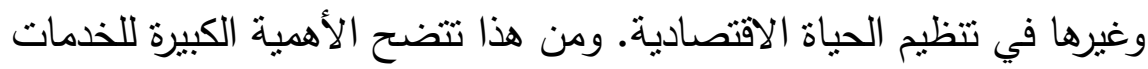
البلدية العامة في الاقتصاد وتتميته. بل أنها حجر الزاوية في المراحل الأولى

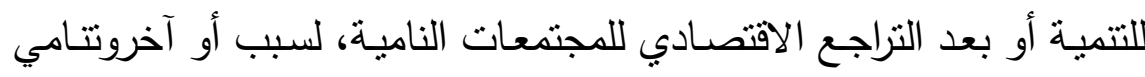

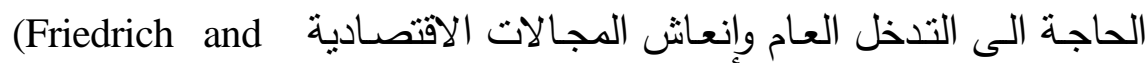

(') $\mathrm{Nam}$ 2009)

تثتـاول الدراسـة بالتحليل خمسـة جوانب عدت المداخل الرئيسـة للتحليل

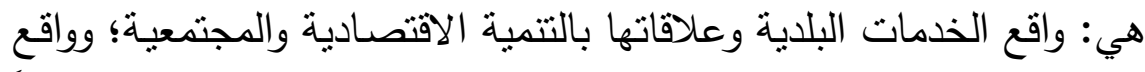

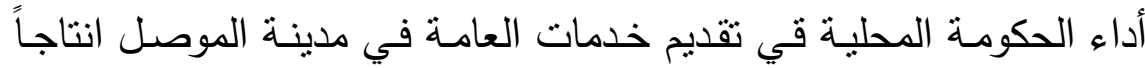
وصناعةً وتخطيطاً ومعالجةًً؛ واتجاهاتها في بلديات أقضية نينوى ونواحيها

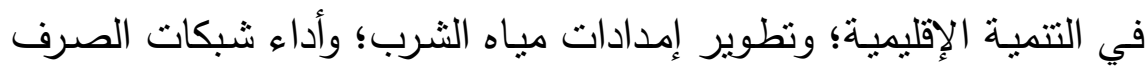


الصـحي، وبيئة الحيـاة الملائكسة للتتميـة الاقتصـادية في المسدن والنـواحي والأرياف.

شخصـت الدراسـة في مجـالات التمويـل، مـن بـين عدة إثـكالات حيـود

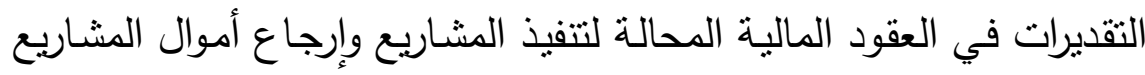
غير المنفذة إلى الدولة وواقع المشاريع الكلية المنفذة في أدائها الاقتصادي

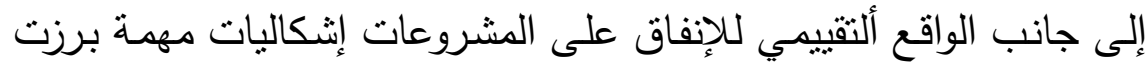
في طريق التتمية المحلية.

تعتمد معظم تحليلات الدراسـة في بياناتها على استبيان محافظة نينوى لعام

2010 الذي شـارك فيـه الباحث بتحليلاته في اعداد الخطة الاستراتيجية "روئية نينوى 2030" عام 2010 في وضعها (Nineveh Governorate 2010)

1- الخدمات البلاية والتتمية الاقتصادية والمجتمعية

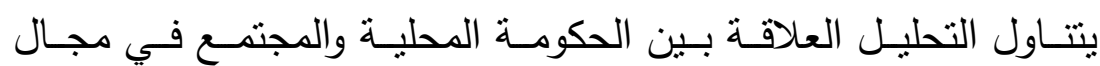

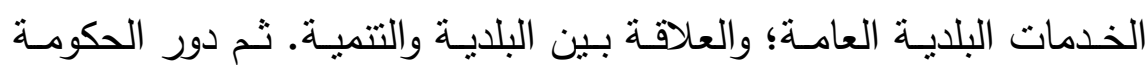

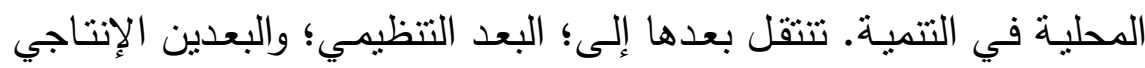
والصناعي للخدمات؛ والى التخطيط البلدي للخدمات. وتتوقف عند: طبيعة إعدة

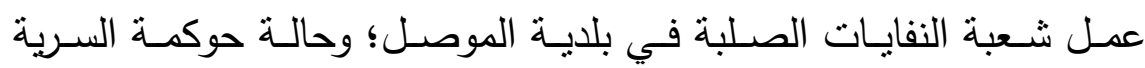

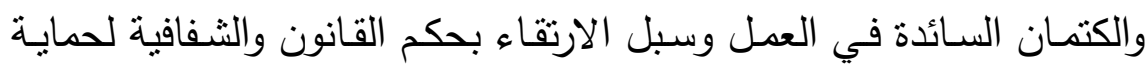
العمل بدل هذا التقليد.

\section{1- العلاقة بين الحكومة المحلية والمجتمع}

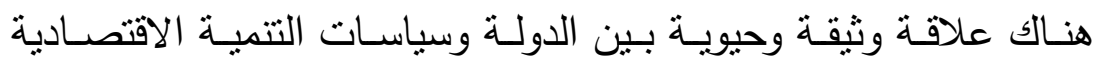

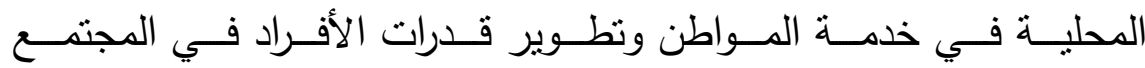
(Bartik1991)(7'). ومديرية بلدية الموصل من البلديات المعنية بقوة بالتتمية ولفية

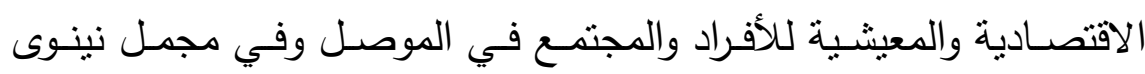




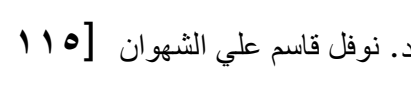
دور الخدمات البلدية في التتمية.

والنـواحي والأريـاف. وعملهـا يعبـر عـن دور الحكومـة المحليـة فـي تقديم الخدمات العامة. من هذه النظرة تتضح الأهمية الركنية للوظائف البلدية في دوري

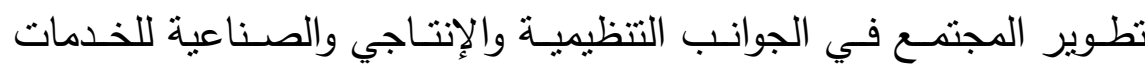
البلديـة العامـة. وطبيعي أن تقوم الجهود على التخطيط البلدي للخدمات.

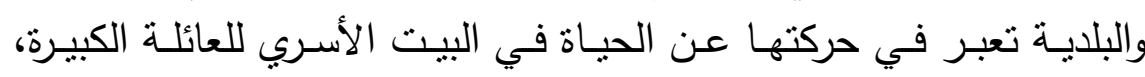

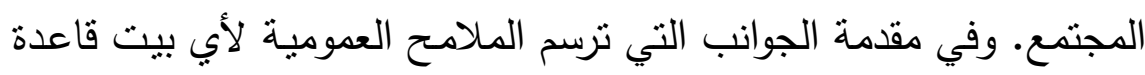
النظافة التي يعمل بها، وهذه القاعدة لأية بلدية هي شعبة النفايات الصلبة. ولا يكتمل الحكم على جودة وتقدم هذه القاعدة بدون مقارنتها مع نظيراتها.

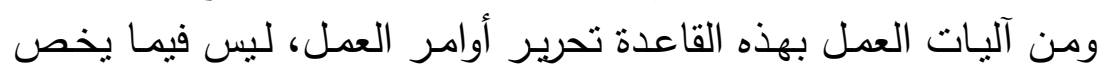

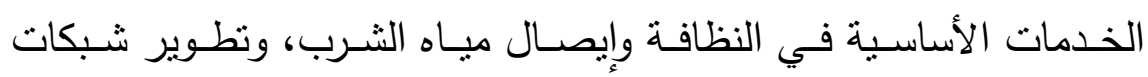

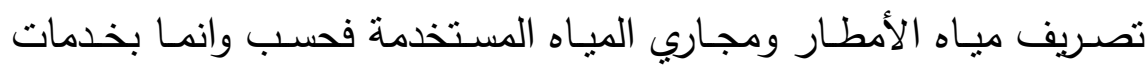

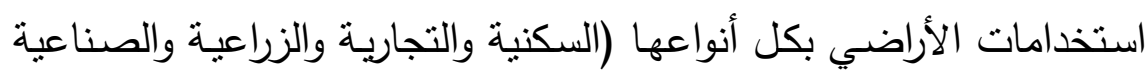
ومدافن الموتى). وهي جميعا تقربيا تخضـع للتصرف التجاري بين شـرائح

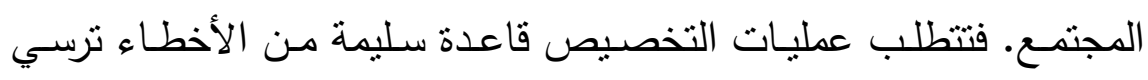
دعائم العدالة الاجتماعية من اجل تفرّغ المجتمع للبناء الصحيح والرصين.

\section{ا ب- العلاقة بين البلاية والتطوير والتنمية}

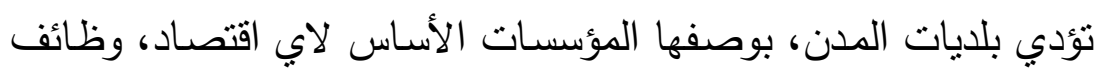
تبدو طبيعية وسهلة. وفي الواقع، وكما هو معلوم فإن تلك الوظائف معقدة بلدي

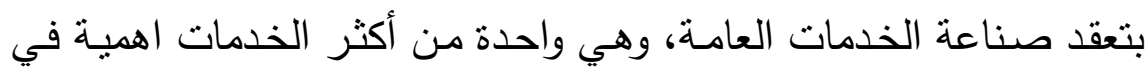

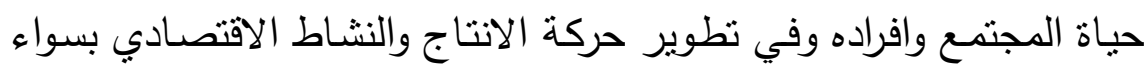
(Eichengreen 1996) البلديات على صناعة كل الخدمات المحلية العامـة الأخرى وعلى نوعيتها

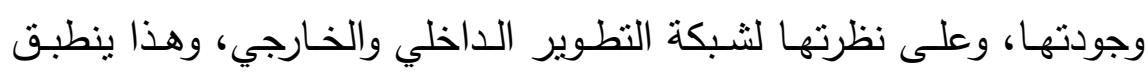
تماما اقتصاد نينوى، موقعاً وتتوعاً. 
الخـدمات البلديـة صــناعة حيويـة تضـم تصـميم وتطـوير اسـس النــو

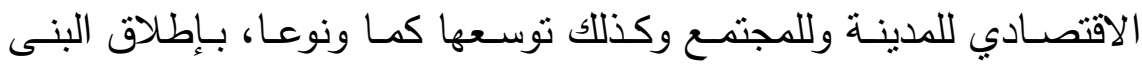
التحتية والفوقية العامة. وتتشمل: بدءا تمليك قطع الأراضي العامة (السكنية

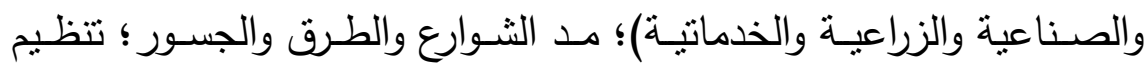

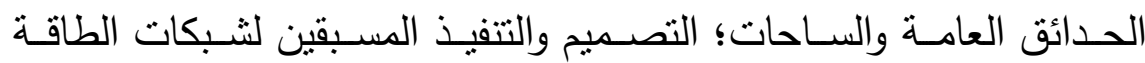

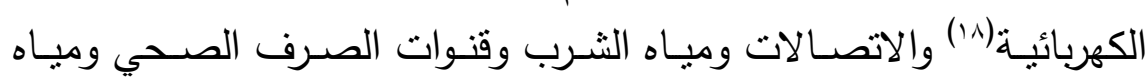
الأمطار ؛ ثم تواصل خدمات الصيانة والتأثنث للمدينة من علامات ولهـات ولوحات

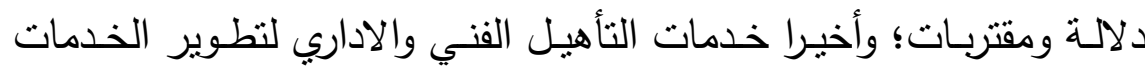
العامة للحكومة المحلية.

\section{بلدية الموصل}

كانـت بلديـة الموصـل، ومنـذ نشـأتها في مطلـع القرن العشـرين، مركز

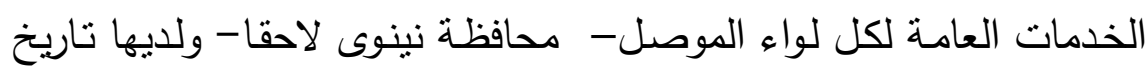
كبير من المنجزات والتميز في الكفاءة والتطوير على مستوى العراق طوال

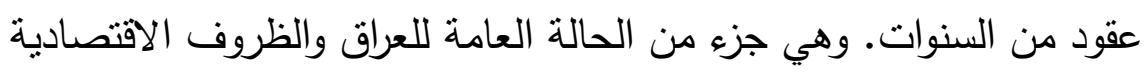

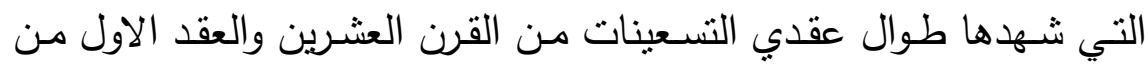

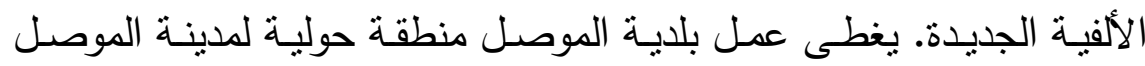

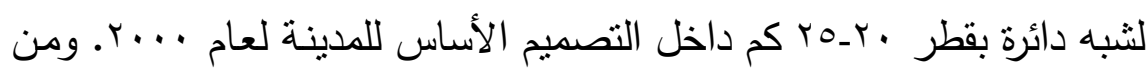

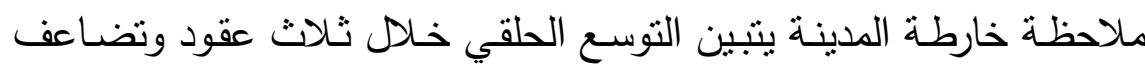
عدد السكان مرّتين ونصف المرّة ثقريبا، من سبعمائة الف نسمة في سبعينات

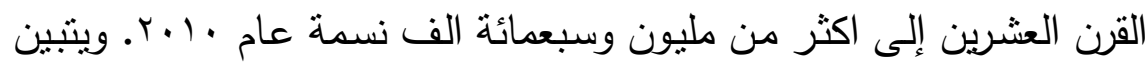
كذلك النمو الجغرافي الثرقي اكثر من الجانب الغربي.

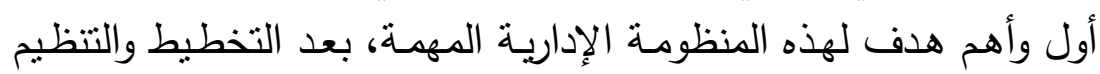
وتخطيط التتمية الاقليمية (Al-Kahtani 1989)(19) هو تنليط الثوارع والطرق

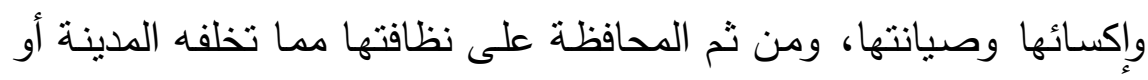


تلفظه من نفايات وانقاض ليل نهار • وهذا الهدف ليس مجرد واجب، فهو يضفي على المدينة وصفها ويعبر عن طبيعتها شكلا وعن طابع الحياة فيها وكذلك مرحلة تقدم المجنمع. لا شك أن لذلك أهمية كبيرة في حركة السكان اجتماعيا واقتصاديا وعمليا، واندفاعا في نشاطهم الانتاجي والعملي. فكلما بلغت المقتربات والطرق العامة درجة أعلى من الجودة والنظافة كلما دل ذلك، ليس على حيوية الحياة ونوعية

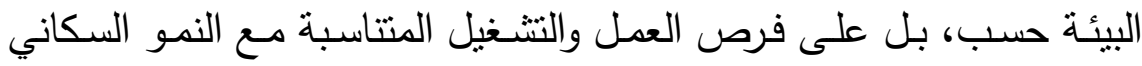
وتشغيل الفئات العمرية الثابة خارج التعليم كلك. بلك.

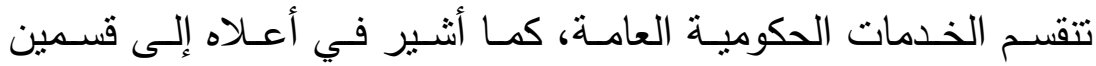

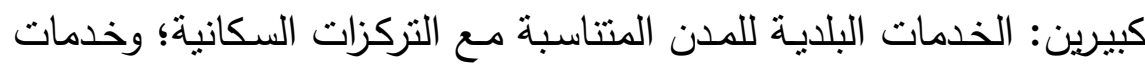
البنـى التحتيـة والفوقيـة المتتاسبة مـع البيئة السـليمة لعمـوم الرقعـة للإقليم المحلي. وفي مراحل التتميـة الاقتصـادية المتقدمة تحتل التجارة الخارجيـة تتظيما ورسـوما وتواصـلا حيزا مهمـا في الاقتصـاد الدولي للبلد. وتأتي بالأهميـة الثانويـة تحريك النمو الاقتصـادي في استقطاب الإهتمـام المحلي للأنشطة الاقتصادية. الاطار الثاني هو ما يفترض ان تركز عليه اعمال البلدية في

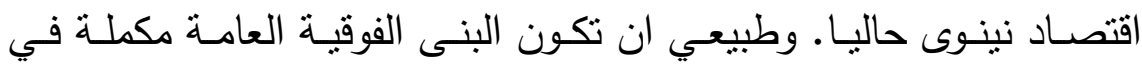

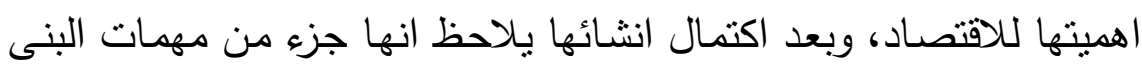

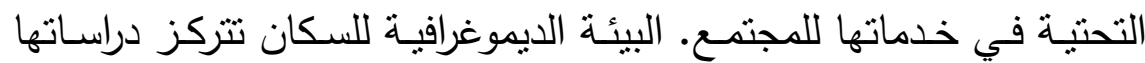

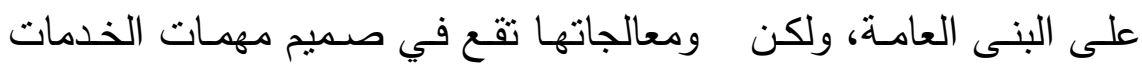
البلدية، من نظافة التربة ونقاوة الجو والمياه من الملوثات. لها علاقة مؤكدة بالنمو الاقتصادي ضمن الدور الخدماتي للأعمال البلدية.

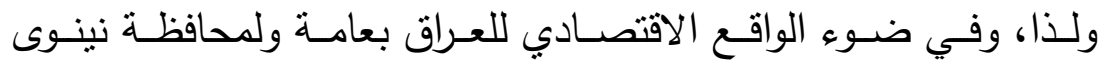

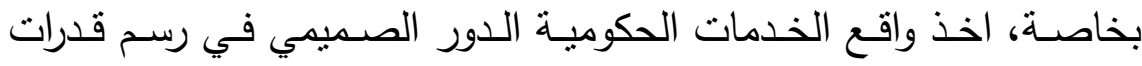
الحكومـة المحليـة في الإدارة الاقتصـادية. اتسـم ذلك الدور ببعدين، همـا: 
الخـمات البلديـة العامـة بالنسبة للبيئة؛ والبنـى التحتبـة والخـدمات العامـة

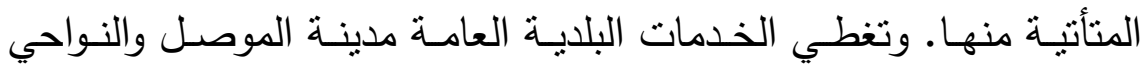

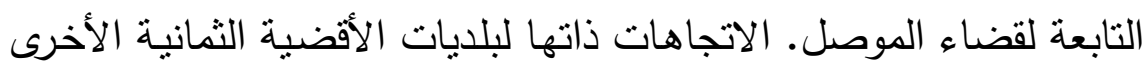

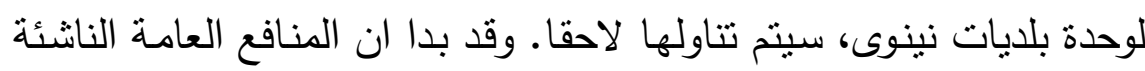

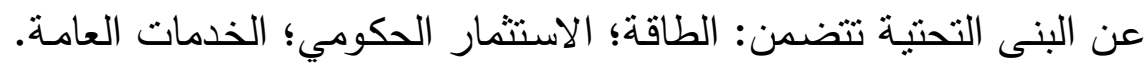

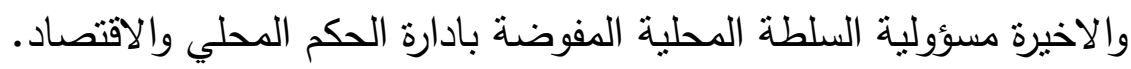

\section{التشغيل في الخدمات العامة}

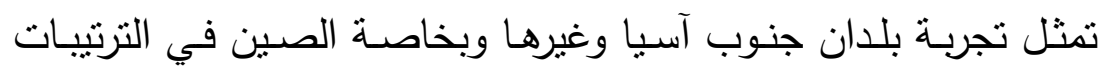

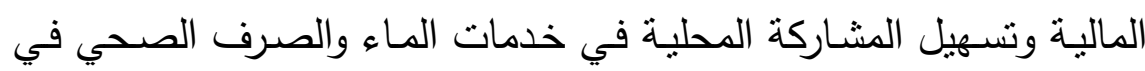

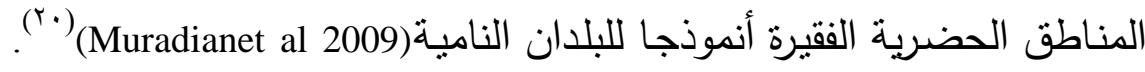

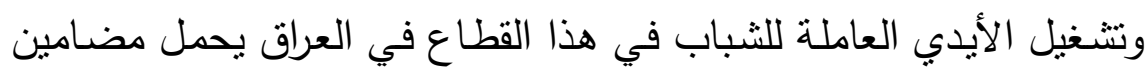
اقتصادية عديدة، هي: الايدي العادية 1- مصدر دخل بالغ الأهمية للعمل غير الماهر. r- حفظ مجتمع الثباب بعامة من مزالق الفراغ ومعانات الأهن البطالة.

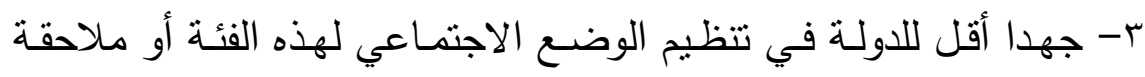
مشكلاتهم الاجتماعية والسلوكية.

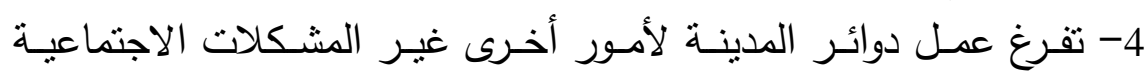

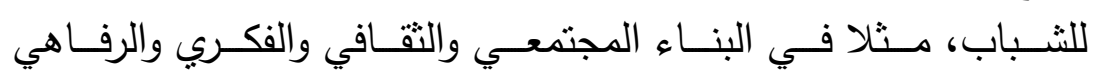
والتنظيمي.. الخ.

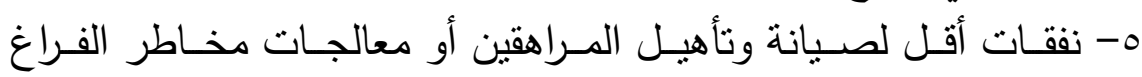
والاستهلاك بدون إنتاج أو عائد على العمل. 
צ- تخفيف العبء على ميزانية الحكومـة في الرعاية الاجتماعية ودعم حد

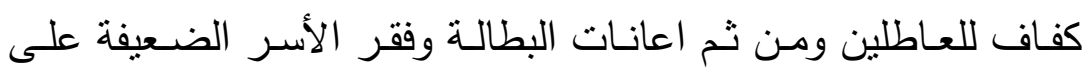
اساس ان كل عاطل يعني أسرة ضعيفة الحال. V- وفورات اجتماعية لبيئات عمل القطاعات الانتاجية. ^- سرعة تدوير المخلفات ومعالجاتها لتخفيض مصادر الأمراض وتدهور

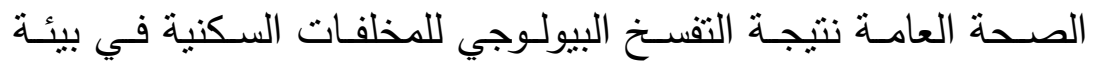
مرتفعة الحرارة تصل في الظل ".0 وتحت الثمس اكثر من · •و في الصيف. مرنه

9- توفير مبالغ كبيرة تتفق على الصحة العامة.

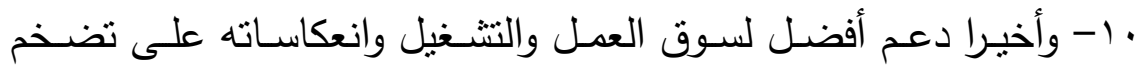
الأسعار ايجابا كلما تقلصت الفجوة بين العرض الكلي للخدمات العامة والطلب الكلي عليها.

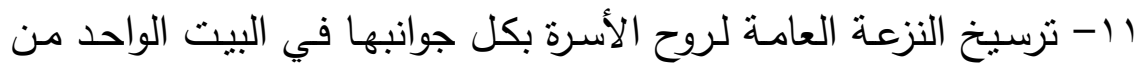
بناء وإسهام وتفاعل وصيانة وتطوير وتتمية قدرات وروابط.. الخ.

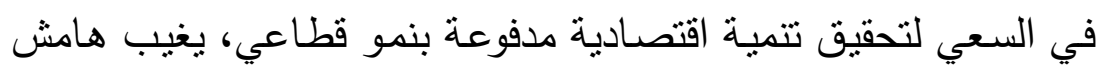

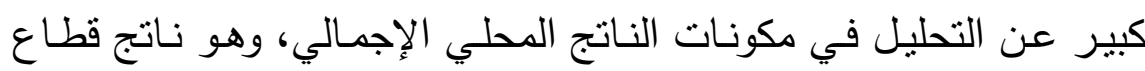

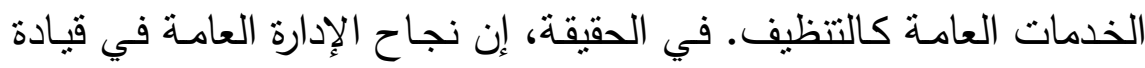

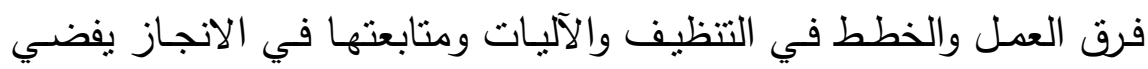

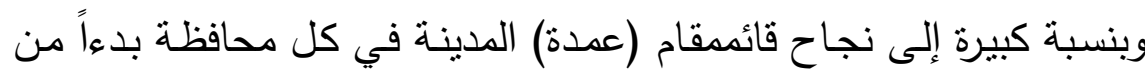
المدينة العاصمة إلى المراكز الحضرية الأخرى. هذه قناة مهمة غير مباشئرة للتتمية الاقتصادية، يتغاضى المعنيون عن أهميتها. البيئة والتشغيل في الأنشطة البلدية هما حجري الزاوية في التنمية المادية والمجتمعية، وهما يرفعان تأهيل وظائف المدينة لخلق فرص العمل وتتمية التهية

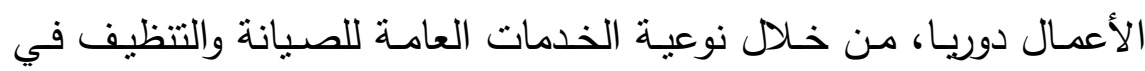

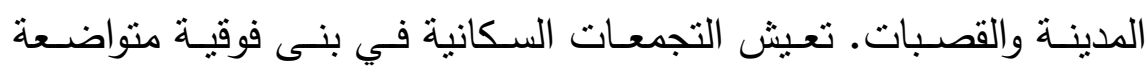




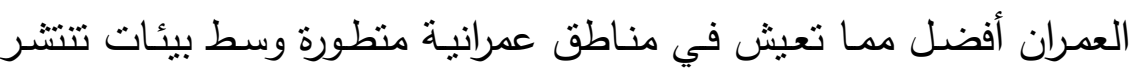

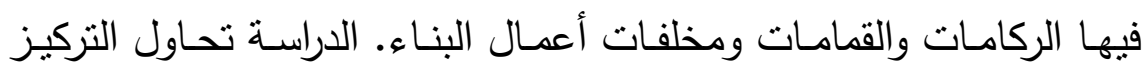

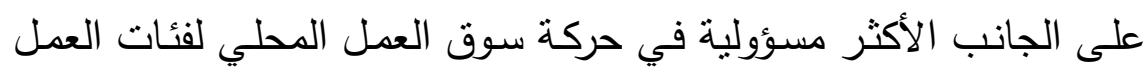

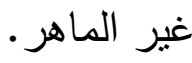

\section{r- واقع الحكومة المحلية في تقديم الخدمات العامة}

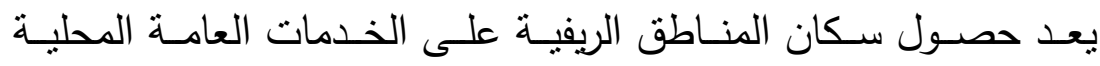

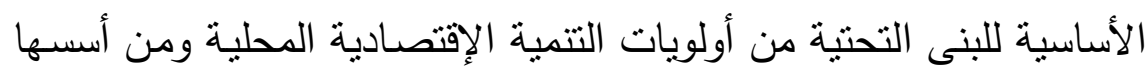

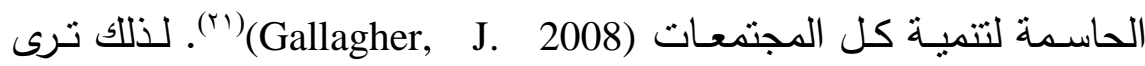

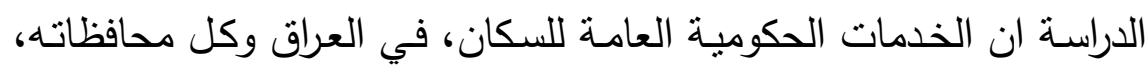
تتنمل البنى الآتية مقسمة في اطارين، هما:

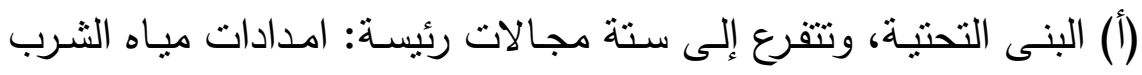

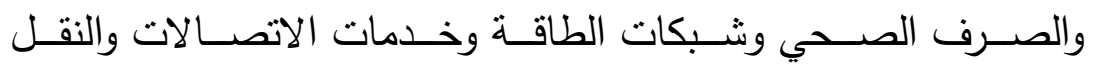

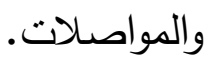

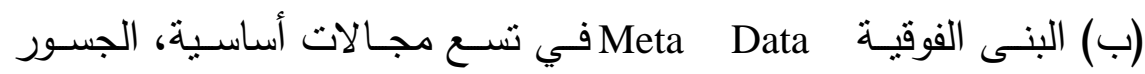
والسايلوات والاسكان والصحة والتعليم وخدمات البيئة والزراعة والصناعة الصاتة

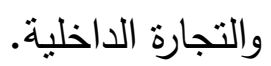

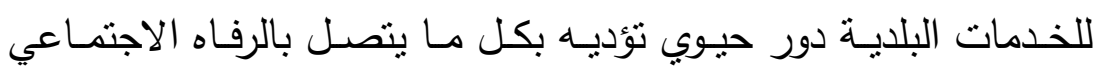

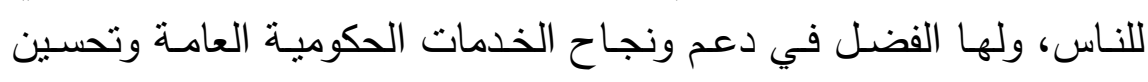

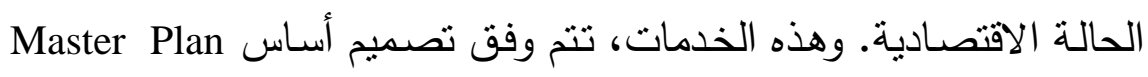

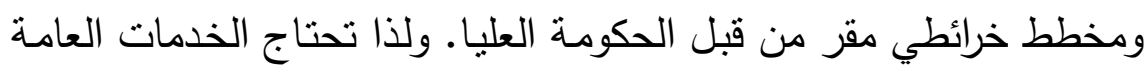

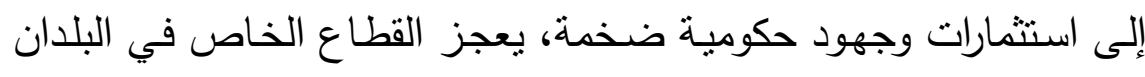

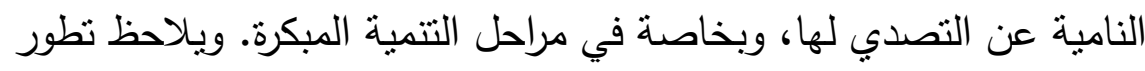

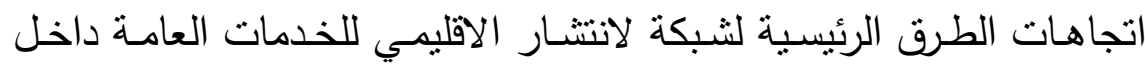

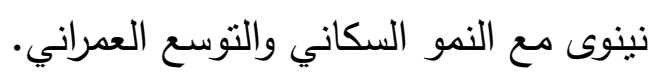




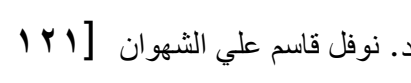
دور الخدمات البلدية في التتمية.

r- 2 - r البعد التنظيمي

يثير الهيكل التنظيمي لمديرية بلدية الموصل إلى بلدية المركز (الصنف

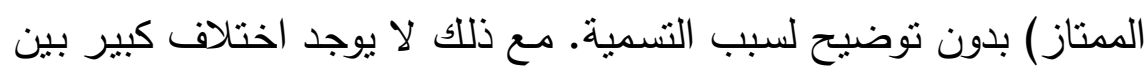

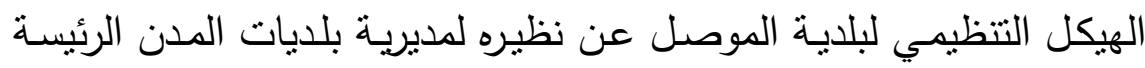
الأخرى للأقضية التابعة لمحافظة نينوى، والأخير موحد لكل البلديات. وهذا

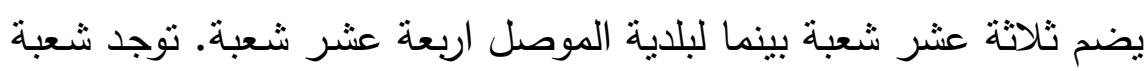

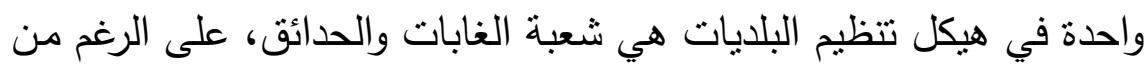

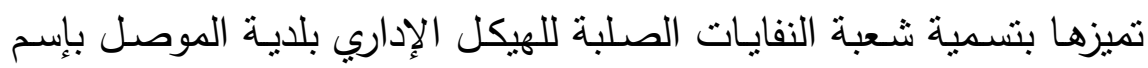
شعبة البيئة.

يتضح من الملاك غياب شعبة البيئة عن بلدية الموصل واهتمام بلديات

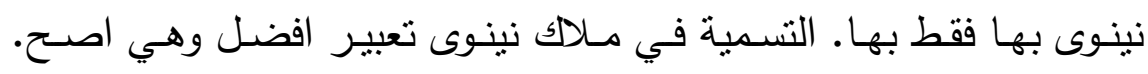

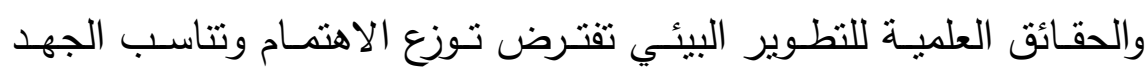

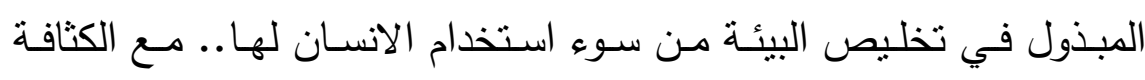

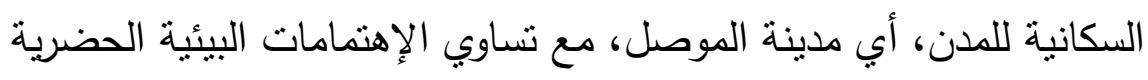

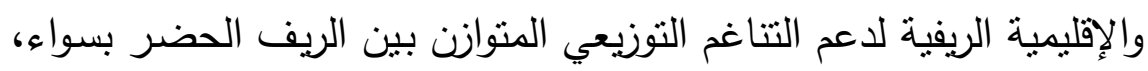
مع فارق خدمات الأسواق الكبيرة فقط.

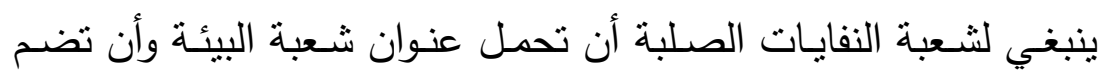

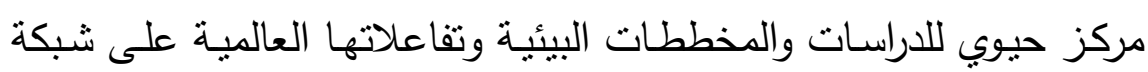
المعلومات ووسائط الإعلام الأخرى. هذا يدفع بالتقافة البيئية لكل منتسبي

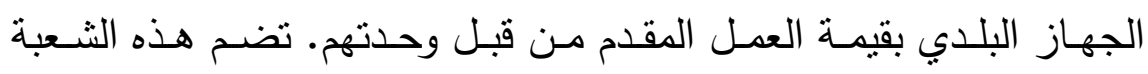

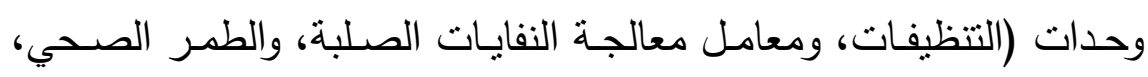
والمجـازر) ف في حين، تضـم بلـديات محافظــة نينـوى وحـدات (الحـدائق

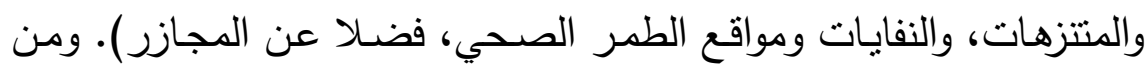
الضروري تصويب تسمية هذه الشعبة في بلدية الموصل وتغييره إلى "ثعبة الثبة 
البيئة" وأن تضم وحدة أخرى بإسم وحدة دراسـات وتطوير البيئة، والحالة

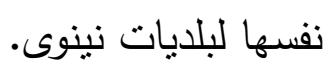

يبدو ان الإهتمامات الوظيفية بالجانب النتكيلي في هذه المديريات أكثر

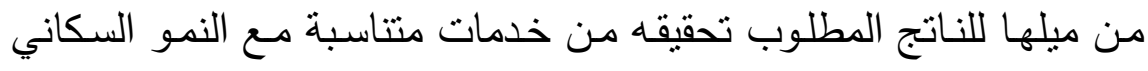

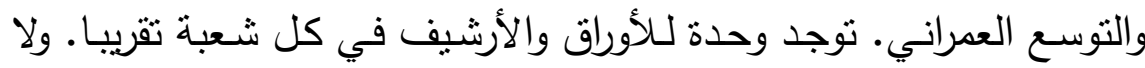

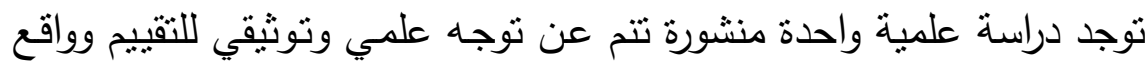

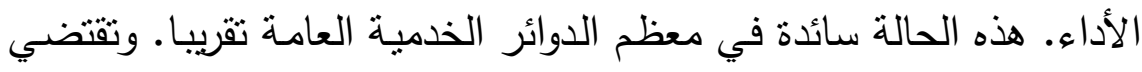

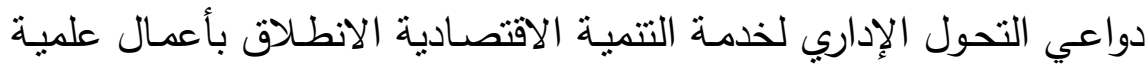

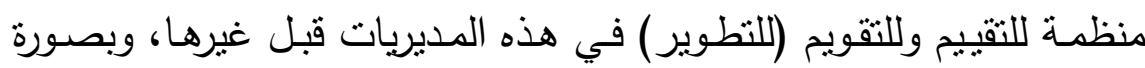

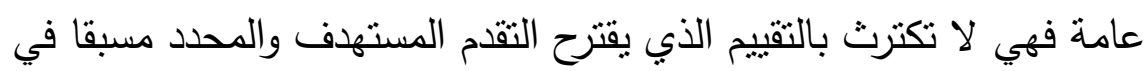

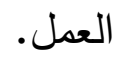

\section{r r-r البعد الإنتاجي والصناعي}

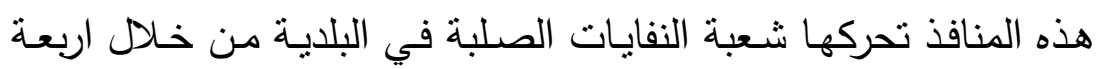

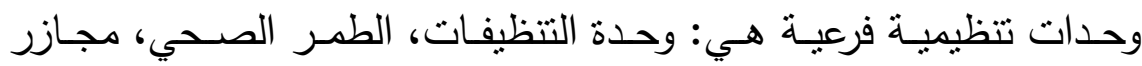

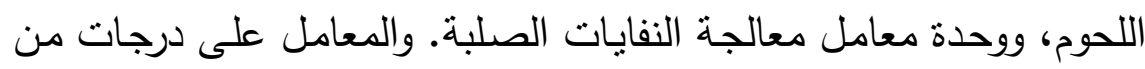

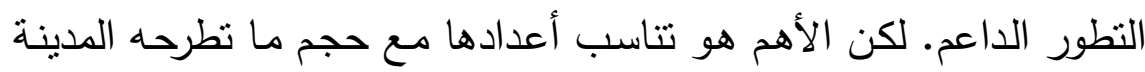

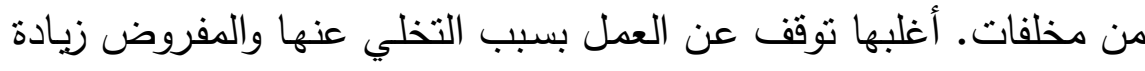

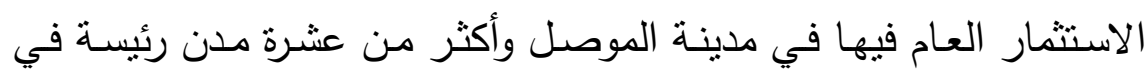

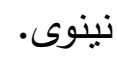

يقترح البحث زيادة اعداد المعامل وتوسيع خطوط التشغيل فيها طرديا مع

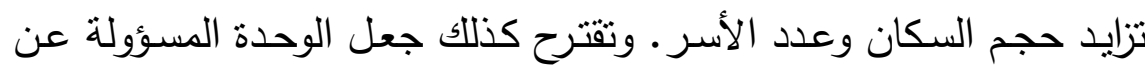

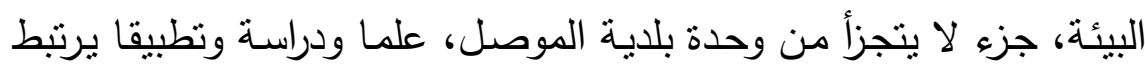
بها كل وحدات البيئة في بلديات الأقضية والنواحي لإني لمحافظة نينوى. 
لا بشمل نمو التنـغيل في المرافق البلدية التنظيف والصبانة فقط، بل

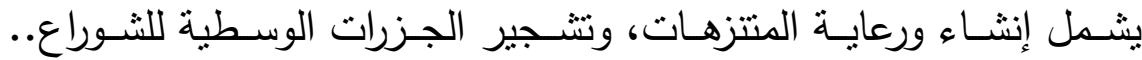

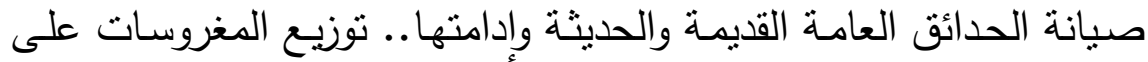

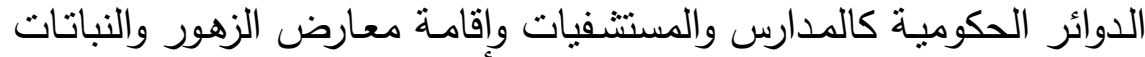

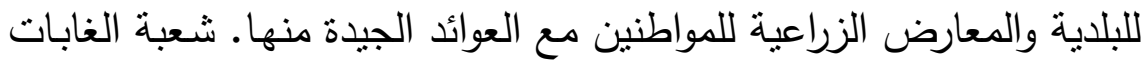

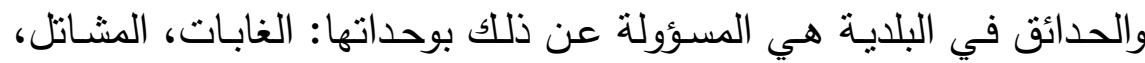
الحدائق والجزرات الوسطية، والكتنزهات.

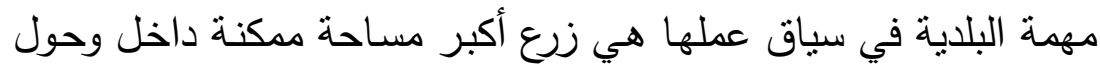

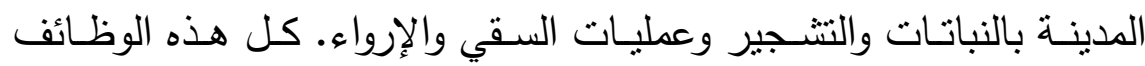

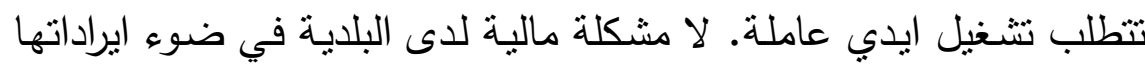

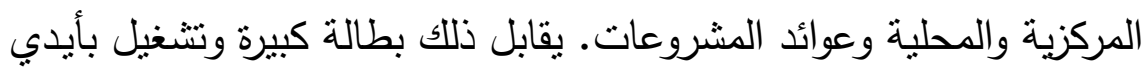
عاملة بأسعار يمكن ببساطة ان تتناسب وكفاءة العمل والإبداعات المبذولة.

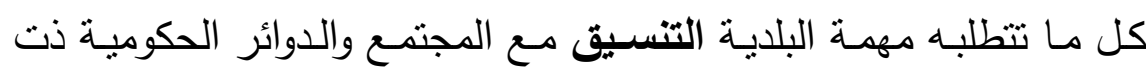

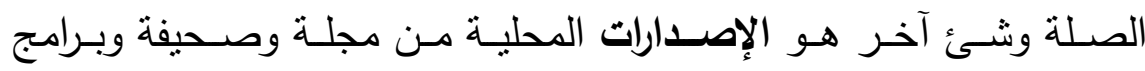

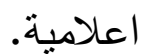

الإصدارات الإعلامية وسيلة فعالة ومهمة في زج الجهود وتفاعلاتها في

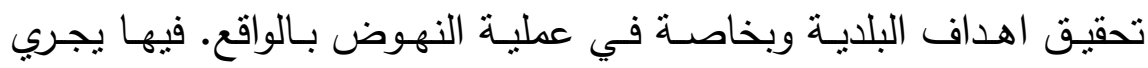

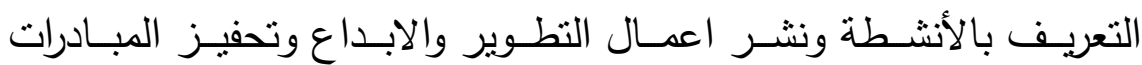

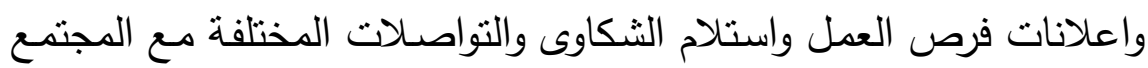

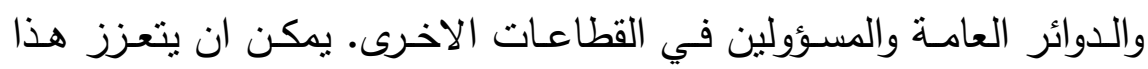

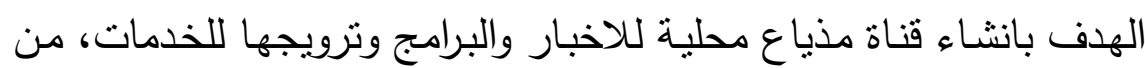
ثقافة وسياحة وتحليل ومناقثات وتوضيحات ومعالجات منوعة. الإعلام المحلي للوظائف المتواصلة لا يكون بالوسائط العامـة بقدر ما

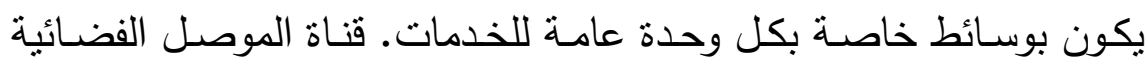
(الرشيد) وقناة الموصلية أو سما الموصل، يمكن ان تسهما في نشر الإعلام 


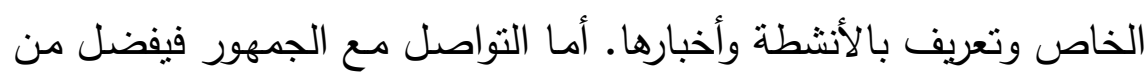

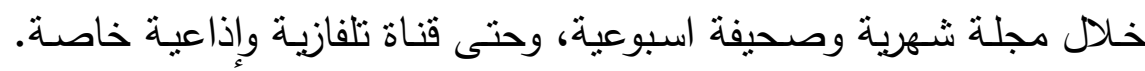

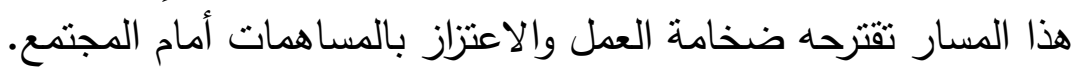

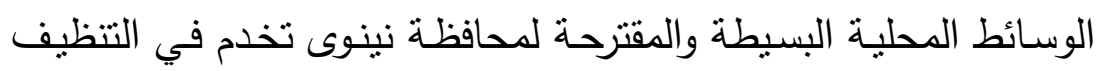

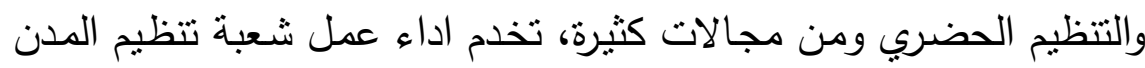

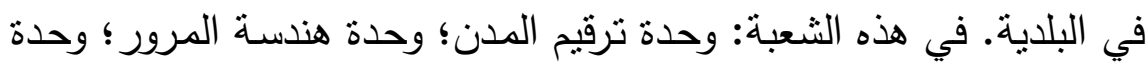

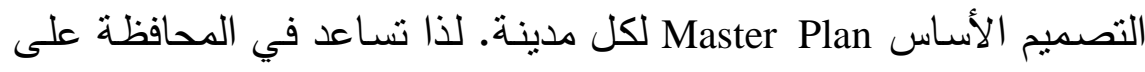

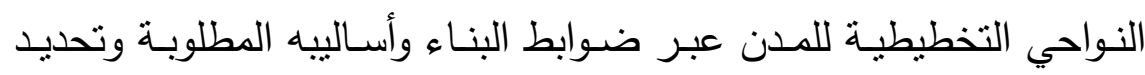

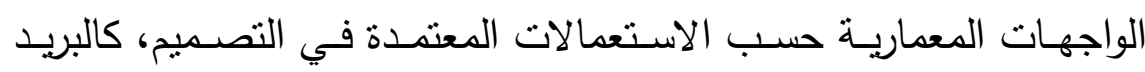

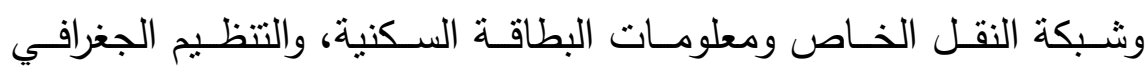

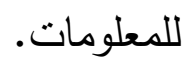

لخدم الإعـام الخـاص عمل شـعبة المشـاريع في البلدية عبر وحدات:

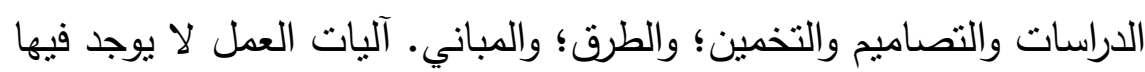

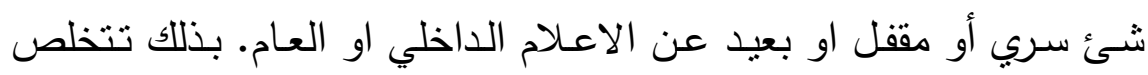

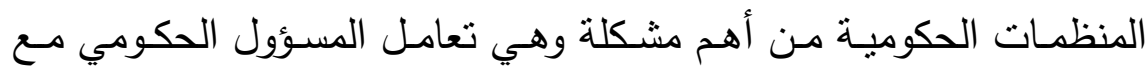

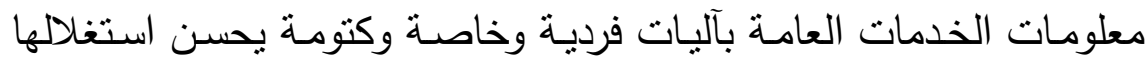

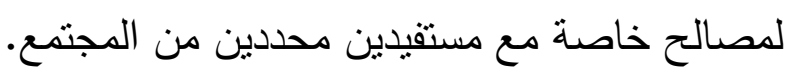

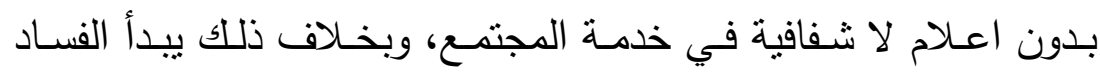

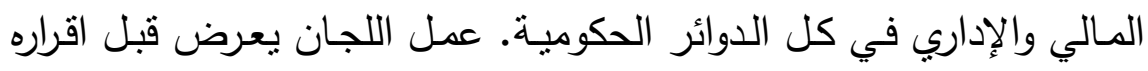

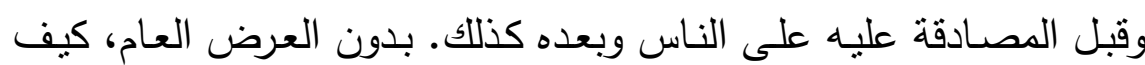

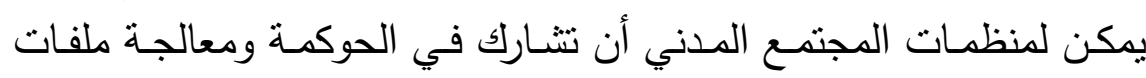
الفساد؟ المنا؟

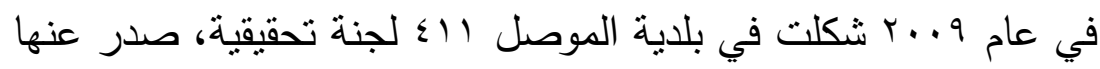

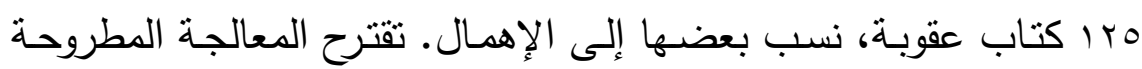

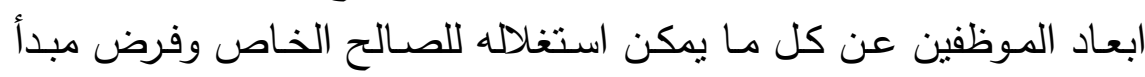




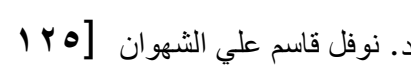
دور الخدمات البلدية في التتمية.

القناعـة الثخصبية بقدرة تحقيق المكاسب الماليـة المشروعة مـن مبـادرات

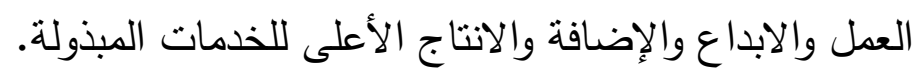
هذه العلاقة تعمل توافقيا وتحفز على المزيد من البذل والمزيد من العائد

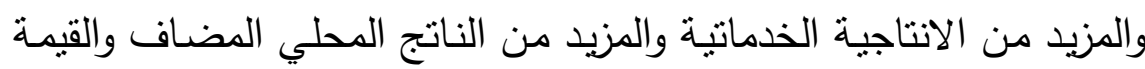

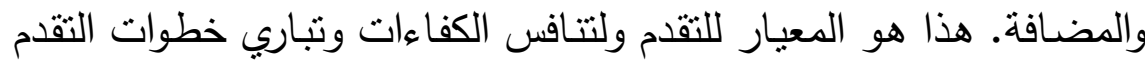

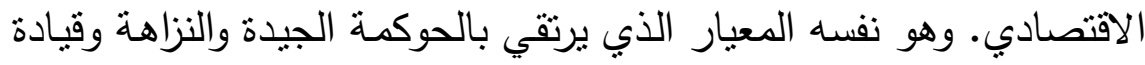

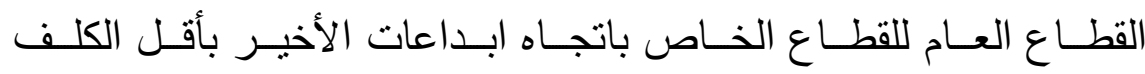

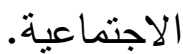

بفضل قطاع الخدمات العامة تثقدم مراتب الوحدات الإدارية على طريق

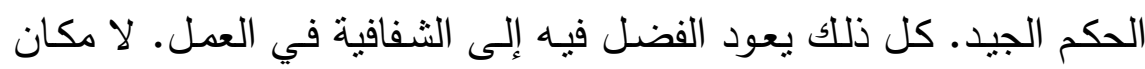

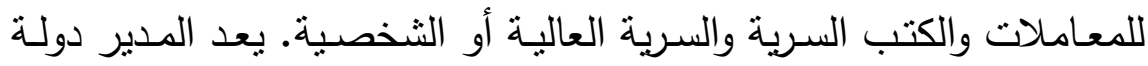

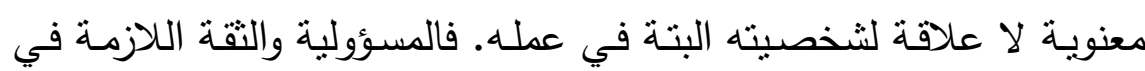

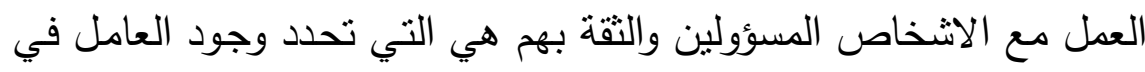

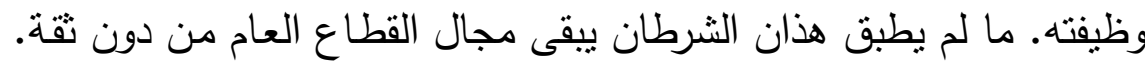
أية علاقة تحصل بين الموظف والمستقيد من الخدمات العامة تعزى لكفاءته

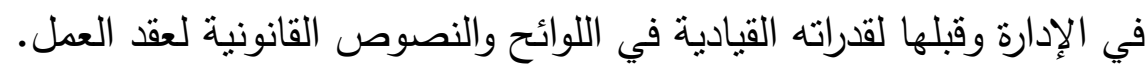

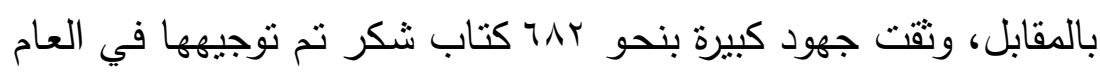

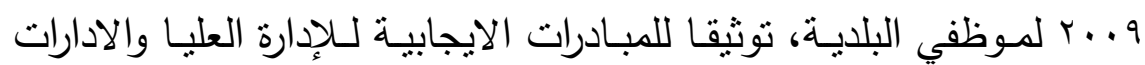

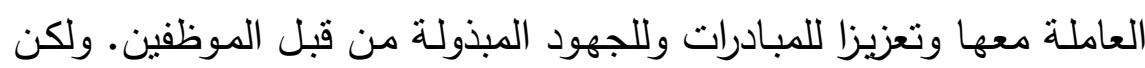

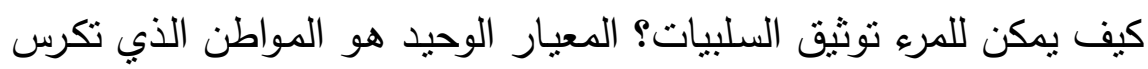

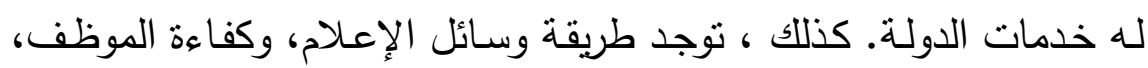

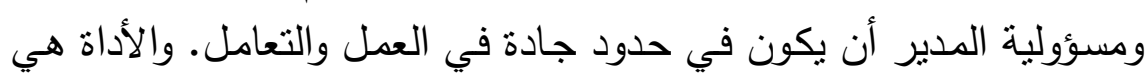

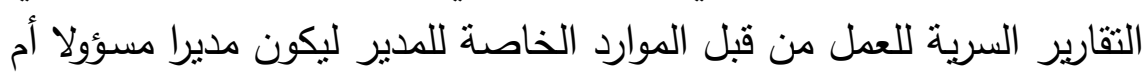
ل الا، في تمثيله الإدارة العامة. 
r-r التخطيط البلاي

يفترض مبدئيا ان بلدية الموصل هي التي تخطط وتتابع تقديم الخدمات

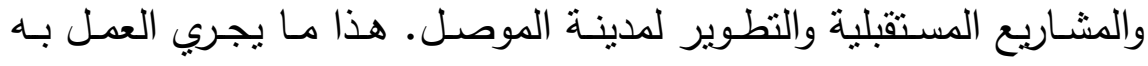
ومثبـت كسياق في مهمـات العملـل للبلديـة والوحـدات الخدماتيـة الاخـرى. ويفترض ايضـا ان هذه المهمـة في نشـاط بلديـة الموصل تعني كل مـا لـه له

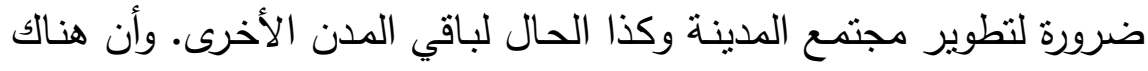
مجلس أعلى، وهو مجلس محافظة نينوى يخطط ويرسم ويتابع، والمسؤولون

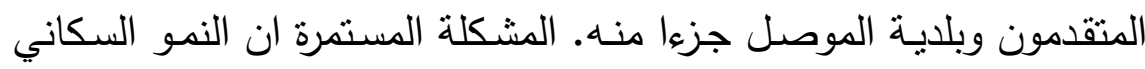
والتركز الحضري مع التوسع اسرع من نمو الخدمات.

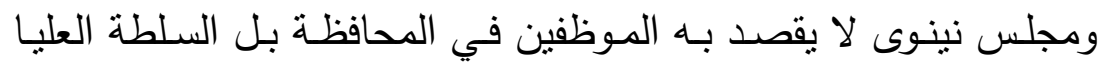

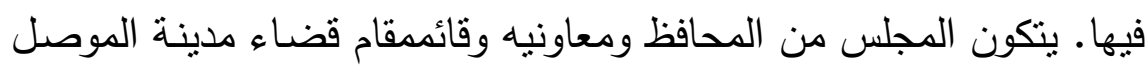
وعدد من كبار الاستشـاريين المتخصصين من اكاديميين وخبراء ومعنيين

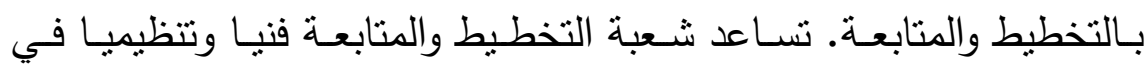

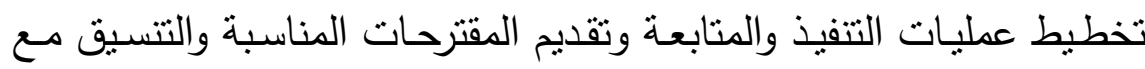

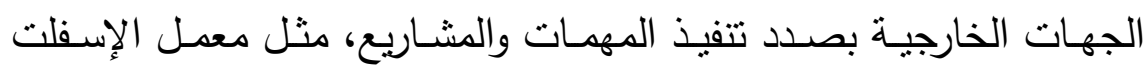

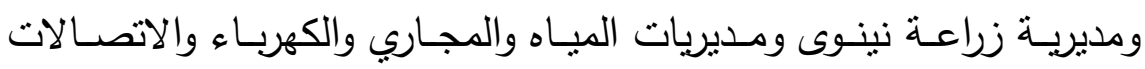
وبلديات المدن الأخرى لمحافظة نينوى وغيرها.

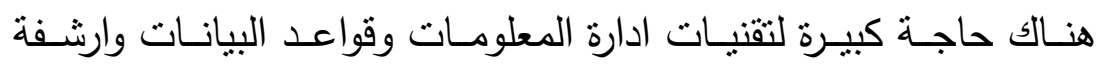
الخرائط. وحدة نظام المعلومات الجغرافية GIS والجدير بالذكر ان تطوير النظـام البلدي يتطلب بالضـرورة تطـوير هـذهـه

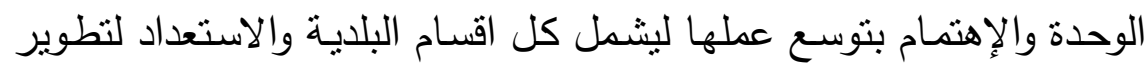
القدرة التقنية للعمل كجزء من الحكومـة الالكترونية المفترضـة. ومنفذ للخبرة التي يستقيد من استخدامها مديري الخدمات العامة في نينوى.

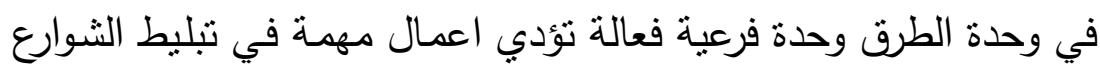

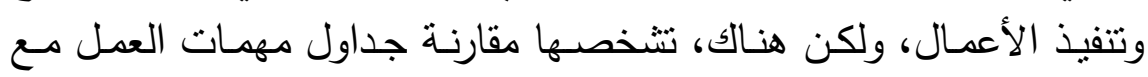


الواقع، تقيد بأن سرعة اعمال الصيانة في الطرق الفرعيـة والثانوية ابطأ من معدل الإندثار والتقادم فيها. وتتجه انتقادات كثيرة لجانب التخطيط لاعبه لاسبقيات

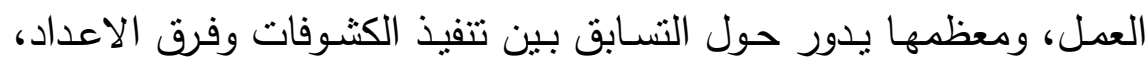

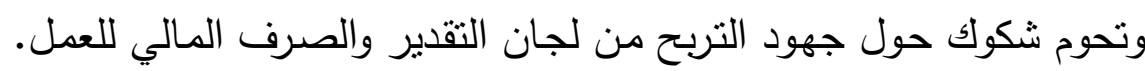
هذه الاستتناجات هي جزء مما ورد في استبيان شخصي للباحث من الجهاز

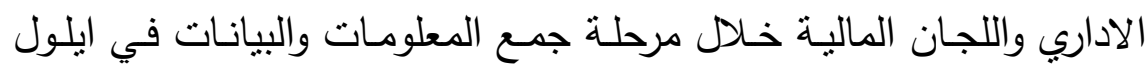

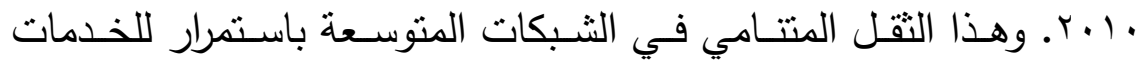

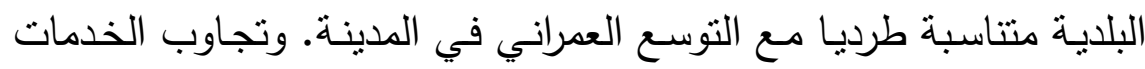
العامـة الحكوميـة بشكل غير متتـامي ومتزايد في مرافقها والأبنيـة الحكوميـة التي تقدم الخدمات العامة.

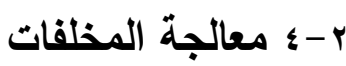

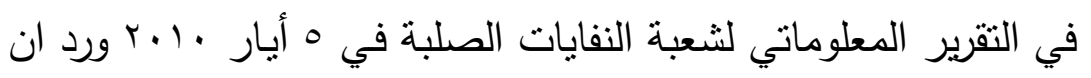

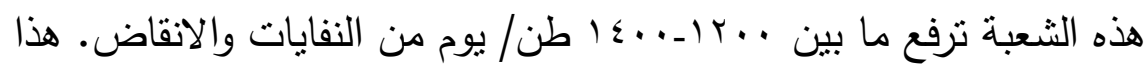

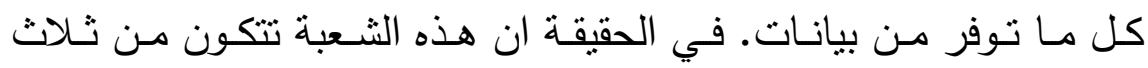

وحدات، هي: وحدة التنظيفات؛ ووحدة الطمر الصحي؛ ووحدة المجازر •

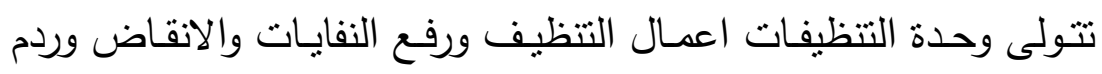
المستتقعات في كافة انحاء مدينة الموصل. يأتي بعدها دور وحدة الطمر

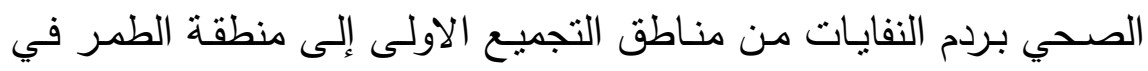

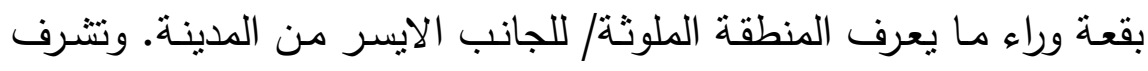

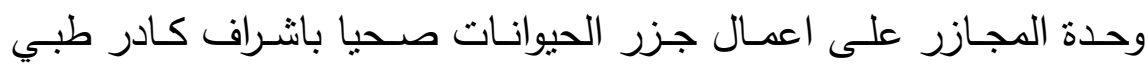
بيطري. هذه المهمة شهدت نراجعات كبيرة بسبب غياب حكم القانون في العقد المنتهي. شهدت نينوى تتفيذ برامج اعادة البناء. بعض البرامج سمي مشاريع تتمية

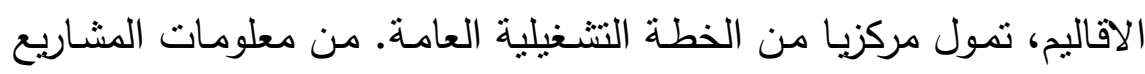




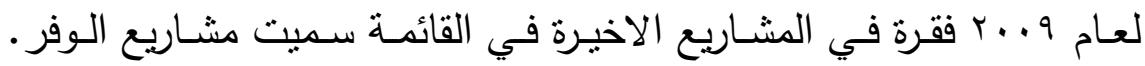

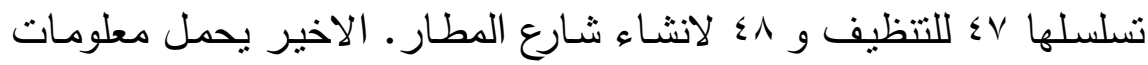

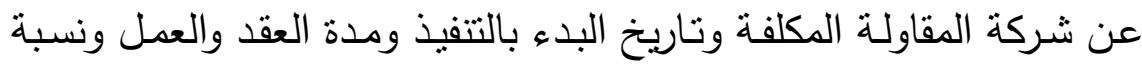
تقدم العمل. اما تتظيف المدينة فلا يحمل سوى معلومات قيد التفيذ.

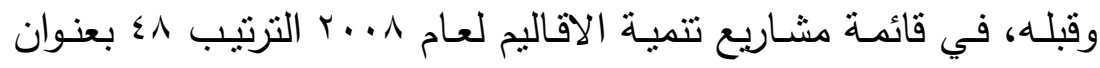

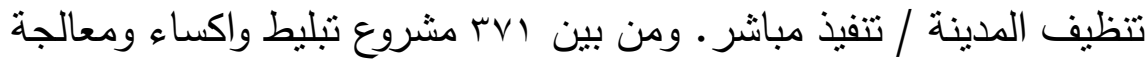

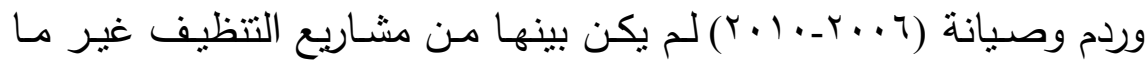

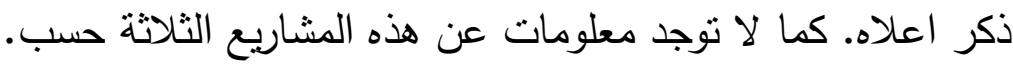
مهمـة جوهريـة في حياة المجتمع الصـحية والبيئية وفي حركية المدينـة. وبحجم عمل يتجاوز الألف طن بوميا من رفع ومعالجة الانقاض الصلبة. لا يعطي أي معلومـات لا عن المنفذ حاليا ولا عن المشروع اللاحق. في في وني

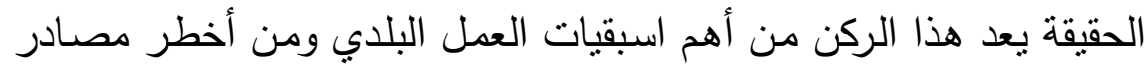

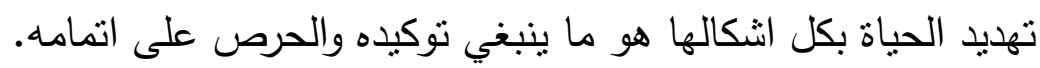

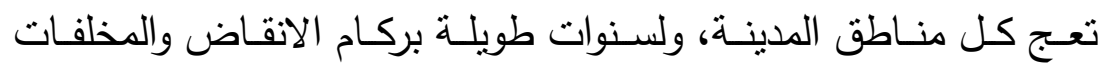

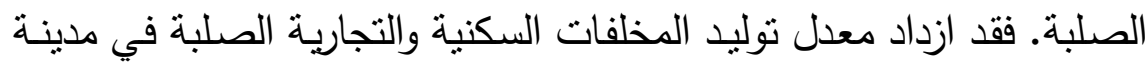

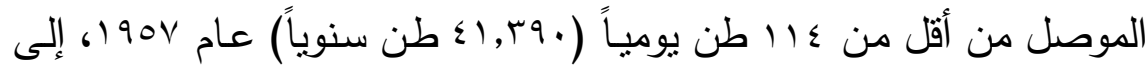

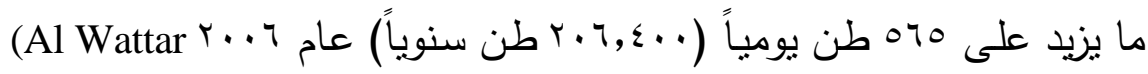

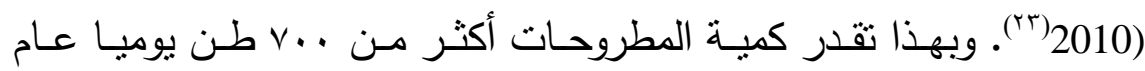

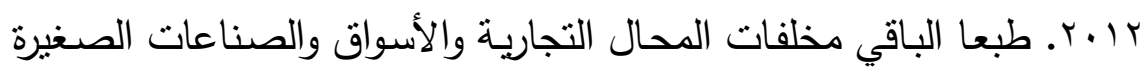

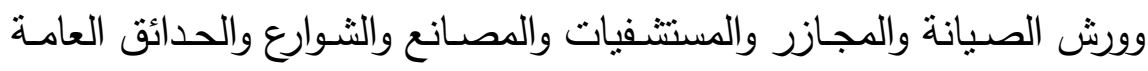

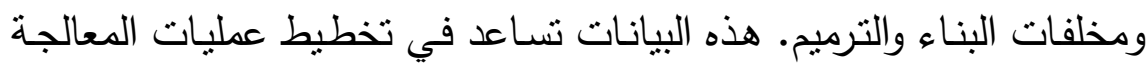

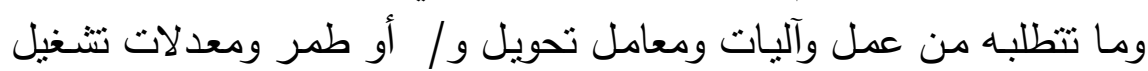
ورصد للتخصيصات ليس للموصل حسب، بل لكل مدن وقصبات نينوى.

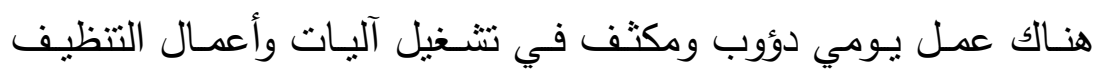

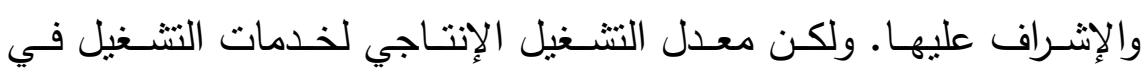


الضواحي ومركز المدينة - الموصل- بمعدل يوم واحد في الأسبوع لكل منطقة، وهذه مشكلة.

تعاني كل مدن العراق تقريبا (باستثاء مدن إقليم كردستان) من هذه ودهان

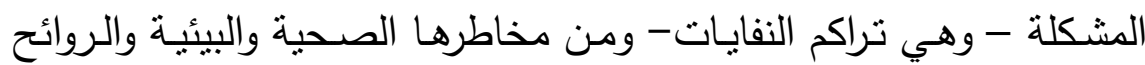
المنبعثة منها والتلوث. ما يسجل ارقاما مرتفعة من الإصابات غير الفيات الموثقة

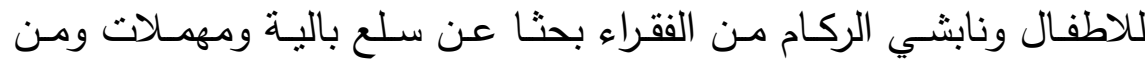

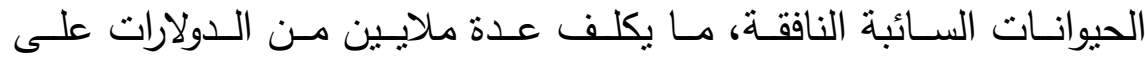

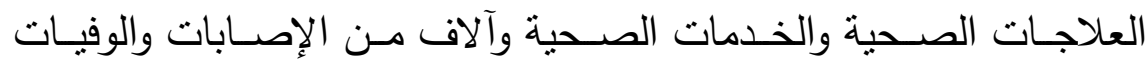

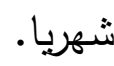

هذا، عدا منظر عمل الأفراد وسط النفايات، وامام عدسات الفضائيات،

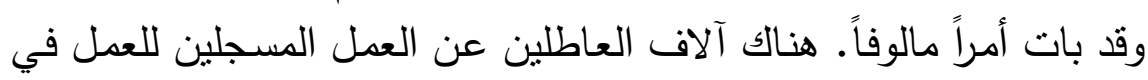

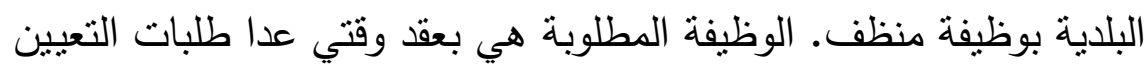

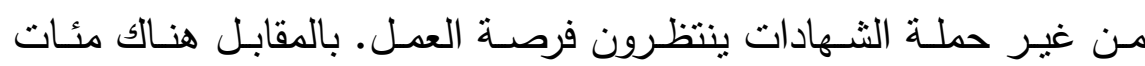

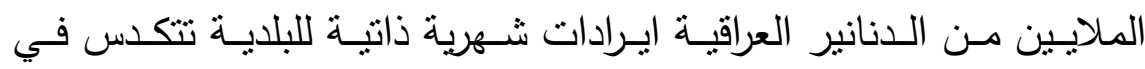

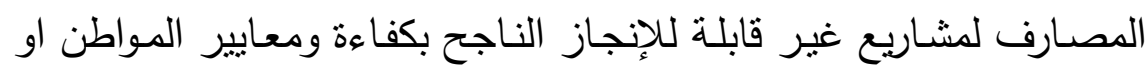
بمعايير الإعمار الحضري، سوى بعض المض المبادرات.

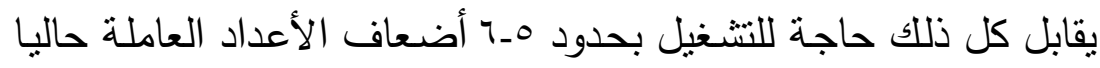

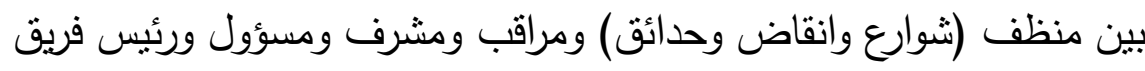

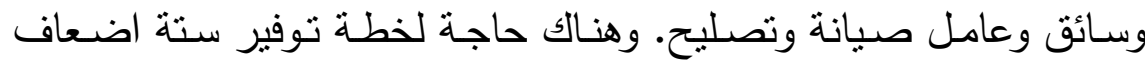

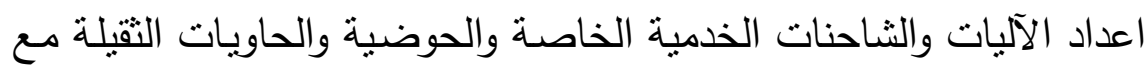

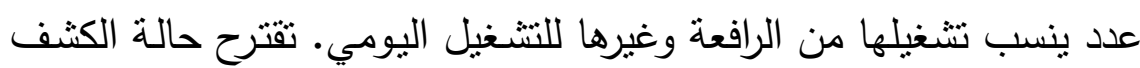
التحليلي هذه برنامج للخطة الآتية:-

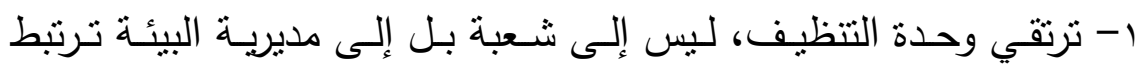
بالمديرية العامة لبلدية الموصل. 
r- تقسيم مديرية نظافة البلدية إلى أربع قطاعات إدارية، اثتتين لكل من جانبي الموصل.

r- خطة عمل للتنظيف اليومي (كل يومين بداية) لكل قطاع تحت إدارة كفوءة ومتمكنة. ع - اعداد آليات مجلس إداري لمديرية نظافة البلدية مسؤول عن ادارة العمل والئل

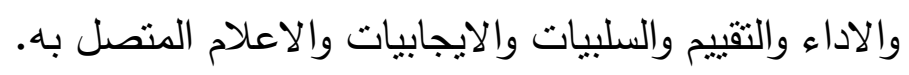

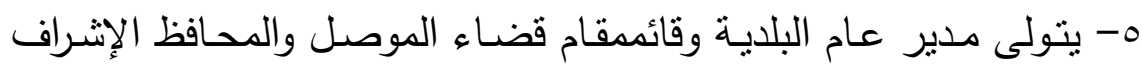

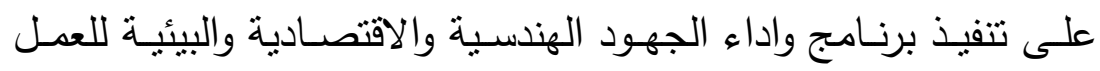

$$
\text { צ- المسوغات: }
$$

- توافر الخدمات الحكومية وتوفير في التكاليف الصحية للمواطن.

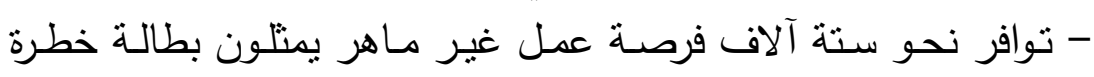

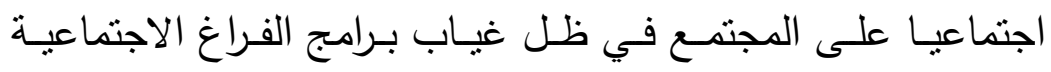

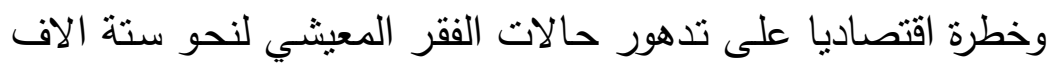

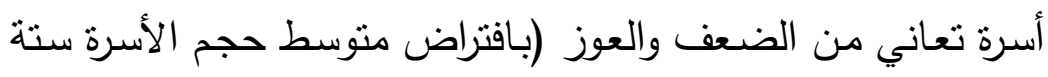

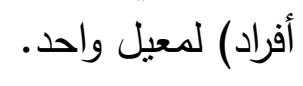

- تجنيب الكثير من تلأك الأسر مآسي عمل الأرملة او المطلقة.

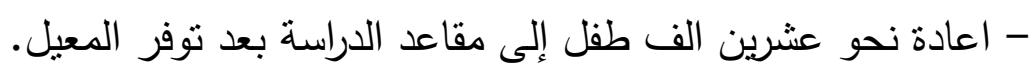

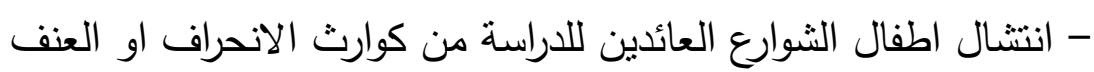

$$
\text { والتشرد. }
$$

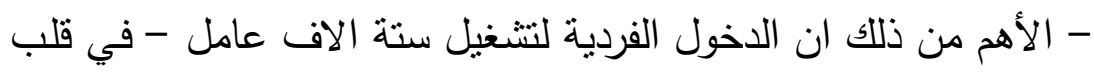

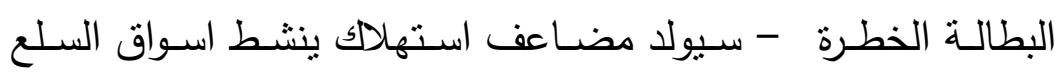

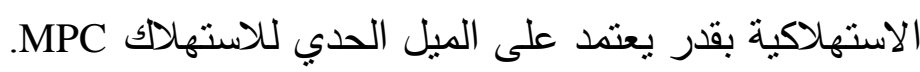

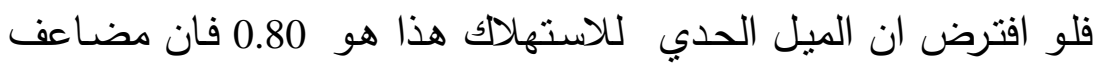

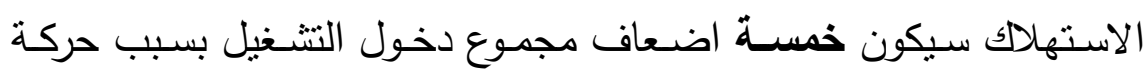


الــخول الاخـرى المتكـررة للإنفــاق في المجتمـع خـلال سـنة. بـافتراض ان متوسط اجر عامل التنظيف \$400 او ما يعادل نصف مليون دينار عراقي

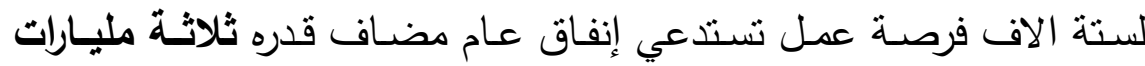
دينار عراقي شهريا، فإن هذا يعني إضـافة خمسة عشر مليون دينار عراقي للناتج المحلي الإجمالي لمدينة الموصل في من هذا التشغيل للشهر الواحد.

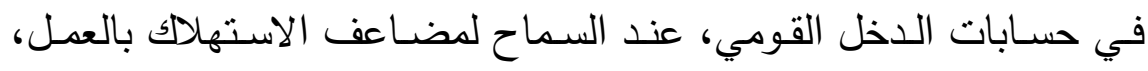

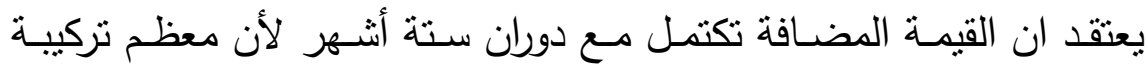

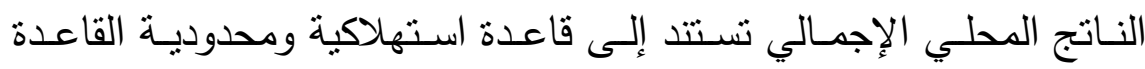
الإنتاجية. أبي ان القيمة الكلية المضافة لستة أثنهر مكتملة في حركة توليد

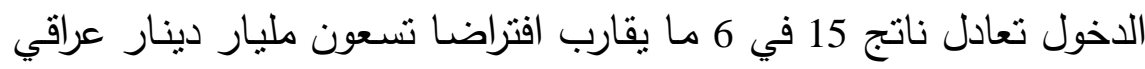
في السنة من تنـغيل سـتة آلاف عاطل وإنفاق عـام لثناثة مليارات دينـار

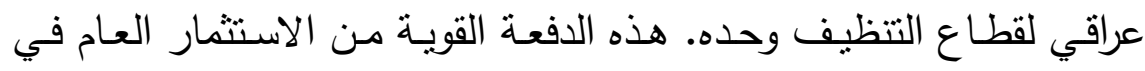

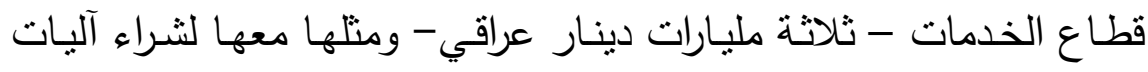
وعجلات وعدد وتجهيزات (زيادة في رأس المال الثابت) تعني دعم الفئات

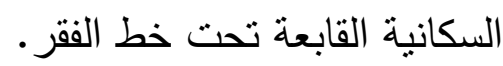

تتوسـع مدينـة الموصـل بشكل حلقي حول المركز وتصـفـ مـن ضــن

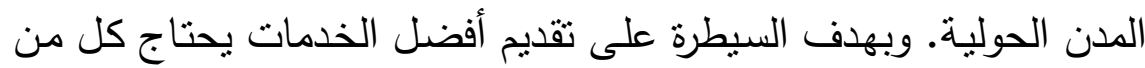
جانبي مدينة الموصل إلى التقسيم على الأقل إلى قطاعين شمالي وجنوبي.

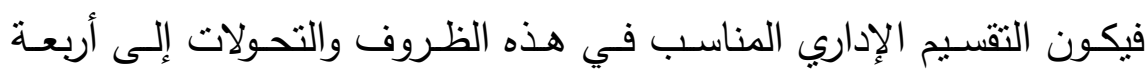

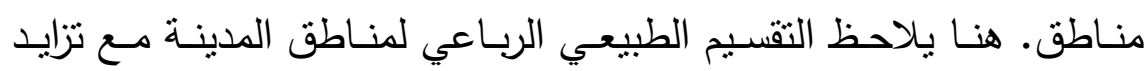

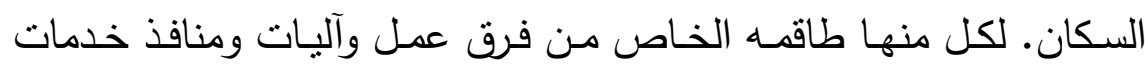

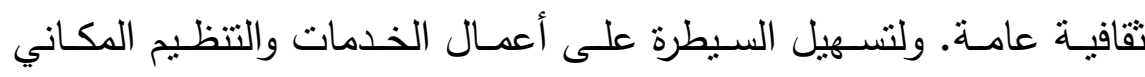

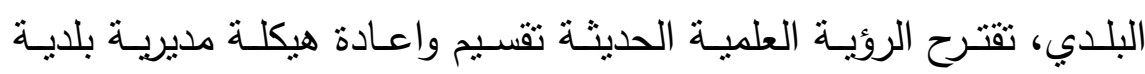
الموصل إلى المديريات الآتي ذكرها، بعد توسع هيكلها التتظيمي إلى مديرية 
الإبرية العامة لبلدية الموصل: ترتبط بها أربعة مديريات تغطي الجهات

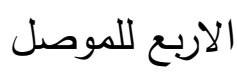

مديرية بلدية الحدباء: النصف الثمالي من الجانب الأيسر ، وكما يأني:

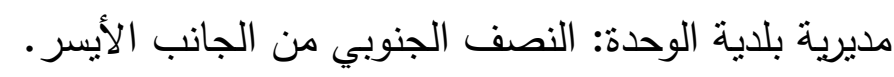
مديرية بلدية موصل الجديدة: النصف الثمالي من الجنانية الجنب الجنب الأيمن. مديرية بلدية الموصل: النصف الجنوبية من الجندية الجنانب الأيمن.

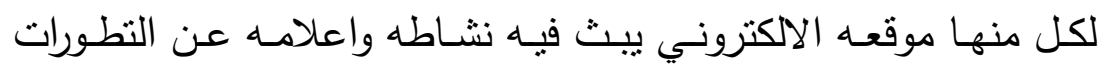

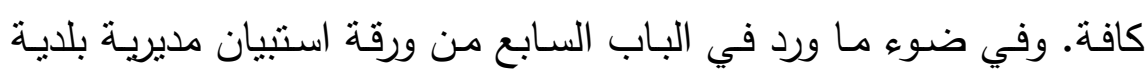

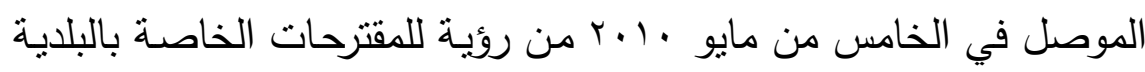

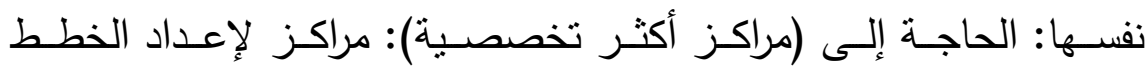
المستقبلية؛ ومراكز لإعداد مشاريع مستقبلية؛ ومركز رقابي لمتابعة الأعمال.

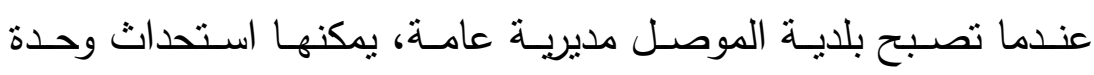

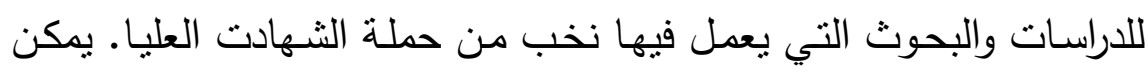

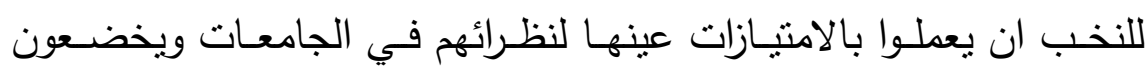

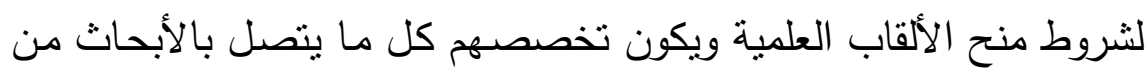

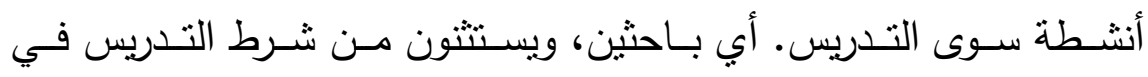

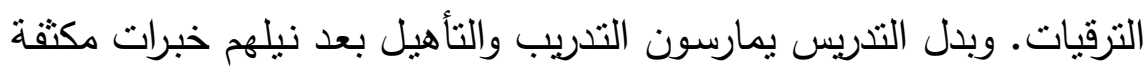
في البلدان المتقدمة.

تتشير معلومات بلدية الموصل لخطة مستقبلية خمسية لمشاريع: لتبليط

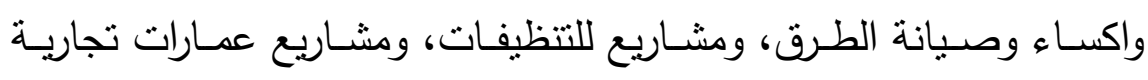

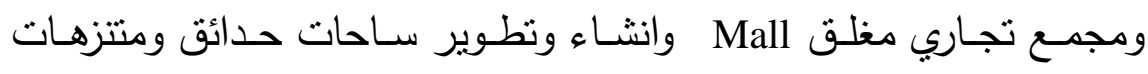

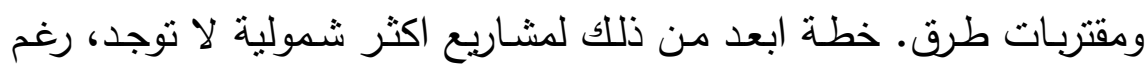
توفر القدرة لذلك. رغم الطلب القوي على الوظائف لحملة الثـهادات الجامعية والعليا في لقاي

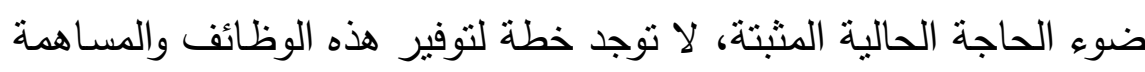


Irr]

د. نوفل قاسم علي الثهوان

في التشغيل. مـع قبول التوسعات الهيكلية المقترحة للدراسـة ستكون الحاجة مضاعفة لملاكات تحمل الشهادات والتخصصات الآتية: دكتوراه وماجستير : هندسـة/ حاسبات، معماري، كهربـاء، ميكانيك، ري،

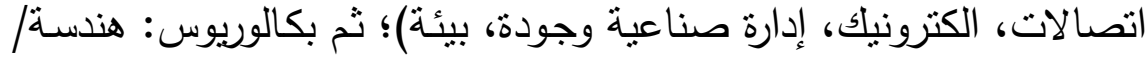

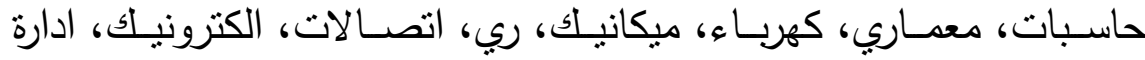

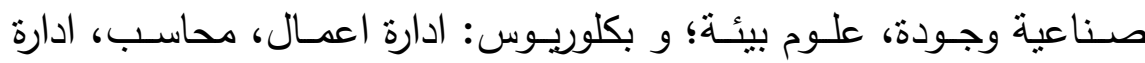

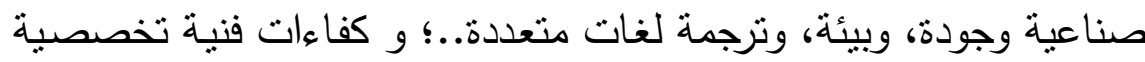
في هندسة التقنيات، ودبلوم تقني؛ يقابل ذلك نسبة غير قليلة من الكفاءات وندات لا تعمل بتخصصاتها.

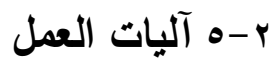

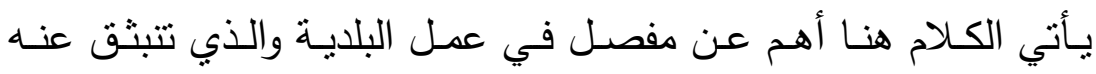

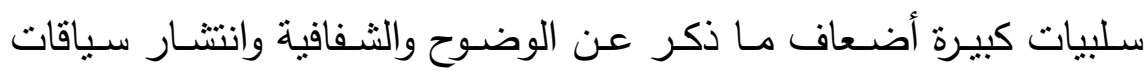
التضمينية والمسائلة وهو حوكمة السربة والكتمان. وكل ذلك بسبب السياقات

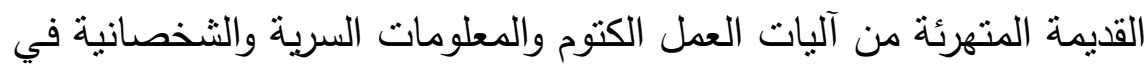
الإدارة، تحت طوق أسرار العمل، التي تحجب طبيعة عمل المدراء وكفاءتهم بعيدا عن التقيهم بذريعـة مصلحة العمل وهي في واقعها تمويـه السلبيات

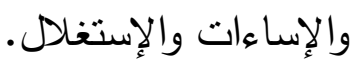

لا زالت الإدارات الحكومية تتعامل فيما بينها وداخليا بكتب رسمية تحمل

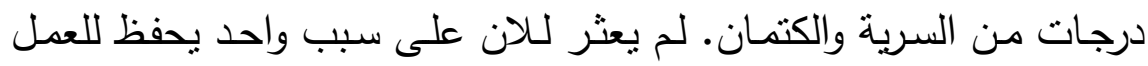

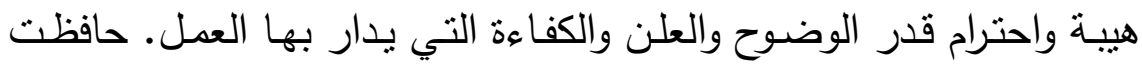

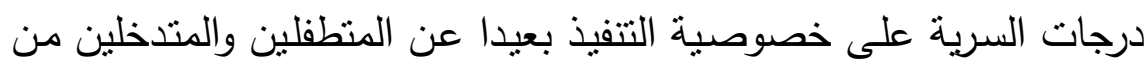

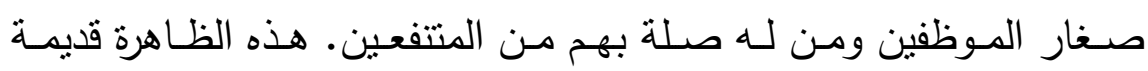
وتعرف بالتجرؤ وحب الفضول وتعويض النقص الثخصي بالحسم والايقاع 
بالعاملين الكفء وغير الكفء حسدا ومزاجا سـاريا وغير ذلك. مـرد ذلك

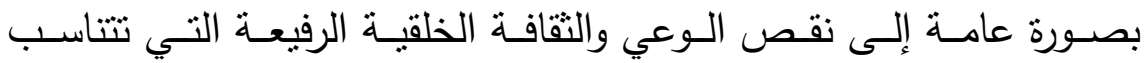
ومعتقدات المجتمع السليم، مما يفسح بهذه الظواهر • بدلا من التركيز العام على معالجات الظاهرة وأسبابها بسياقات ترصن عمل الدوائر لجأ المدراء

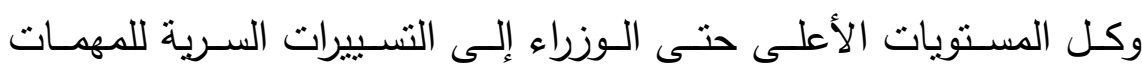
الحساسة.

في عالم تحرر الأسواق تتحرر الأعمال والوظائف من كل المقيدات، مثل السرية وآثارها من بيروقراطية واستغلال شخصي وفساد. وبدل الروتين

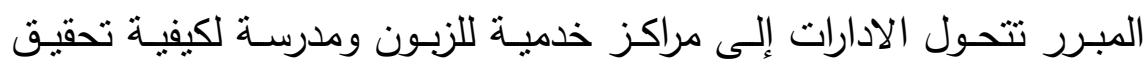

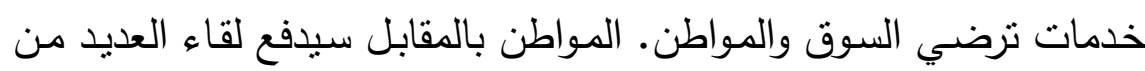
الخدمات العامة وبسعر مجزي للخدمة، فضلا عن الرسوم و / أو الضرائب. تعزى هذه بدورها إلى السياقات الخاطئة التي باتت بأمس الحاجة للتغيير

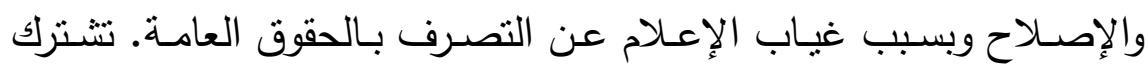
جميعا بغياب المعلومات لدى المجتمع عما يدور في دهاليز العمل الوظيفي

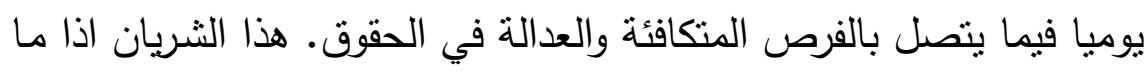

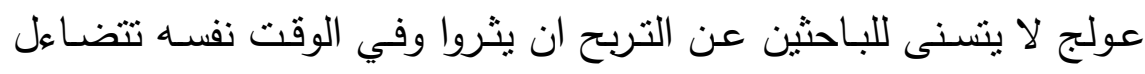

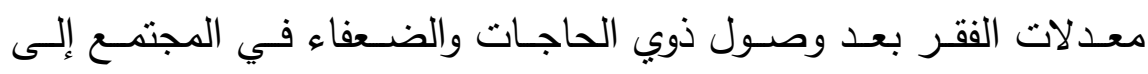
الخدمات العامة.

الركن المسؤول عن الكثير من المشكلات البلدية في المجتمع هو أنشطة

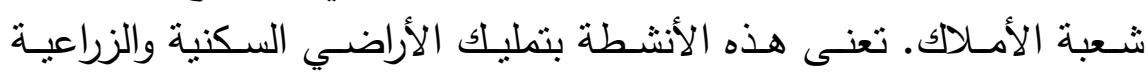
والصناعية والخدمية- التجارية. ولا يعرف، حقيقة كم نسبة العقوبات الادارية الصـادرة واللجـان التحقيقيـة المشـكلة بقضـابيا تتصـل بهـذهـ الثـعبة. تـدور التوقعـات حـول نسـبة كبيـرة جـدا تخـص تخصـيص الأراضــي السـكنية والصناعية والتجارية، للخدمات رغم الضوابط والسياقات. وهنا بطرح السؤال على شعبة الأملاك عن السبب في ذلكا 


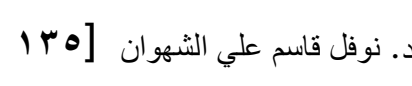
دور الخمات البلدية في التنمية.

نشأت نلأك الحالات ونمت بشكل مريع، لأسباب منها ما ذكر أعلاه عن

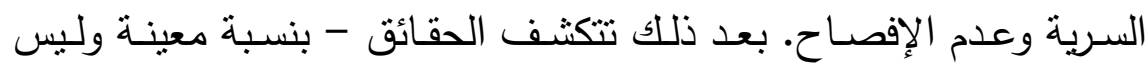
كلها- وتظهر الانتهاكات لكل الضـوابط مـن قبـل المسـؤلين عنهـا. فتـتم

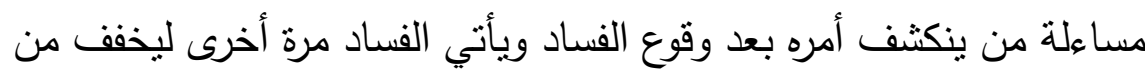

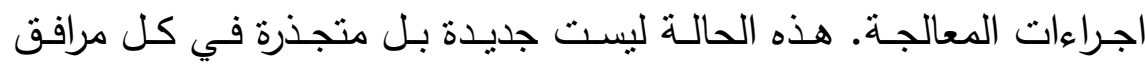

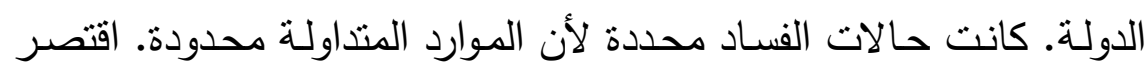

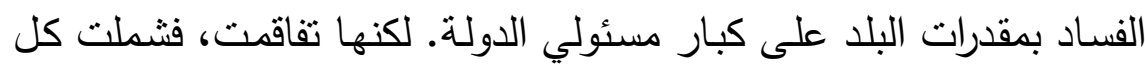

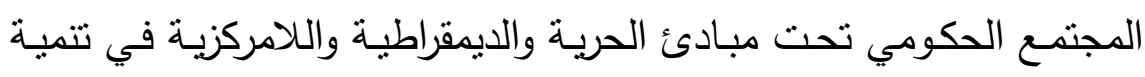
الأقاليم.

الحريسة واللامركزبـة لم تسبقهما قوانين اضـافية لمحاربـة الفسـاد بعقوبـات

أقسى، بل تسربت اتهامـات وقضـايا على قضـاة ومديرين عامين في هيئة

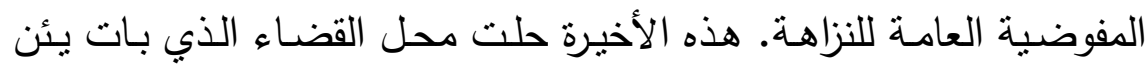
أكثر من قبل تحت التهميش والضعف وعدم الاستقلال عن هيمنـة السلطة التتفيذية. الأمور تسير عكس ما تتطلبه المعالجات تماما. هل المدعي العام

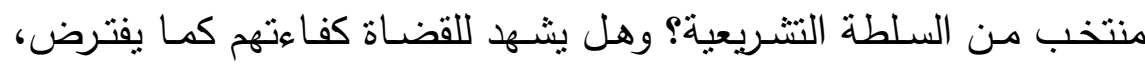

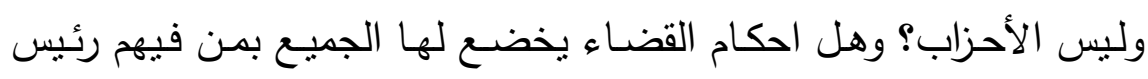

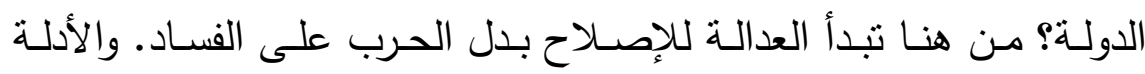
الدراسية تؤكد مدى الضرر الذي يلحقه الفساد الإداري بالتتمية الإقتصـادية العربية (Kutan, Douglas and Judge 2009)

إدارة الموارد البشرية للإصــلاحات الإقتصـادية تـأثنير بـالغ فـي تتميـة رأس المـال البشـري الخطوات الأهم في طريق النمو الاقتصادي وفي ذلك أمنتة ونماذج مدعمة

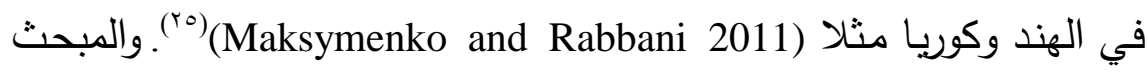
الآتي يتعامل مع جوانب دور مديرية بلديات الأقضية والنواحي في التنمية، 
وحيود التقدير في احالة العقود المالية لتنفيذ المشـاريع والعديد من مـع نظرة عامة للخدمات العامة للدولة وملاحظات التقييم.

\section{r -}

من الروية التقويمية لواقع عمل بلديات نينوى في المبحث السابق، تبين

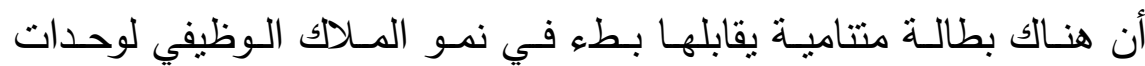

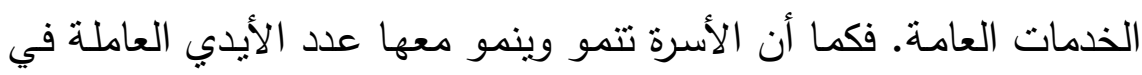

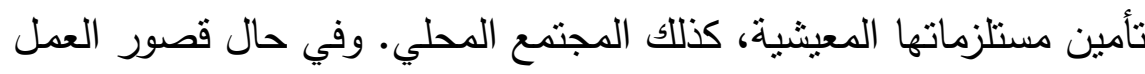

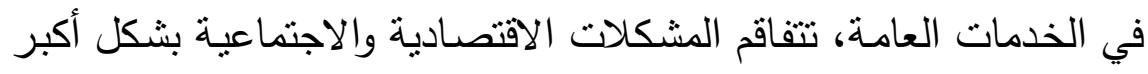
مع تنامي اعداد العاطلين عن العمل، سواء من حملة الثهادات ومن غير الثهاء

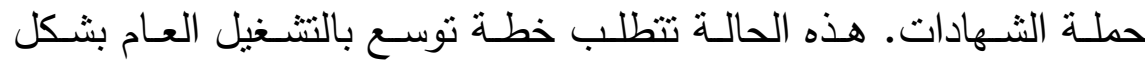
يتتاسب والنمو السكاني. أبي الحفاظ على نسب معينة من عدد كل العاملين إلى حجم الثريحة السكانية التي تغطيها البلديات، من سنة لأخرى.

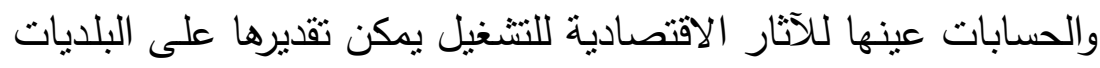

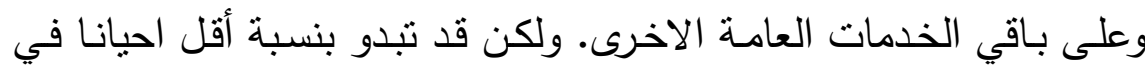

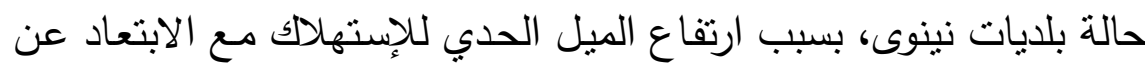

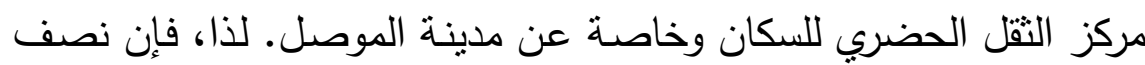
الآثار المقدرة تقريبا لنسب التشغيل/السكان في مدينـة الموصل يمكن التنبؤ بها ومنها لباقي اجزاء محافظة نينوى.

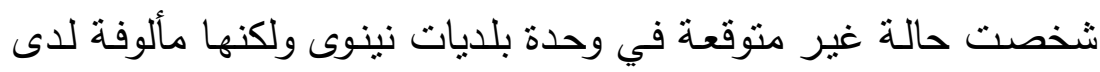

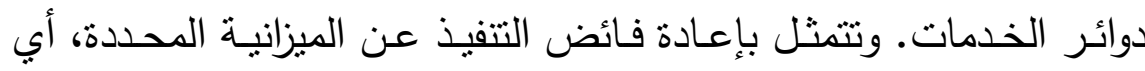

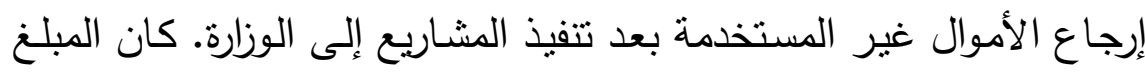

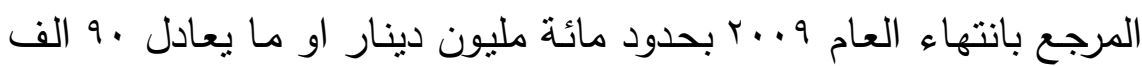

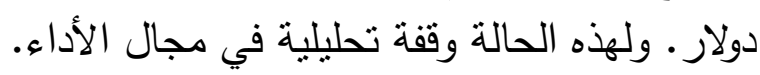


بفرض ان متوسـط الأجـرة اليوميـة لعامـل التتظيـف عشـرة آلاف دينـار

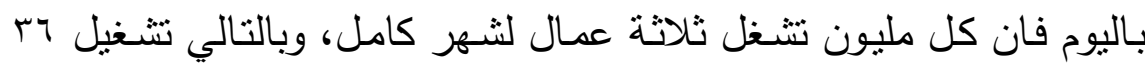

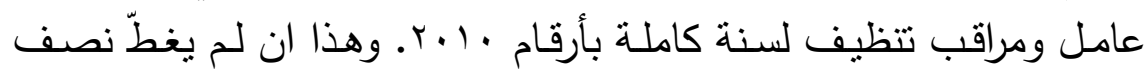
الاحتباجات المشار إلبها آنفاً فمن المؤكد يسهم في رفع كفاءة عمل وحدة

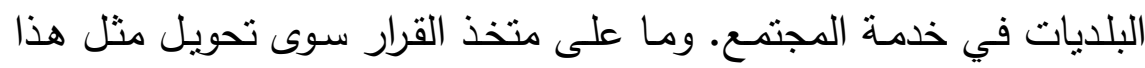

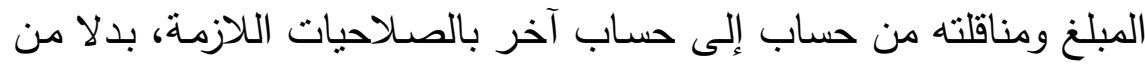

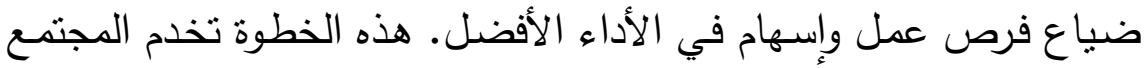
بطريقة مضاعفة الأولى بتقديم خدمات إضافية، كمية و / أو نوعية والثانية توليد حركة دخول تعمل مسع مضـاعف الاستهلاكك على مضـاعفة الدخول الفردية بحسب الميل الحدي للإستهالاك السائد وهو مرتفع لدى هذه الثرائح.

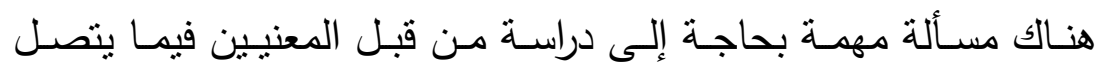

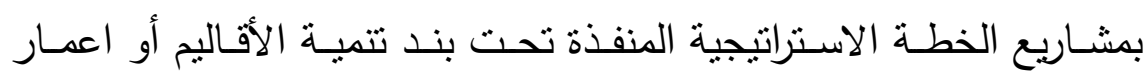
المحافظة أو دعم واسناد وغير ذلك. ففي أعمال التبليط وهي عميلة مهمة ومستمرة للشوارع الجديدة او الموجودة عند اعادة التبليط والتجديد.

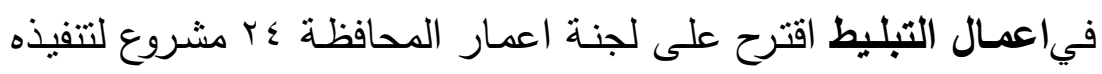

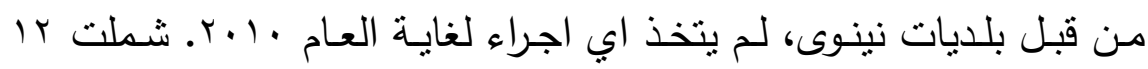

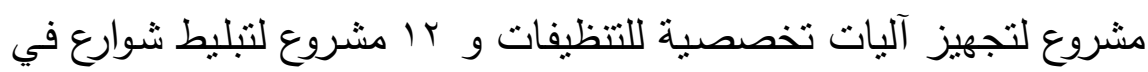

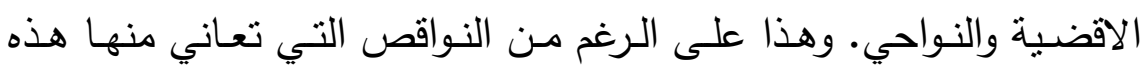
الوحدة التي تعمل على تقليل نسبة الإنجاز لاهدافها المحددة.

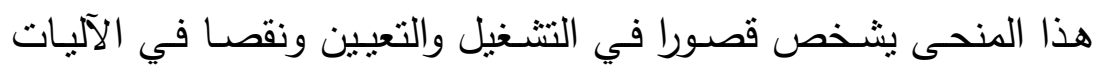

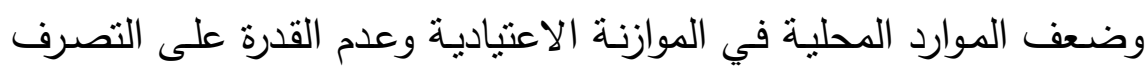

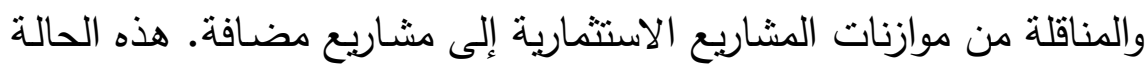

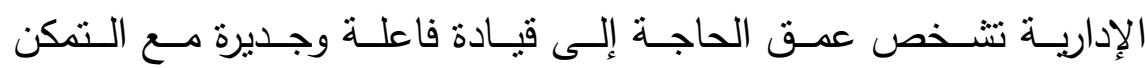

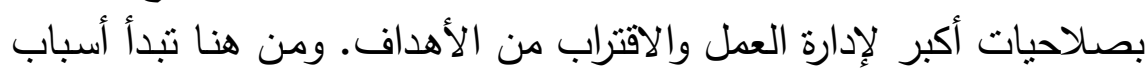

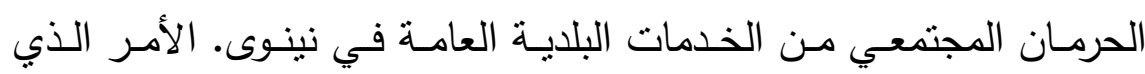


ينعكس بشكل كبير ومباشر على الأداء التتموي العام للأقضية والنواحي.

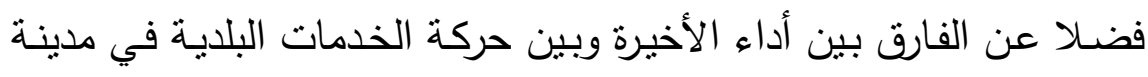

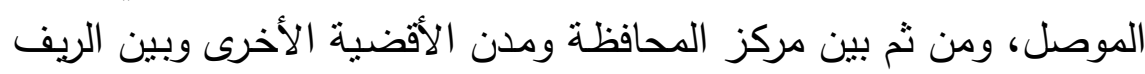

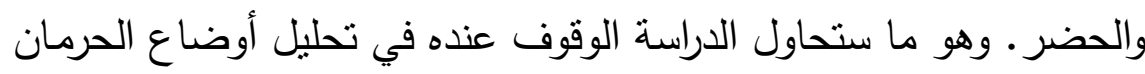
من الخدمات العامة في الفصل القادم.

r- بلديات نينوى والتنمية الإقليمية

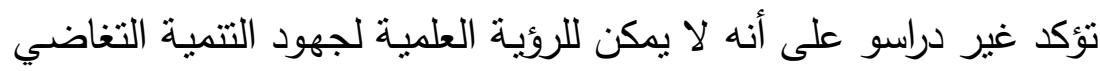

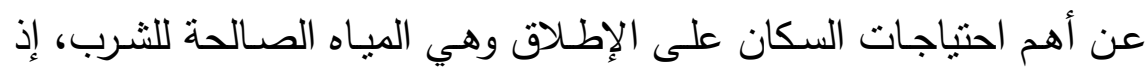

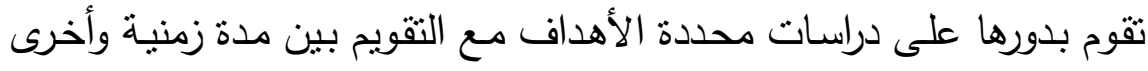

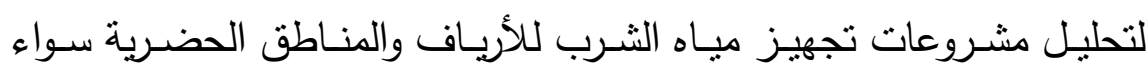

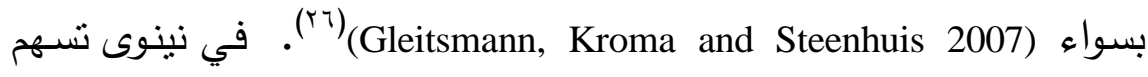

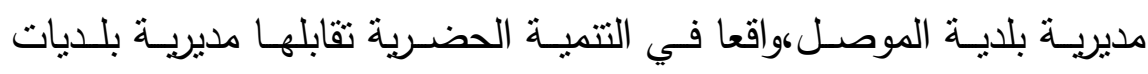

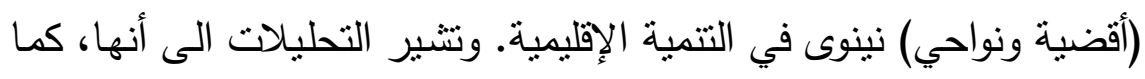

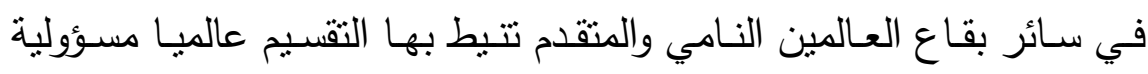

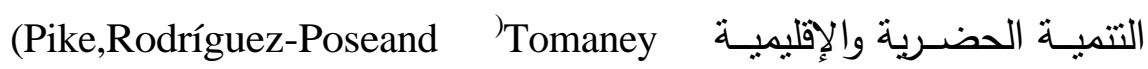

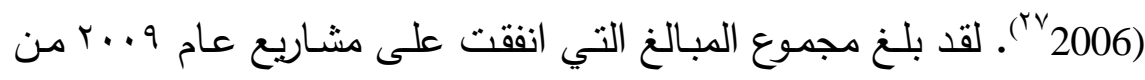

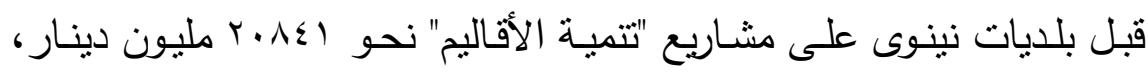

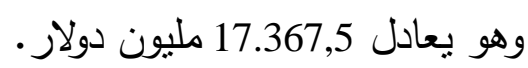

أكثر من نصف الإنفاق الكلي وتحديدا 52.4\% انفق على إنى إنشاء وتبليط

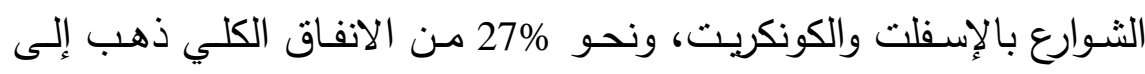

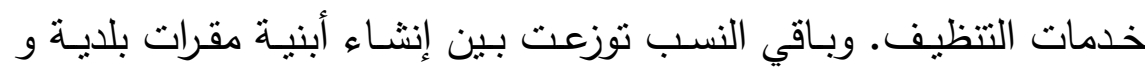
أسواق تجارية و حدائق ومنتزهات و شراء آليات تخصصية للبلديات. وكان النياء 


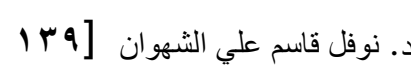
دور الخدمات البلدية في التتمية.

مجموعها نحو 17.8\% وهذا توزيـع مناسـب يـتلائم مـع الحجم المطلـوب

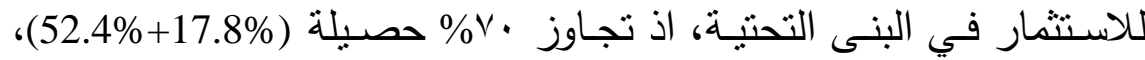
والباقي انفاق استهاكي على أعمال النظافة.

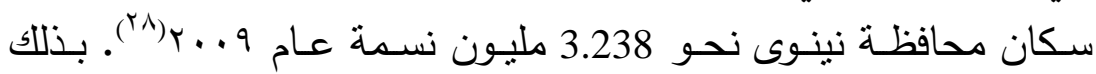
يكون منوسط نصسيب الفرد الواحد من الإنفاق الكلي العام على مشـاريع

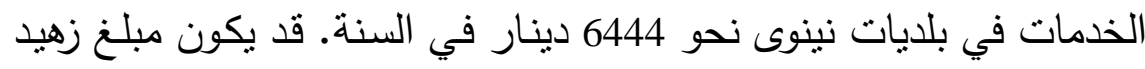
على مستوى الفرد لكنه انفاق جيد على المستوى الكلي، كميزانية مخصصة

فإذا كان متوسط حجم الأسرة سبعة (تقرببا في نينوى) فكل أسرة يقع عليها

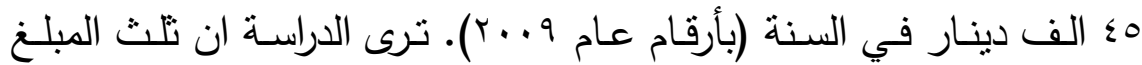

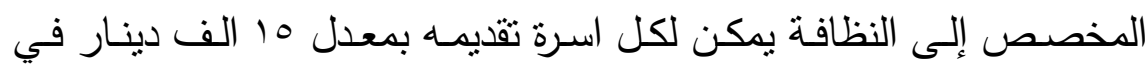
السنة. بعبارة أخرى لو ان كل فرد يسـد الف دينـار (اقل من دولار واحد) في

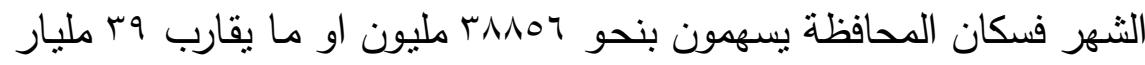
دولار وهو يقارب ضـعف مـا انفق على المشـاريع البلديـة في تنميـة الاقاليم.

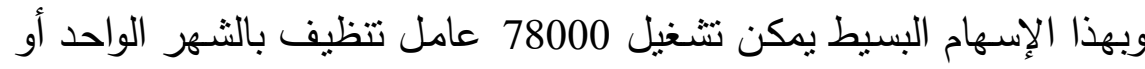

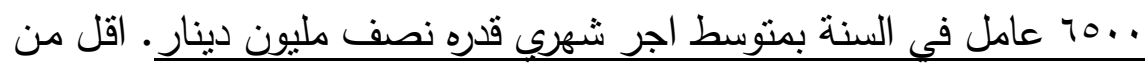

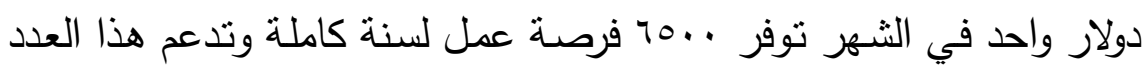
من الاسر وتحصل على نظافة بيئية كاملة من خدمات البلدية.

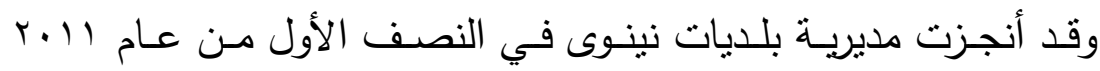

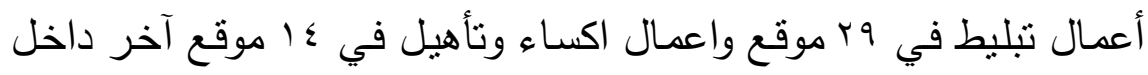
وخـارج مراكز الأقضـية والنواحي في نينـوى وبضـنها مشـاريع في نواحي تابعة لمدينة الموصل مثل حمام العليل والثنورة والقيارة. بلـغ المجموع الكلي لأطوال الشوارع المبلطة والمؤهلة 488000 مثر • وهو ما يعادل تقريبا مجموع 
بعدي ارض محافظة نينـوى (العرض مـن الثـرق إلى الغرب والطول مـن

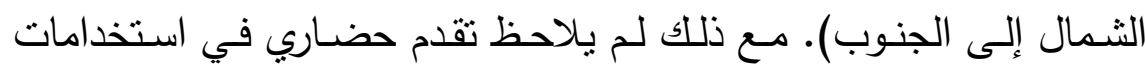
الطرق ونظافتها بسبب أعمال العنف وتأخر أعمال الصبيانة والإصـاحات

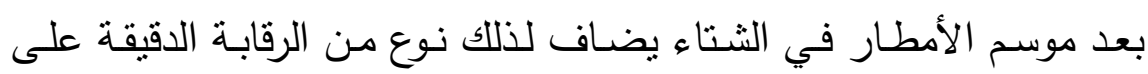
أعمال التتفيذ بالجودة المطلوبـة في عقود التنفيذ من قبل شركات المقاولات التي تتفذ المشاربع.

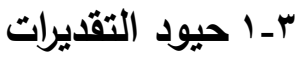

عند احالة العقود تطبق شروط المنافسة السربة على العطاءات المقدمة

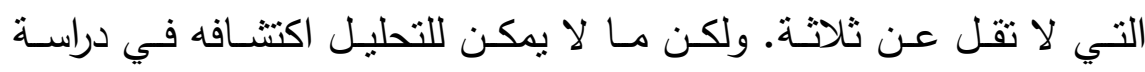

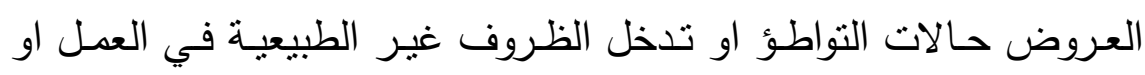
حراجة وقت التتفيذ. لذا يلجأ المحللون إلى استخدام طريقة معروفة بتحويل

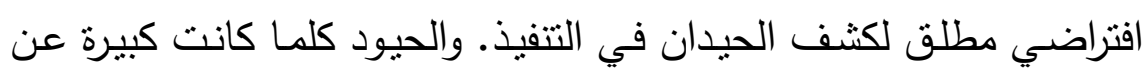
الوسط الحسابي كلما دل ذلك على اهمبة التقوبم المالي للتنفيذ. بفرض ان مبلغ الكلفة هو محور التقييم مسع مدة التنفيذ، يسمى المتغير

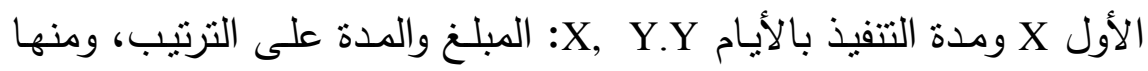
يمكن صباغة العلاقة الخاضعة للتخمين كما يأتي:

\section{$\mathrm{X} * \mathrm{Y}$ and $\mathrm{X} / \mathrm{Y}$}

Size Factor, $\mathrm{SF}=\left(\mathrm{X} *(\mathrm{Y} * \mathrm{X}) /(\mathrm{X} / \mathrm{Y})=\mathrm{y}^{2}\right.$

$$
\mathrm{DF}=|/ \mathrm{SF}=| / \mathrm{Y}^{2}
$$

So: 


$$
\begin{gathered}
S F=\frac{X^{*} Y}{X / Y}=\left(X * Y^{2}\right) / X=Y^{2} \\
\mathrm{DF} \leq \mid / \mathrm{Y}^{2}=\mathrm{Y}
\end{gathered}
$$

$$
Y^{\prime \prime}=\left(\operatorname{Max} . Y^{\prime}+\text { Mi. } Y^{\prime}\right) / 2
$$

$$
\mathrm{Y}>\mathrm{Y}^{\prime \prime}
$$

وهذه العلاقة صحيحة بقدرٍ مـا. ومقارنة Y مـع Y" تعطي عامل حيود

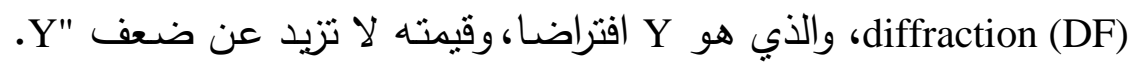

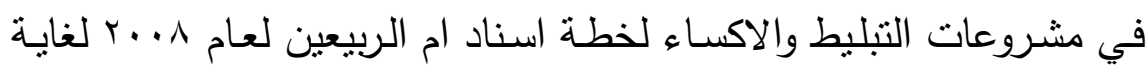

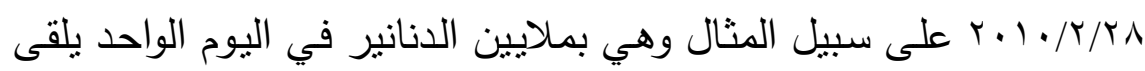

$$
\text { الضوء على واقع الحيود. }
$$

يبين جدول المشروعات ان معدلات الصرف تتراوح بين ب إلى V مليون

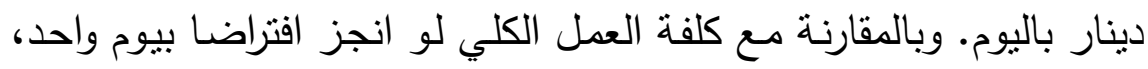

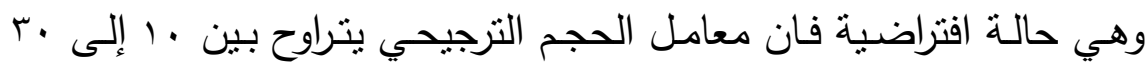

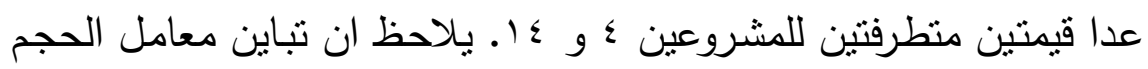

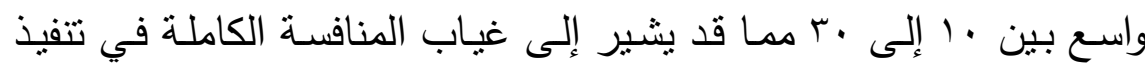
المشاربع.

ولمعرفة الحيدان، تطبق الخطوات السابقة، وفيها:

$$
\mathrm{DF}=(5.69+1.89) / 2=3.79
$$

القيمـة العليـا ' اقل مـن ضـعف القيمـة المتوسطة DF. فإذا استبعدت القيمتـان المتطرفتـان ع و ـ ا ترتفع قيمـة DF إلى (4.4) ويقل الفـارق بـين

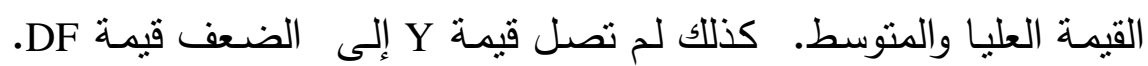
الاتجاه العام ضمن المديات الطبيعية للتنفيذ، دون أن يعني هذا بديلا عن تقييم الأداء. 


\section{r-r الحالة العامة للخدمات العامة}

يتضـح مما تقدم ان مرافق الدولة المعنية بالخدمات العامـة لها الأهميـة

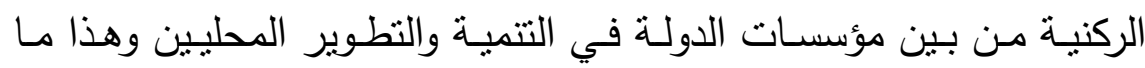
تؤكده تجربة بلدان أوروبا بعد الحرب العالمية الثانية (Eichengreen 1996).

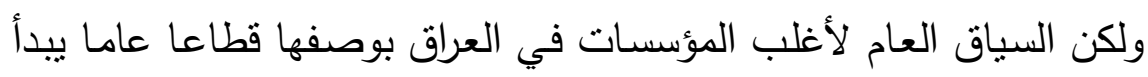
بالمناقنات والمداولات لطبيعة العمل في المكاتب أو على مستوى الإدارات في مقر المحافظة في الموصل والمديريات الرسمية وتتنهي فيها بعد زيارات وكتب رسمية. وبعد مدة، تجد الحكومة المحلية أن الأمور قد ازدادت سوءا

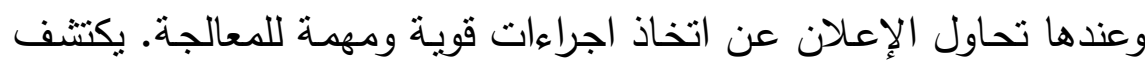
المواطنون بعد مدة قصيرة، وبعده يكتشف الجهاز الحكومي، إن الاجراءات

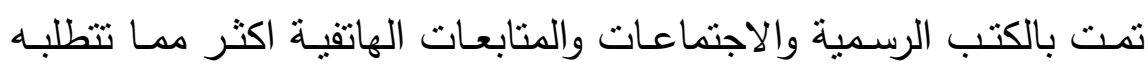

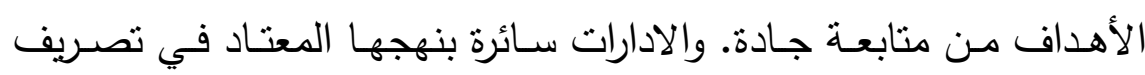
الأمور التي تسير مع النشاط الاقتصادي. لم يكن حتى للعادات والتقاليد البالية تأثير في سير القدرات الحكومية. كان عامل الجذب الرئيس في نوعية الخدمات المبذولة هو السياق الرتيب

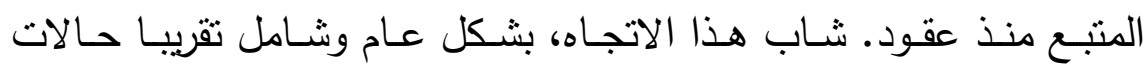
التباطؤ في التنفيذ في جميع المجالات لأسباب آليات العمل الحكومي.

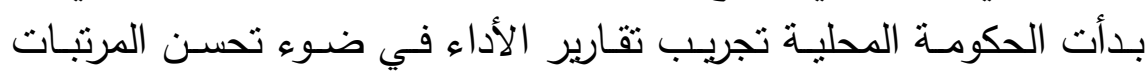

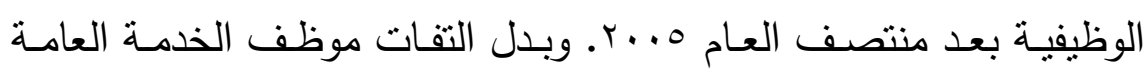

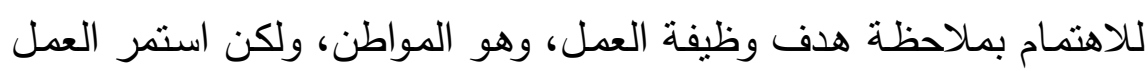
بنظام الروتين. واستمرت حالات البطؤفي مواكبة الاحتياجات من الخدمات

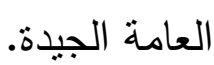
كانت الخدمات بهيكلها الأساسي منتاسبة مـع الحالة الاقتصسادية للأسرة

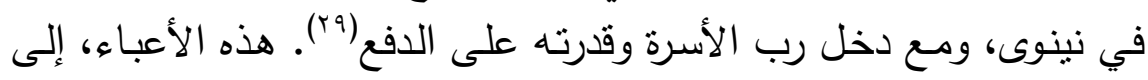

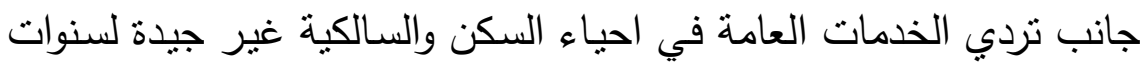




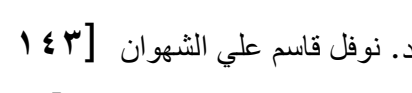
دور الخمات البلدية في التنمية.

طويلة بعيدة عن التحسن وغياب خدمة النقل العام منذ اكثر من عقدين في

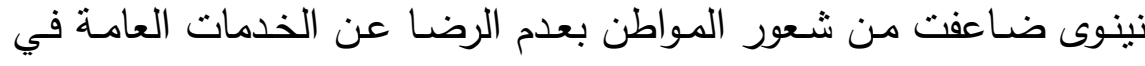

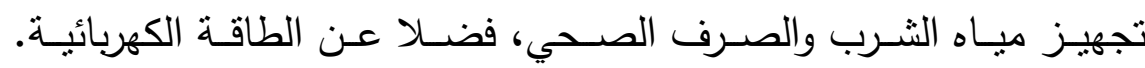

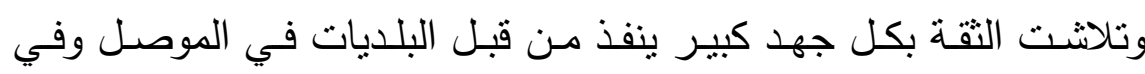

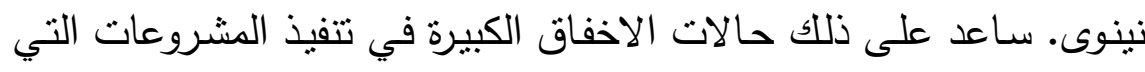
تواكب نمو الحاجات إلى الخدمات العامة. ولم يكن الاعلام المحلي يتفاعل بمسؤولية واضحة للحفاظ على علاقة جيدة مع الجمهور (·r). r-r ملاحظات تقييم ختامية

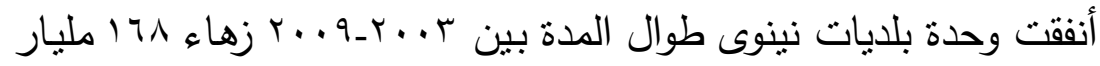

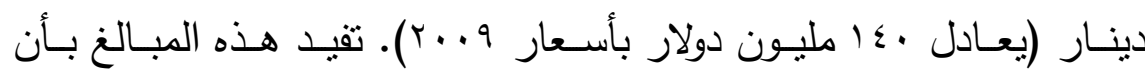

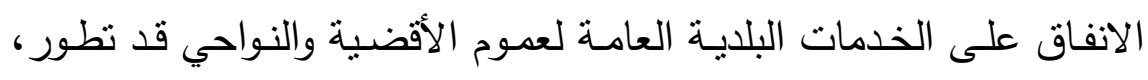

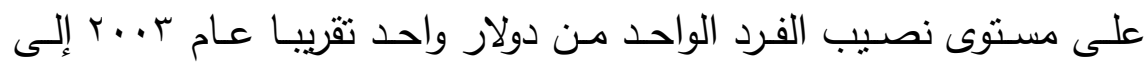

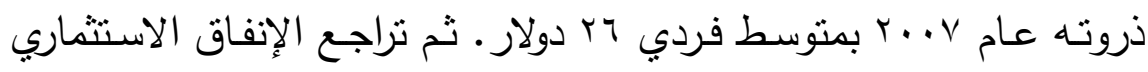
على الخدمات العامة بعد ذلك بشكل ملحوظ.

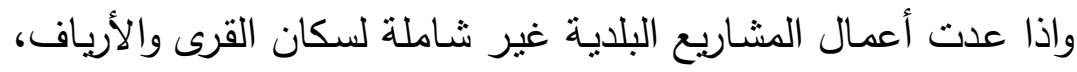
وعلى افتراض أنهم يمثلون نصف سكان أقضية نينوى تقريبا، عدا قضـاء

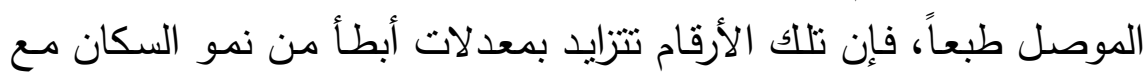
تضخم الأسعار . فكل ما أنفق تراكميا طيلة تلك السنوات بلغ لأن 83962 دينار

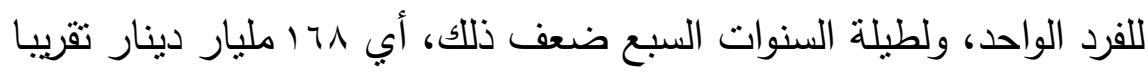

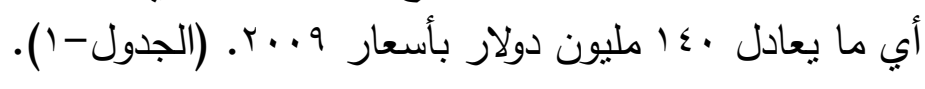

جلول-1: تطور الصرف على الخدمات العامة لبلايات نينوى ونصيب الفرد منه

\begin{tabular}{|c|c|c|c|c|c|}
\hline نصيب & سعر صرف & نصيب الفرد & سكان بلايات & الصرف & \\
\hline الفرد & الدولار & الواحد & نينوى عدا & (ألف دينار) & السنة \\
\hline 5 5(دولار) & 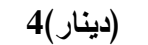 & 3(دينار) & الموصل (نسمة) & & \\
\hline
\end{tabular}




\begin{tabular}{|c|c|c|c|c|c|}
\hline 1 & 1500 & 1421 & 1500000 & 2132005 & 2003 \\
\hline 2.214 & 1500 & 3321 & 1566000 & 5200504 & 2004 \\
\hline 7.323 & 1500 & 10990 & 1630000 & 17913615 & 2005 \\
\hline 13.339 & 1400 & 18675 & 1690000 & 31561000 & 2006 \\
\hline 26.196 & 1400 & 26196 & 1756000 & 46000000 & 2007 \\
\hline 20.251 & 1200 & 24301 & 1822000 & 44276276 & 2008 \\
\hline 9.142 & 1200 & 10970 & 1900000 & 20841000 & 2009 \\
\hline & & $\mathbf{8 3 9 6 2}$ & $\mathbf{2 0 0 0 0 0 0}$ & $\mathbf{1 6 7 9 2 4 4 0 0}$ & ع \\
\hline
\end{tabular}

المصدر: الحقل 1 معلومات المريع - 1 من بيانات واقع الأداء، والحقلين 2 و4 تقديرية من قبل الباحث والحقلين 3 و 5 محتسبين.

في الواقع هذه المشاريع جد متواضعة ولا تخدم عملية التطوير العمراني ولا الحضري للسكان. والكلام بدور حول المشاريع المنفذة وهي لإعادة تأهيل واعمار العراق. وتبقى عملية التتمية ذات تكاليف صيانة مرتفعة مـع التقادم

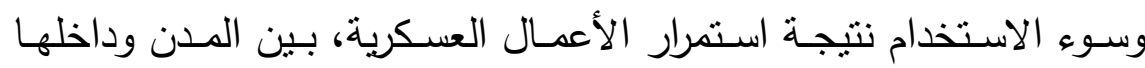
للمساعدة في حفظ الأمن. هنـاك انفاقـات اسـتنمارية أخـرى نفــنها القـوات الأميركيـة مـن خـلال Iraq Relief الوحدات المكلفة بالإعمار ، وهي صندوق اغاثة واعمار العراق anم نينـوى وصـندوق الـدعم (IRRF)

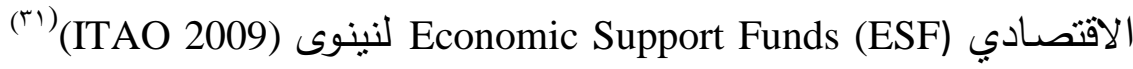
وقد سجلت مبالغ غير قليلة بحاجة لتقييم خاص بها لاحقاً، بسبب إجمال معظم القطاعات الاقتصادية والخدمية تقريبا ببرامج انفاق غير سنوية. 1 - تنمية امدادات مياه الثرب مسألتان مهمتان تستحقان وقفة في وحدة ماء نينوى، هما: ارجاع الاموال

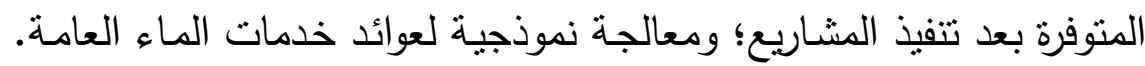

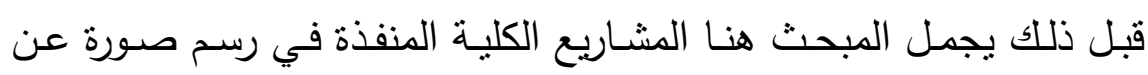
الأداء الاقتصادي في هذا المجال. 


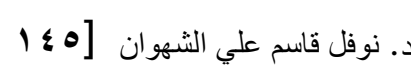
دور الخدمات البلدية في التتمية.

\section{؛ - 1 أداء وحدة الماء وتغطية الإحتياجات}

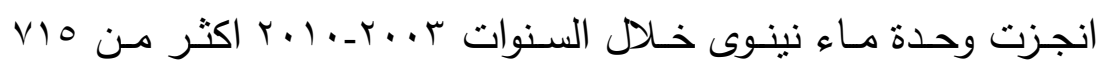

مشروعا نصفها انجاز كامل، والنصف الآخر تراوحت نسب الانجاز فيه بـوات بين

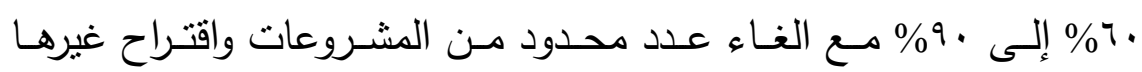
لدواعي الضرورة والسياسـة المائية. تم احتساب أطوال شبكات انابيب الماء

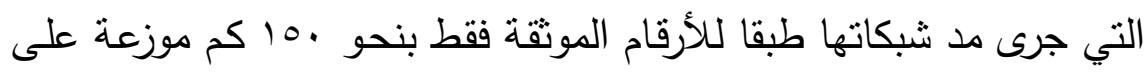

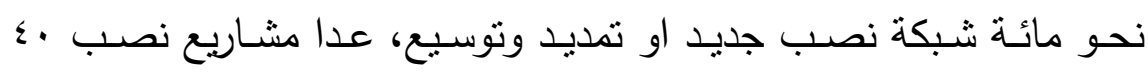

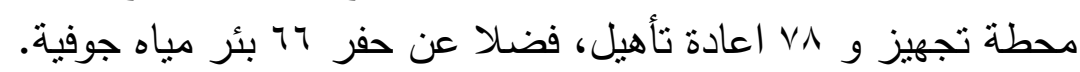

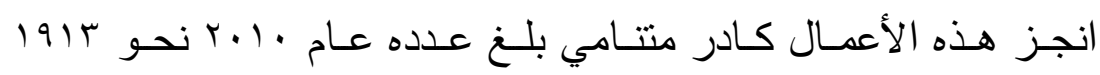

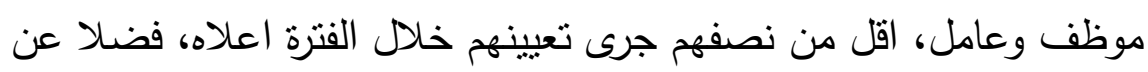

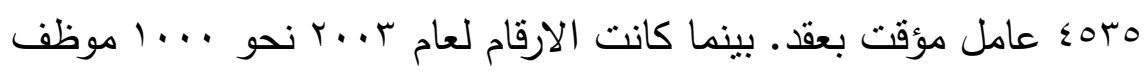
و إOب عامل مؤقت عملوا في هذه الوحدة. سكان نينوى كان عددهم زهاء

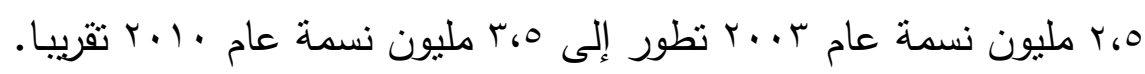

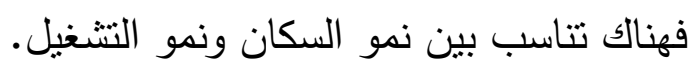

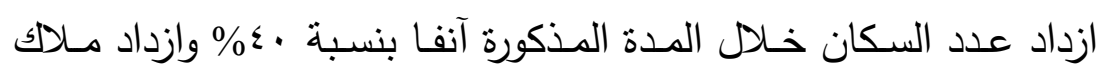
العاملين بنسبة كلية مrVY وهو تطور جيد. فكان نمو العمالة المائية اسرع

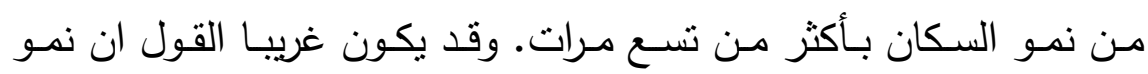

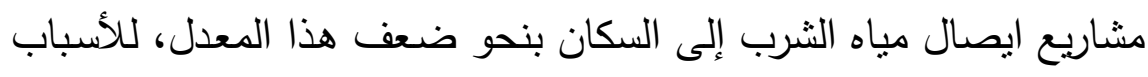
التي سنرد بعد قليل.أو بمقياس آخر نجد من هذه الارقام ان نسبة المبلاهك

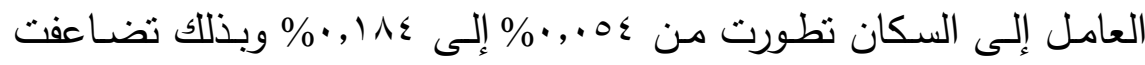

$$
\text { النسبة ع، كـ مرة. }
$$

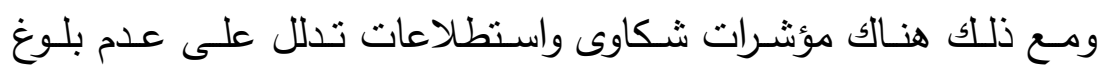

الخدمة العامة في هذا القطاع ما يتتاسب والاحتياجات المنزايد كما والمنزايدة

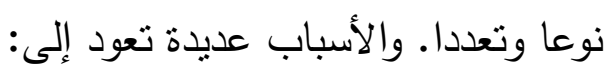


1- ان كل تلك الجهود غطت الزيادات السكانية الطبيعية. r- وغطت الزيادات في الثمول من نحو نصف عدد النكان النهان المحرومين

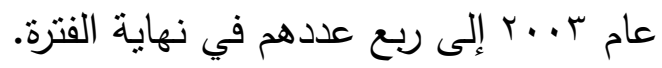

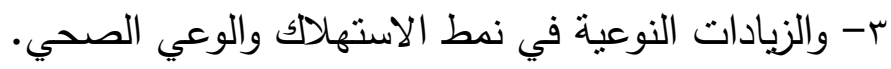

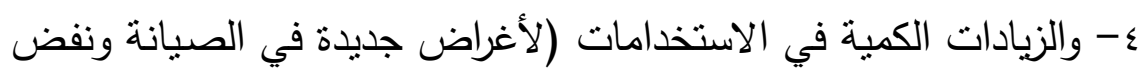

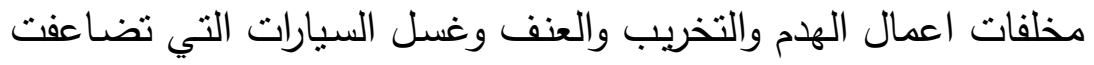

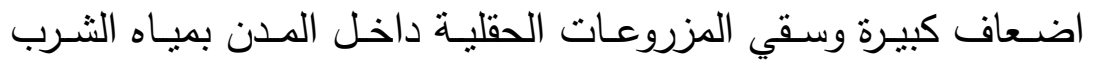

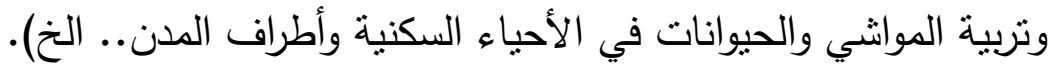

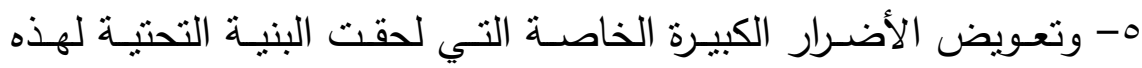
الخدمات بسبب الأعمال العسكرية واستمرارها داخل المدن. 1- وتعويض الإندثار والتقادم في هذه البنية وهي من البنى سريعة الاندثار بالتآكل بالماء نفسه. v- وأخيراً الهدر المتزايد وسوء استخدام المياه بعد غياب الرقابة البلدية التي التي

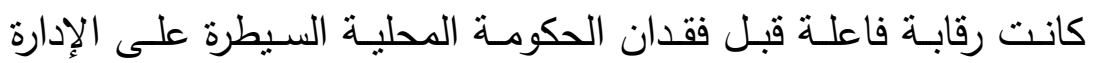

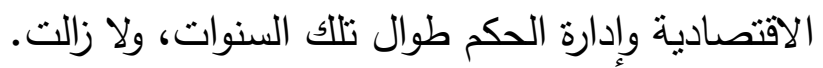

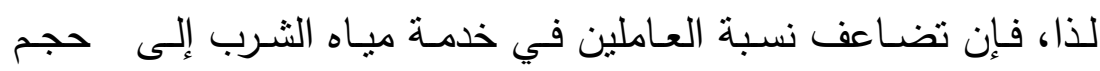

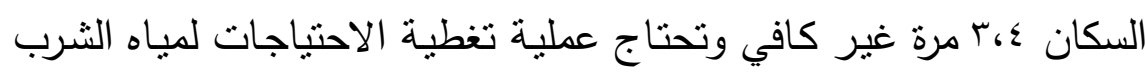

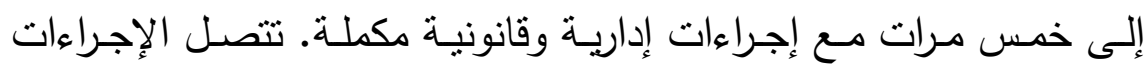

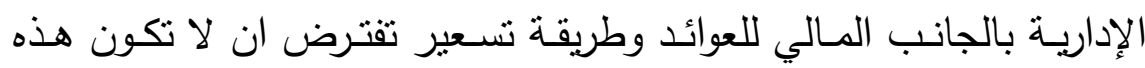

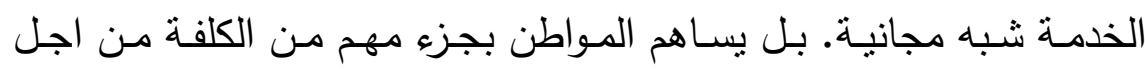

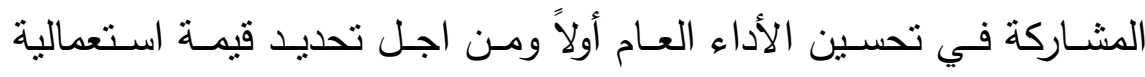

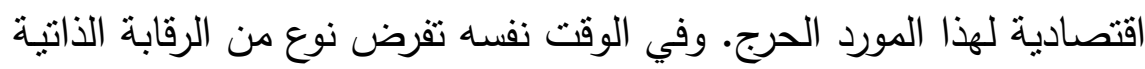

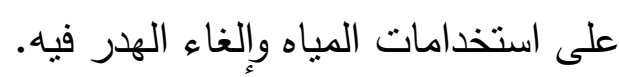
وتتصل الإجراءات القانونية بصياغة اقتراحات تشريعية من قبل خبراء

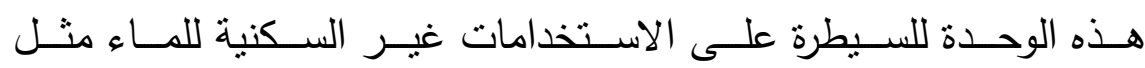


الاستخدامات الواسعة الزراعية والصناعية والورشية وحالات التجاوز على

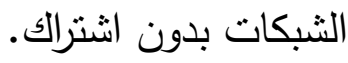

\section{ع - ب الأموال المرجعة}

لوحظت في الفصل السـابق المسألة غير المنطقية في الاستغلال غير الكامل للموارد المالية المتاحة وإعادة جزء متروك من الرصبد المالي المتاح

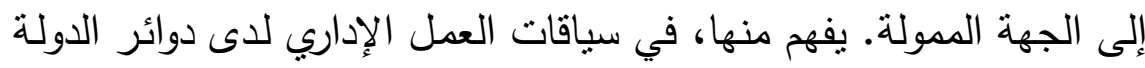

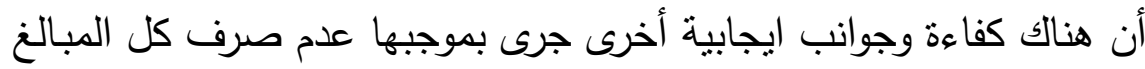
المحولـة للتنفيذ. وفي الوقت ذاتـه تبرر الوحدات الحكوميـة قصور اكتمـال تحقيق الأهداف المحددة لأعمالها، في الغالب بعدم كفاية التمويل.

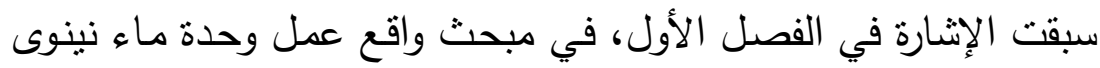

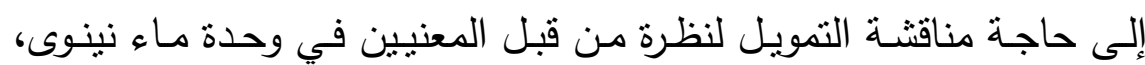
المبالغ المحولة والمبالغ المصروفة والمرجعة. ومـن المعروف جيدا لـى الجميع الجهود التي تبـلل مـن قبـل مسؤول

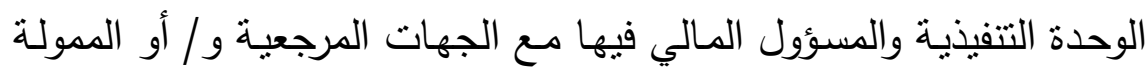

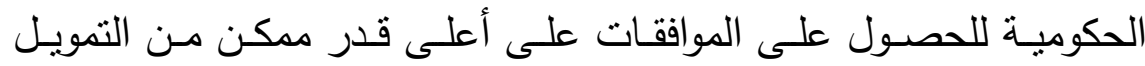

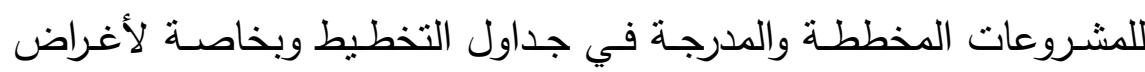

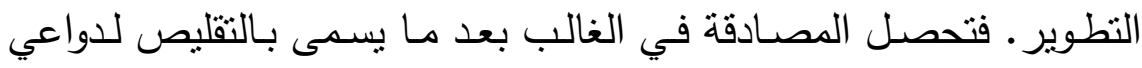

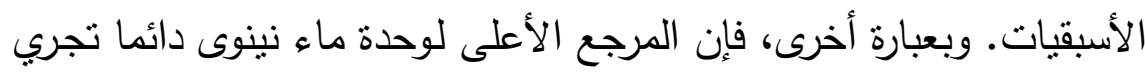
تخفيض على المبالغ المقترحة لإدارة مشاريع المياه.

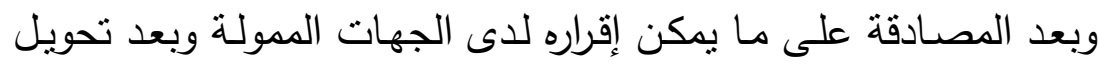

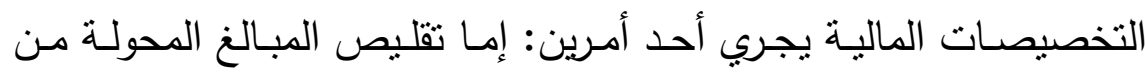

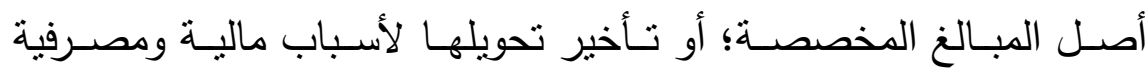
وتمويلية للميزانيات العامـة لدى الجهات الأعلى. ويجري تبرير ذلك برغم الجهود السابقة في الإقرار بأن الوحدات الفرعية تبالغ في الغالب بخططها 
واحتياجاتها. وما لا يذكر في الحقيقة هو مسألة الكفاءة المالية والفنية في

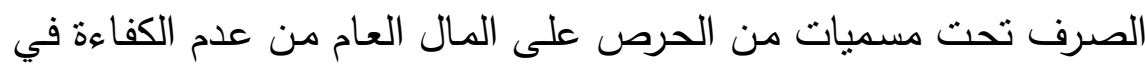

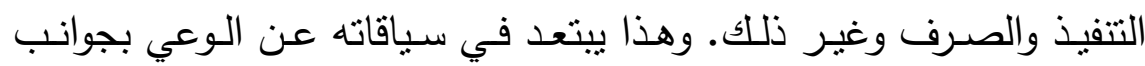
التتمية والتطوير وأهينها في التتمية الاقتصادية بعامة.

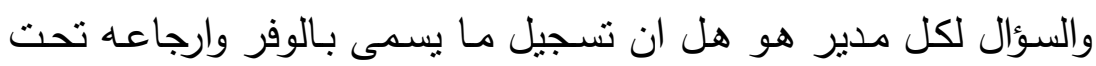

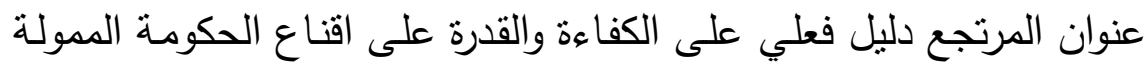

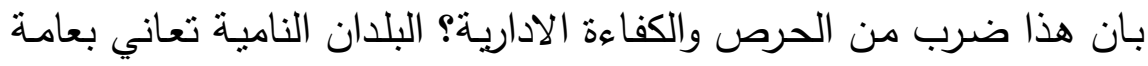

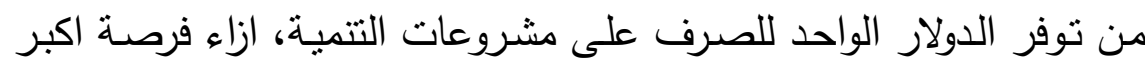
في تحقيق الأفضل في العمل.

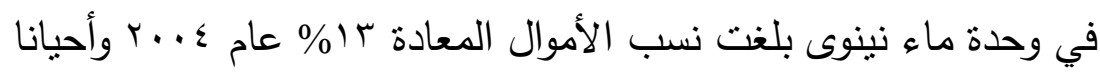

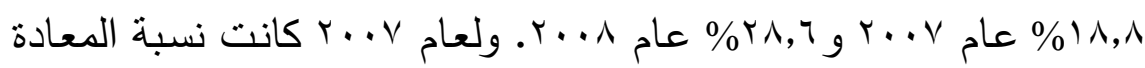

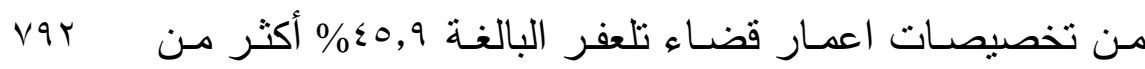

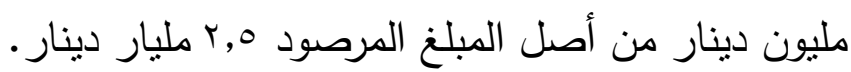

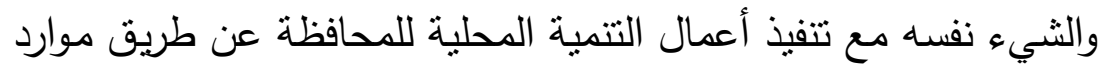

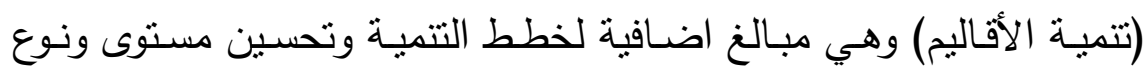

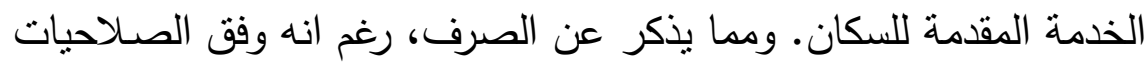

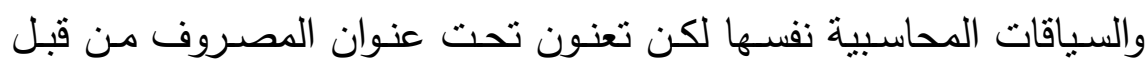

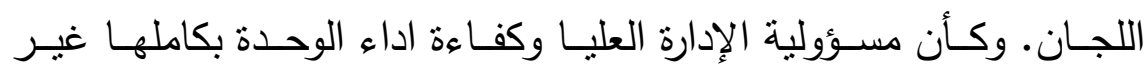

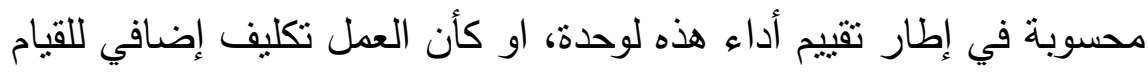
به بهانب أعمالها. في الحقيقة ان أعمال التطوير والتتميـة جزء لا يقل أهميـة عن أهميـة

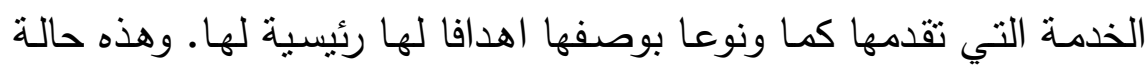
عامة لكل الوحدات الحكومية ولا تقتصر على الوحدة الحالية قيد الدراسة.

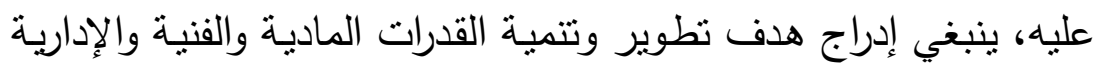
ونمو الوحدة مع النمو السكاني والنطور النوعي للخدمة عالميا من صميم 
واجبـات الوحدة. فالسياقات الدارجـة مـن الأعـراف التقليديـة لأعمـال دوائر

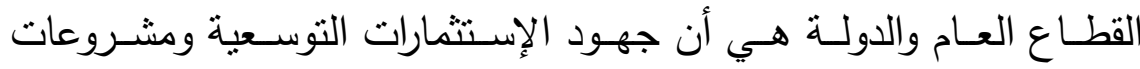

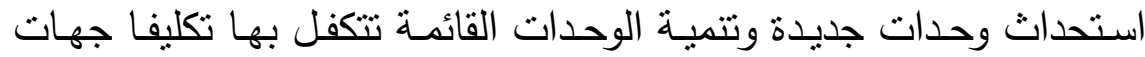

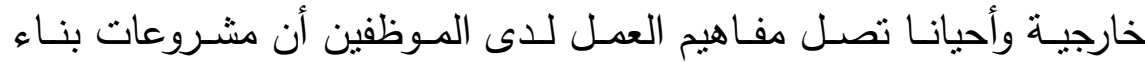

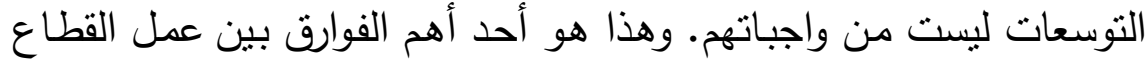
الخـاص والعمل السـائد لدى القطاع العـام في البلدان الناميـة Poulson) .$\left.^{(r)} 1994\right)$

يمكن لبعض الوحدات احالة تنفيذ الأبنية والأقسام وأعمال البناء بشكل

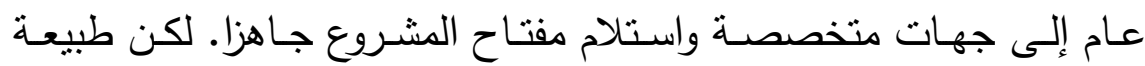
تأهيل وتطوير العمل من ورش ومعامل تخصصية ومختبرات او محطات ومراكز ووحدات تتفيذة ملحقة هي من أصل التطور المطلوب للوحدة نفسها

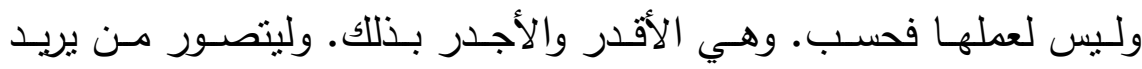
الحرص أن عائدية البنى المادية للمدير، فليفكر كيف أن المدير عليه تتفيذ ولافيذ

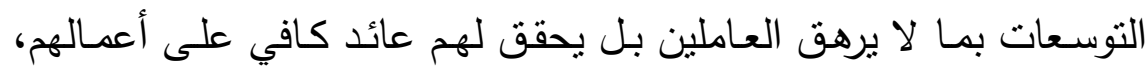

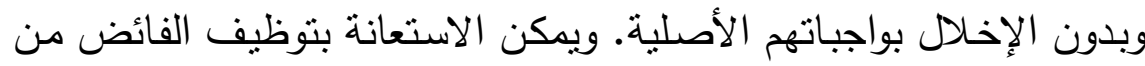

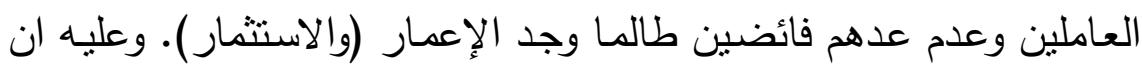
يجعل ذللك من صميم اهدافه وتطلعاته لنمو الوحدة التي يقودها وبطورها. هذا المسار هو التطور الذي يقيس جودة الأهداف وجودة الأداء. فالبناء والنمو هو نمو وتطور الأهداف كما ونوعا.

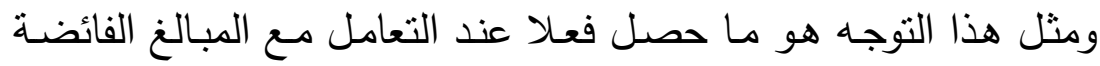

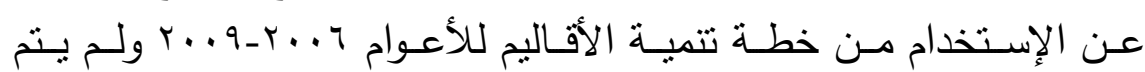
ارجاعها، وهو ما ينبغي اتباعه في كل الميزانيات المناحة من قبل الوحدات الخدماتية في المحافظة وفي أنحاء العراق كذللك. 
كذلك لوحظت في الفصـل السـابق مسـألة شــة المـوارد الماليـة لقطـاع

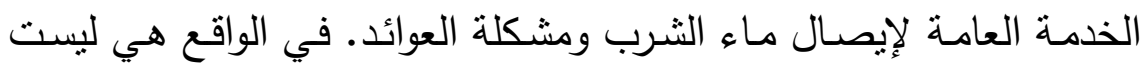

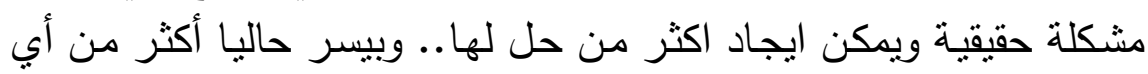
وقت مضى. نقطة البدء هي في التحسن العام في مدخولات الأسر وبساطة

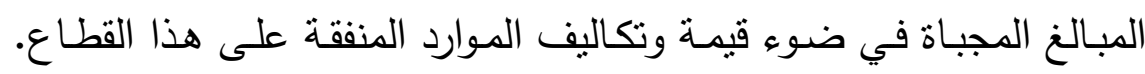

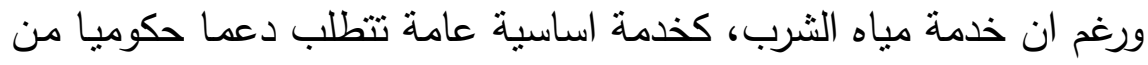
موارد الدولة ايا كانت، ريعية او ضرائبية او غيرها، فلا بأس من قيمة معينة

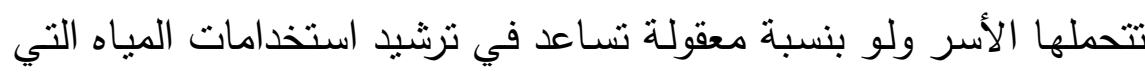

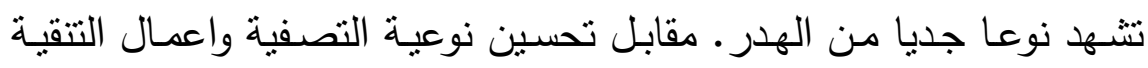

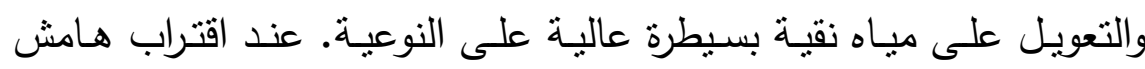

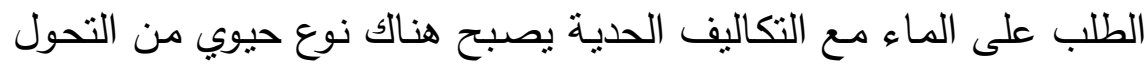

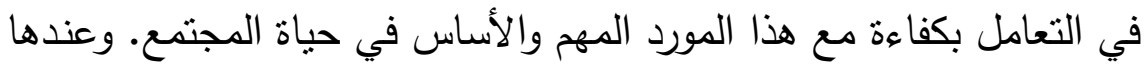

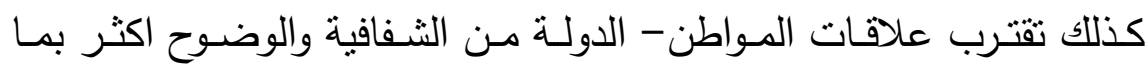
يتلافى مشكلات النوعية والخدمات العامة في مجال الماء وتتحول الثكاوى مئه إلى مسؤوليات مشتركة للتنمية المستدامة مع الجيل التالي.

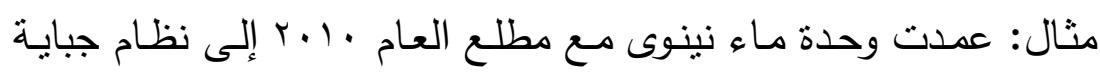

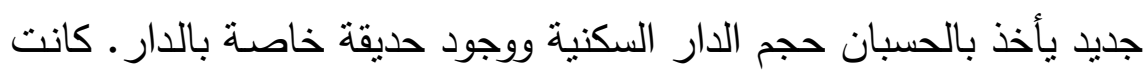

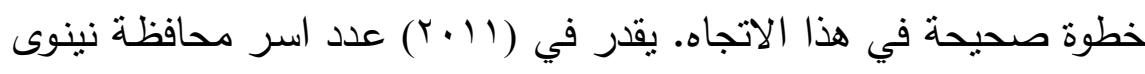
اكثز من نصف مليون أسرة (متوسط حجم الأسرة > افراد)، وكل اسرة تسدد

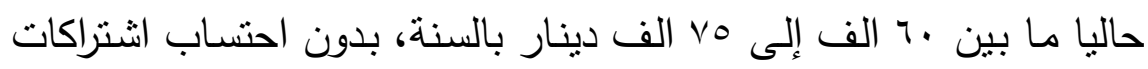
الدوائر الحكوميـة. عليه تحقق وحدة ماء نينوى بالحد الأدنى ثناثين مليار

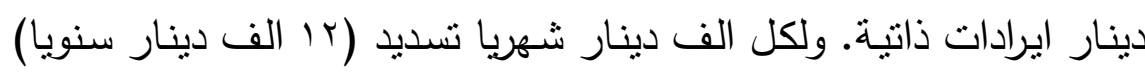

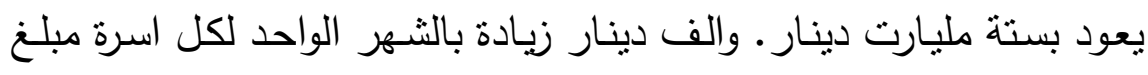
زهيد جدا ولكنه مهم تماما لميزانية الدعم الذاتي. 


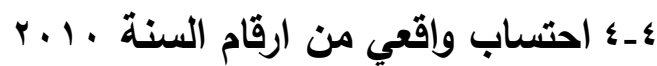

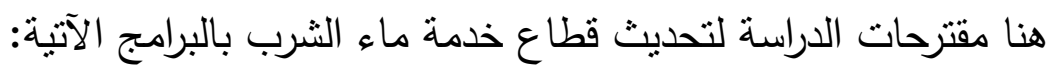

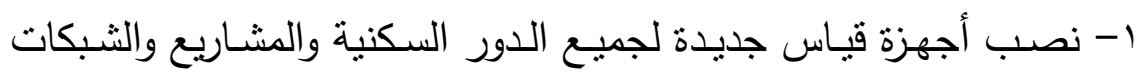

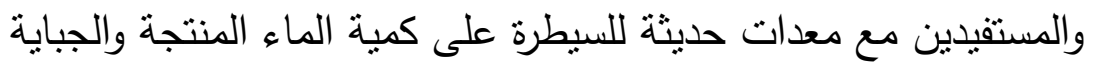
وتقليل والضائعات.

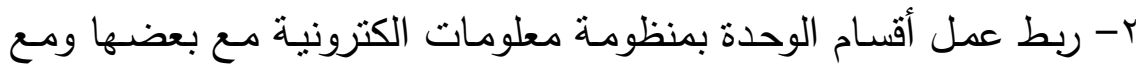

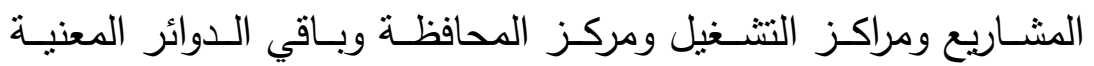
للسيطرة على عمل المديرية.

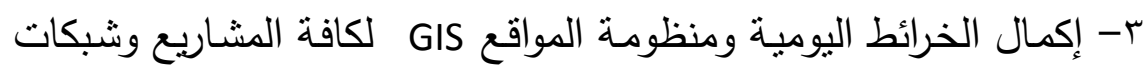

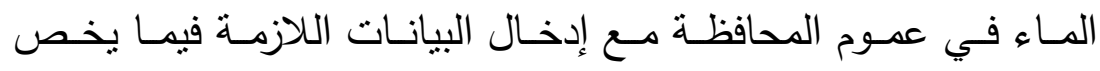
الصيانة والتتفيذ والتتشيل.

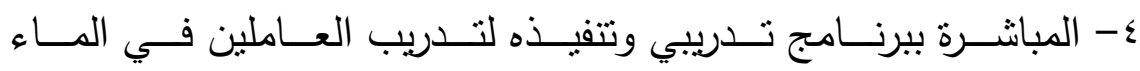
وللتخصصات كافة. 5- توسيع عمل مراكز الثنكاوي في عموم المحافظة بالتتسيق مـع مراكز الصيانة وتوسيعها بما يضمن معالجة الثكاوى يوميا.

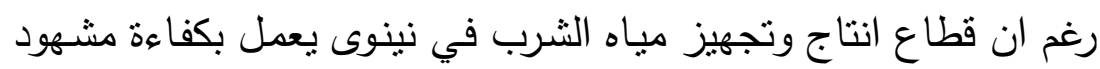

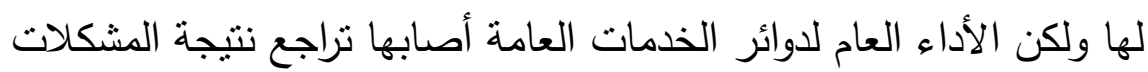

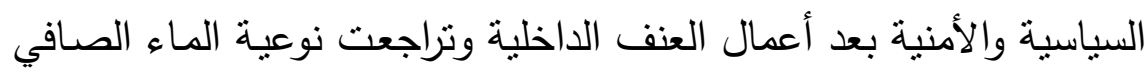

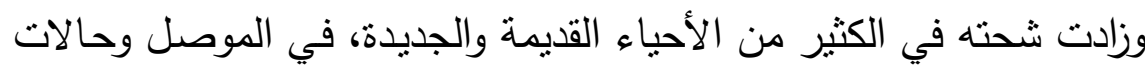

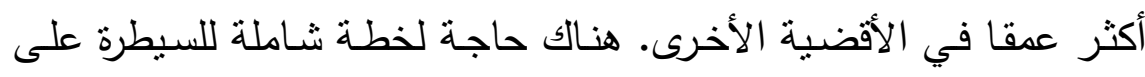

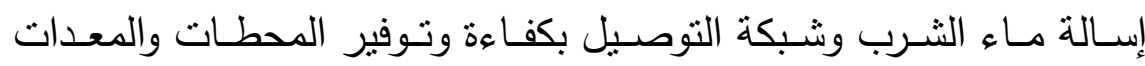

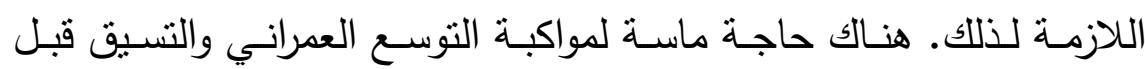

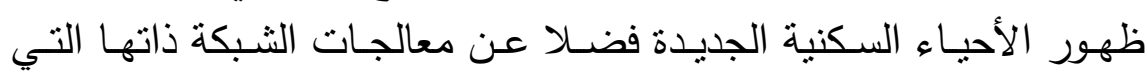


تقادمت وارتفعت تكاليف واعمال الصيانة فيها. اي انها بحاجة لنظوير ونمو التون

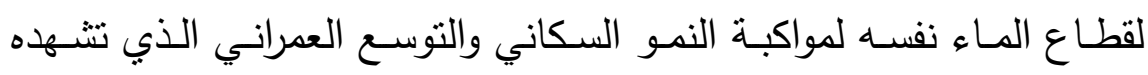

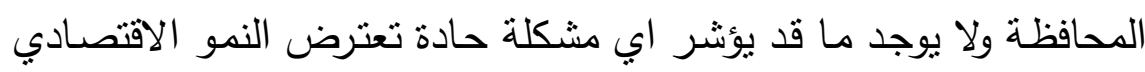
لهذا القطاع بحد ذاته.

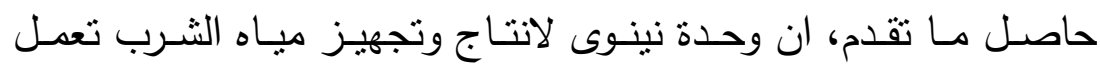

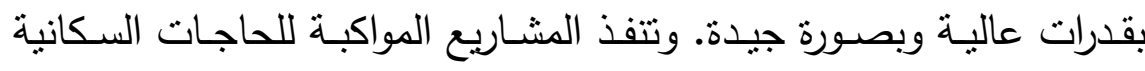

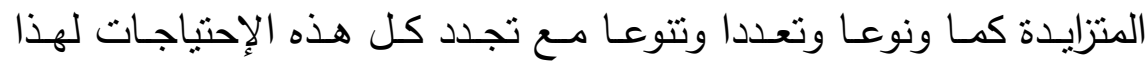

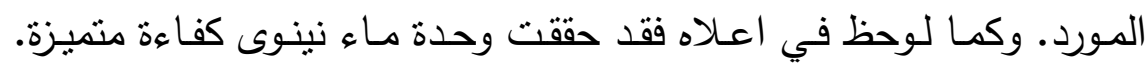
ولكن معايير التتمية الاقتصادية تقتضي: اعلاه 1- ايصال ماء الثرب لأعلى نسبة ممكنة من السكان في اقصى الفي المناطق والقرى والارياف.

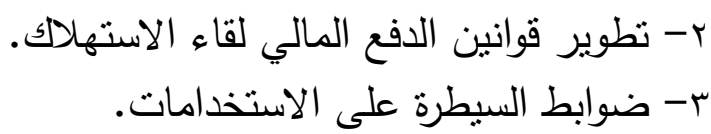

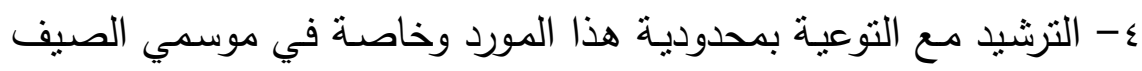

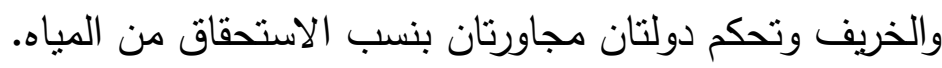

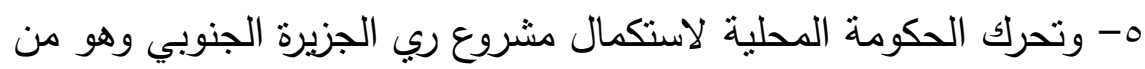
اهم المشاريع الاستراتيجية.

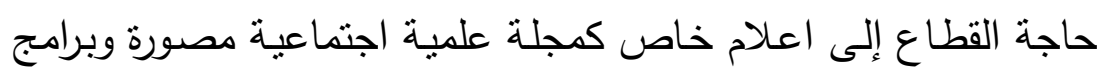
فضائية مباشرة عن تفاصيل مشكلات وايجابيات العمل مع شفافية التعامل مع السكان في المعلومات.

$$
\text { 1- أداء شبكات الصرف الصحي }
$$

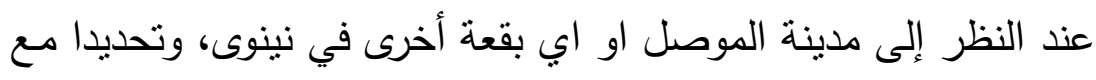

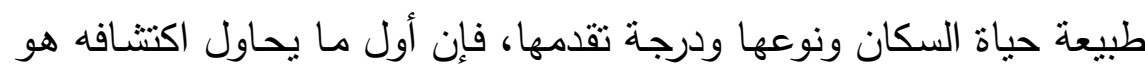

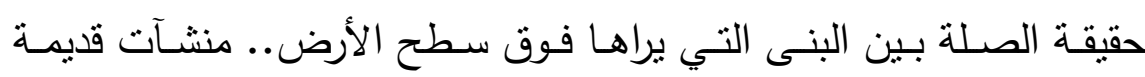




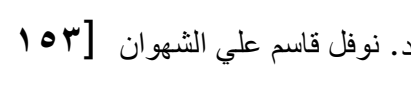
دور الخمات البلدية في التنمية.

ومتقادمــة ومؤسسـات متعبـة. مـع الأسـس التحتيـة والبنى الهيكليـة للمعـالم

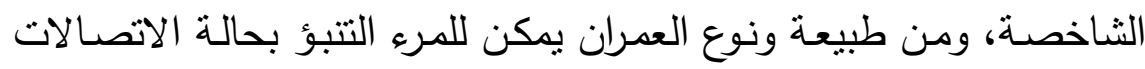
الهاتفية وقابلوات الإثارت الضوئية وجودة الطرق الممتدة، والثوارع الرئيسة والفرعية وربما الأسس التي بنيت عليها كذلك.

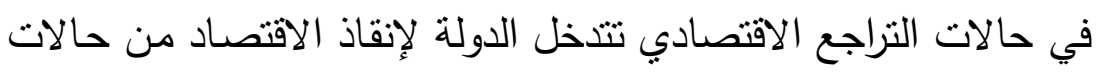

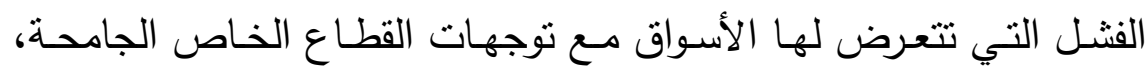

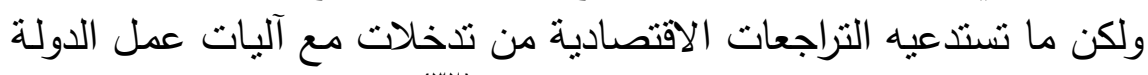

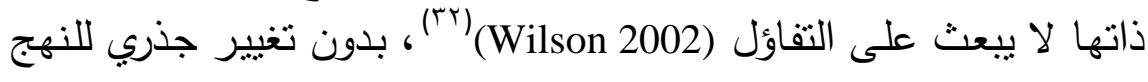

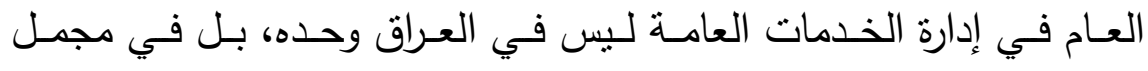

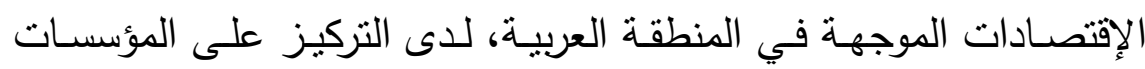

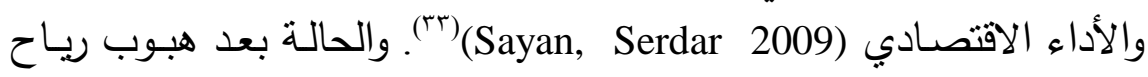

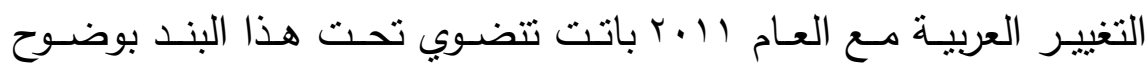
(World Bank (Etheredge 2011) (2011) وما لا يمكن التنبؤ به في العراق هو حالة تعرف بدورة الماء في المدينة

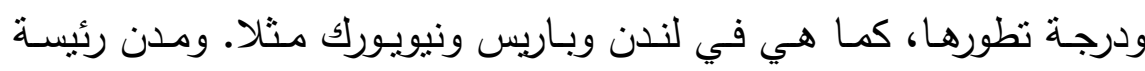

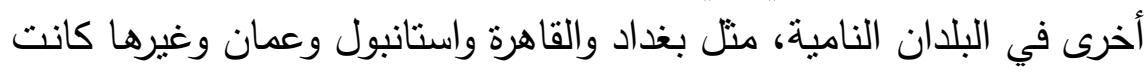

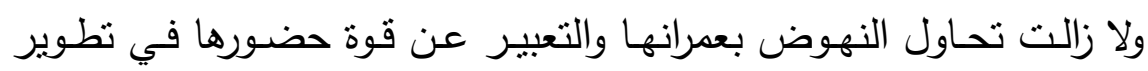

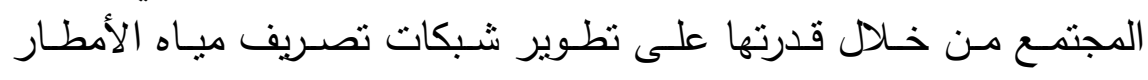

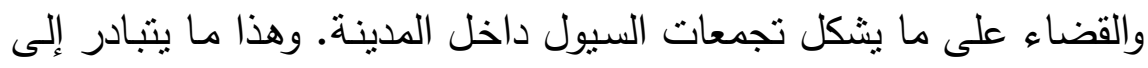

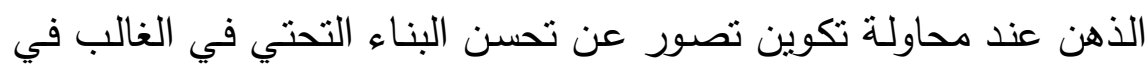
مواسم هطول الأمطار وخلاولها.

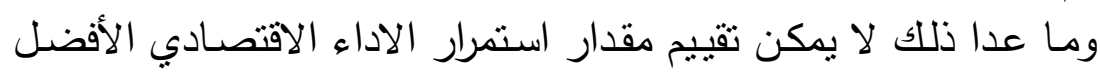

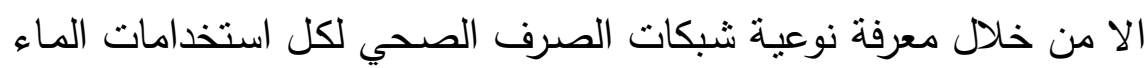

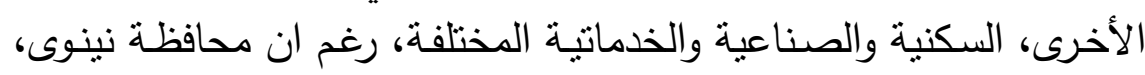

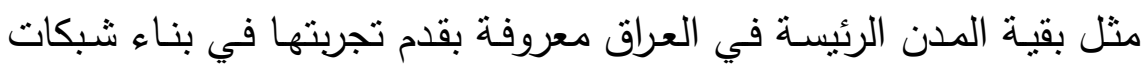


تصريف مياه الأمطار • والسؤال هو : إذا كانت الدولة دومـا تقدم كل شئ

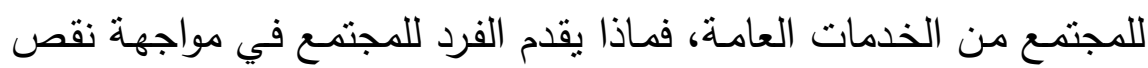

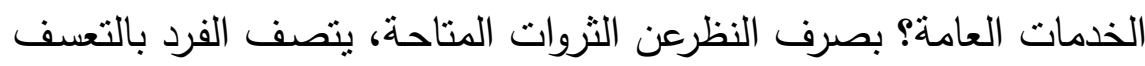

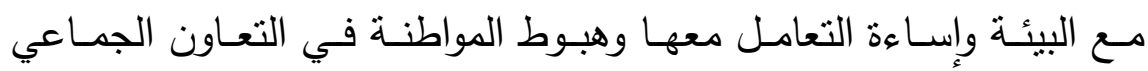

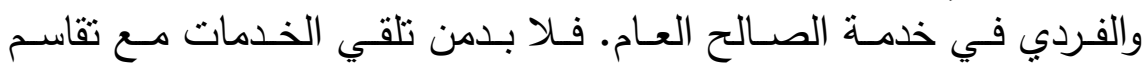

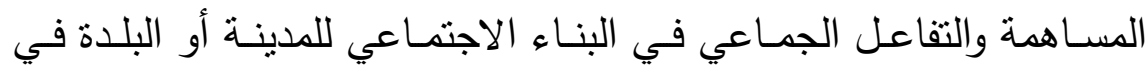
الحفاظ على البيئة قبل صيانتها، ولابد من المشاركة بالمسؤولية والتكاليف.

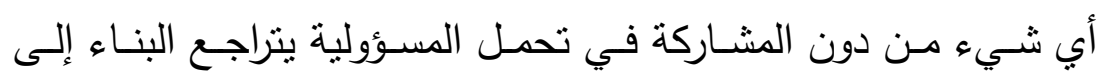

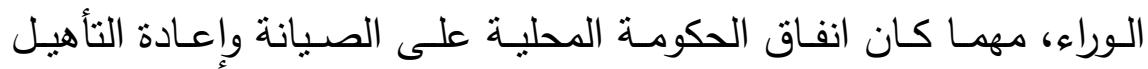
واللحاق بالركب، والتحسينات. ذللك التقاسم للمسؤولية هو الأسـاس الحقيقي الوحيد لأي بناء مستدامة، وكذلك لأي بنية التحتية وفوقية.

\section{ــ الإنفاق على مشروعات شبكة المجاري}

لنتناول التمويل السنوي المركزي على الميزانية المحلية في نينوى: 2003 \$ $32089555(* 1500)=$ Thousands ID 48134332.500

2004 Invest. Th.ID 549949.975

الف دينار

2005 Invest. Th.ID 5376575.2

الف دينار

2005 Dev. \$ $999959(* 1500)=$ Th.ID 1499938.500

2005 Assist. \$ $13662(* 1500)=$ Th. ID 20493.000

2006 Dev. ..

2006 Reg. Dev. Th.ID 39057132.688

2007 Dev.

2007 Reg. Dev. Th.ID $25894537.64 \quad$ ألف دينار

2008 Reg. Dev. Th.ID 15673000 ألف دينار

2008 Invest. M.ID $1774.4=$ Th.ID 1774400

2009 Reg. Dev. Th.ID $15498000 \quad$ ألف دينار 


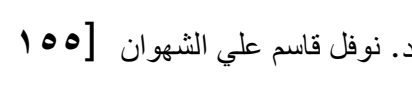
دور الخمات البلدية في التنمية.

Sub. SUM= Th.ID $153478359.503=$ ID 153478359503

2009 Tellafer ID 373503000

2010 Reg. Dev. ID 12439000000 المقرة لعام · · · ألف دينار 2010 Reg. Dev. ID $104620000002010 \quad$ 2010 Isnad Th.ID 1145182.5 الف دينار= ID 1145182500

Total SUM = 167436045003

المجموع الكلي للمبالغ 167 مليار و 436 مليون دينار لثــان سنوات بين

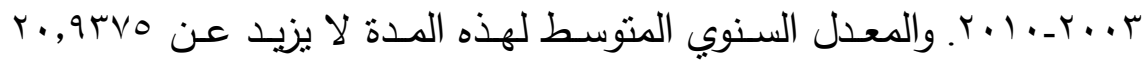

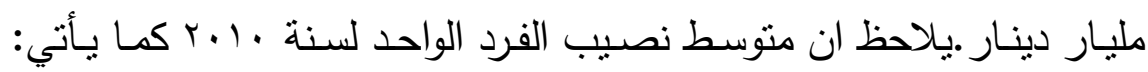
ف في السنة §00ب دينار وهي أقل من ثلاثة دولارات، وحصة الفرد الواحد لعام

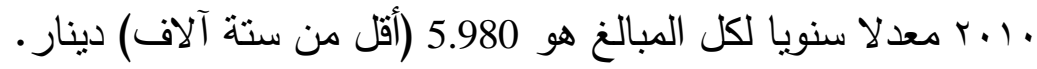

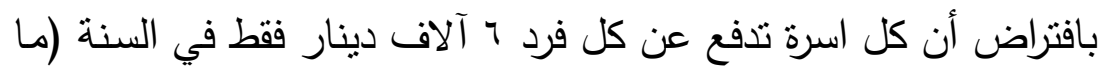
يعادل 5 دولارات فقط) عن البنى التحتية (شبكات المجاري) يكون مجموع

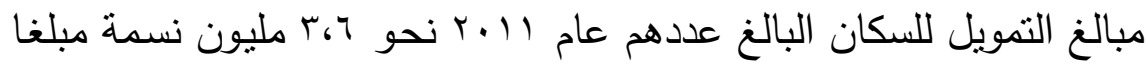
قدره 18 مليون دولار وهو يعادل 21.6 مليار دينار .

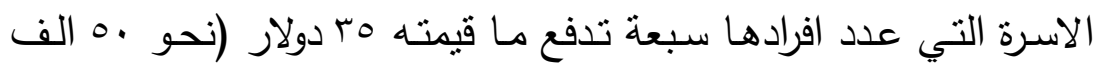

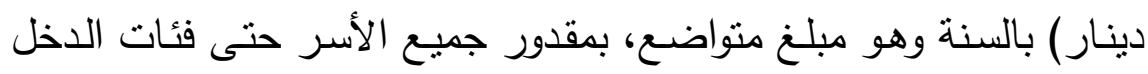

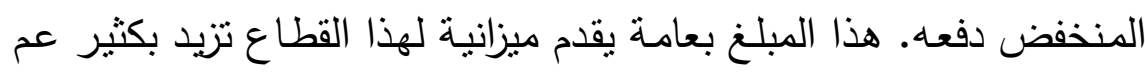
تخصصه الدولة للقطاع الاستثاري فيه.

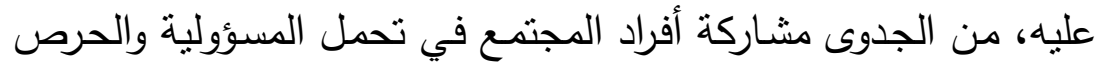

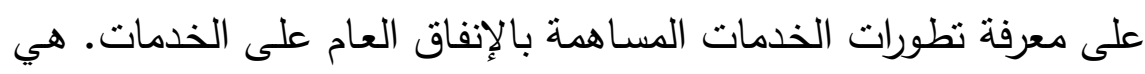
ليســت ضـريبة وان عـدت ذلك فهي مشـروعة وضـرورية للإنمـاء ومبـررة

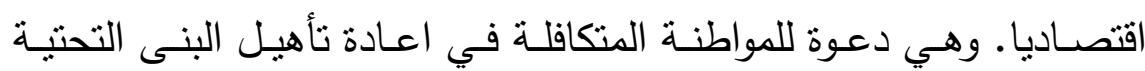




\section{1- الاستتتاجات والمقترحات}

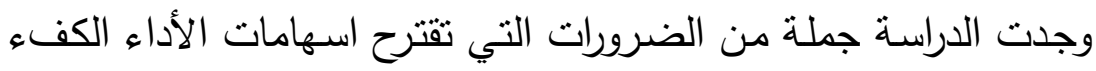

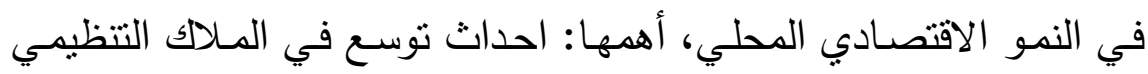
باتجاه تغيير شـعبة النفايـات الصلبة ومعها وحدة التظبفيات ضـمن نتظيم

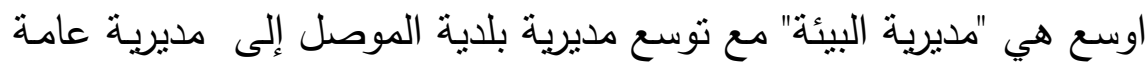

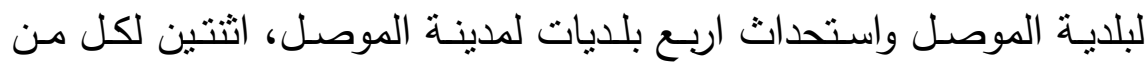

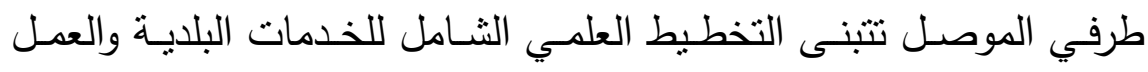

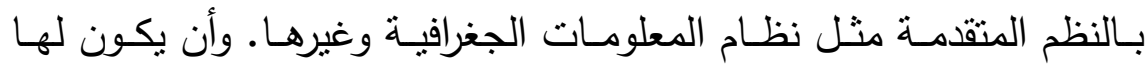
إصدارات إعلامية دورية ورقية والكترونية واذاعة خاصة وموقع مفتوح على ولى

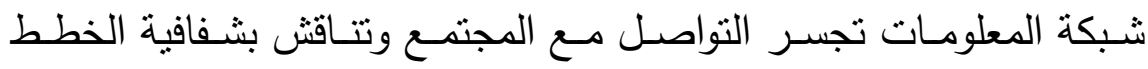
والبرامج. تبني مقترح معالجة النفايات والحاجة الملحة لزيادة أعداد معامل ولتهل

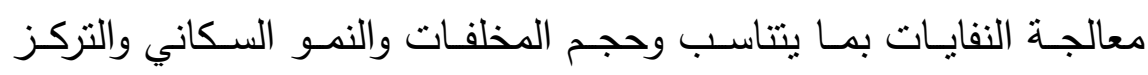
الحضري.

إلى جانب بقاء تكاليف الاستثمار في البنى التحتبـة والفوقيـة للخدمات

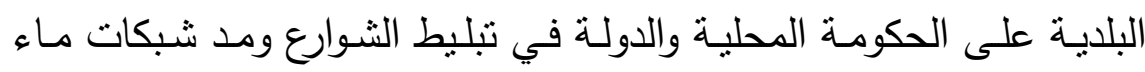
الثـرب واقنيـة الصـرف الصـحي والمعامـل والمنشـآت والأجهـزة والمكـائن

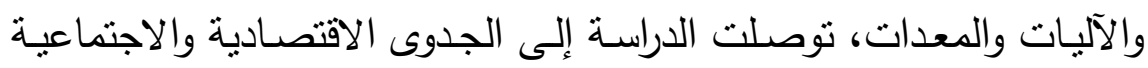
لتعويم تكاليف الخدمات البلديـة في مجال التتظيف بسـب النيات النفايات ومـاء الشرب ومياه الصرف الصحي في الاستهلاك واهميتها للتنمية والتطوير .

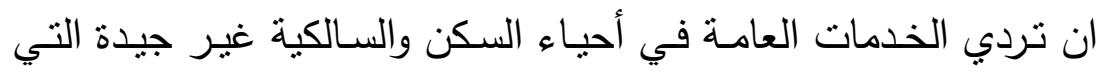
امتدت سنوات طويلة بعيدة عن التحسن إلى جانب غياب خدمة النقل العام

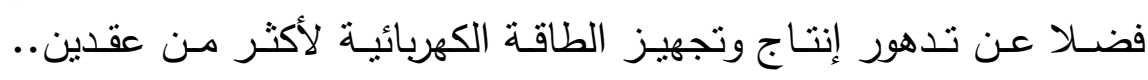
ضاعفت شعور المواطن بعدم الرضا عن الخدمات العامة وبخاصـة تجهيز

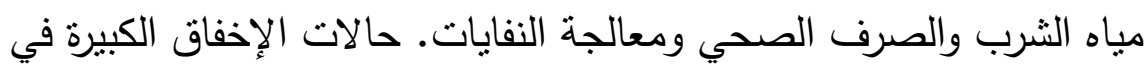
تتفيذ المشروعات التي تواكب نمو الحاجات إلى الخدمات العامـة. ولم يكن 


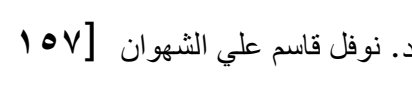
دور الخدمات البلدية في التتمية.

الإعلام المحلي كاف ولم يتفاعل بمسؤولية واضحة ويقدم المصداقية عن

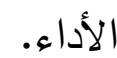

ونمو الإنفاق على مياه الثرب في الأرياف جيد وكذللك نمو التشغيل جيد

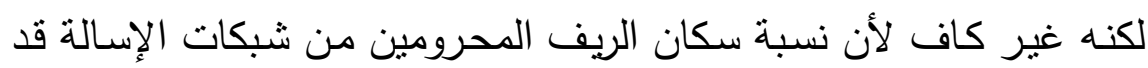

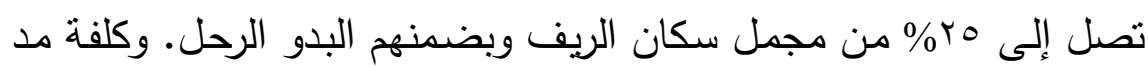

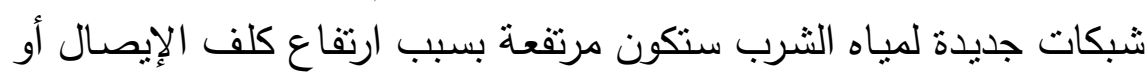

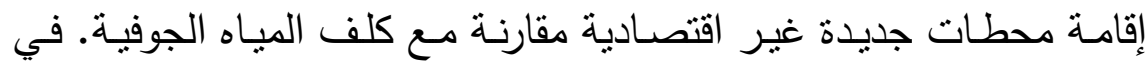

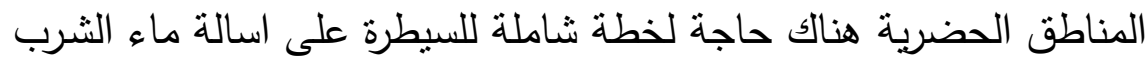

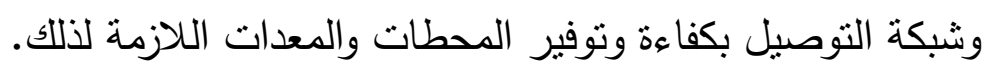

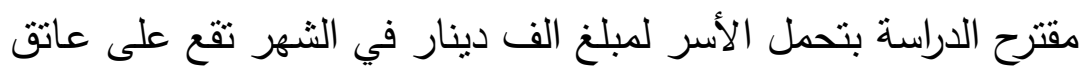

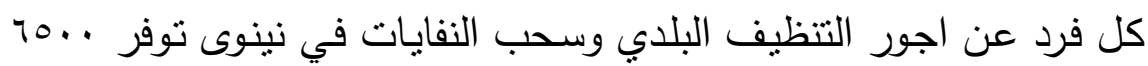

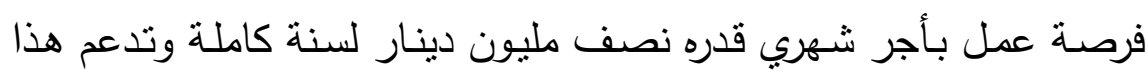

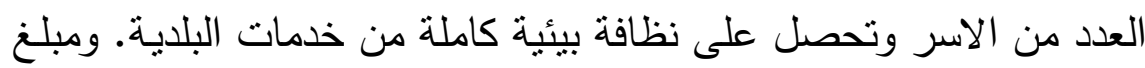

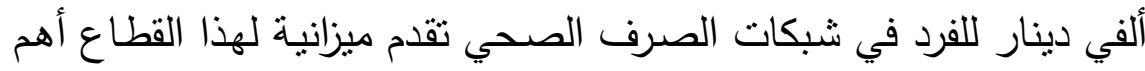

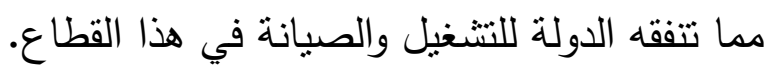

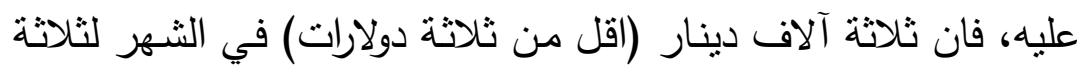

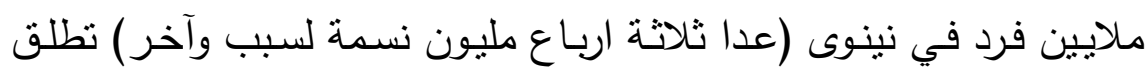

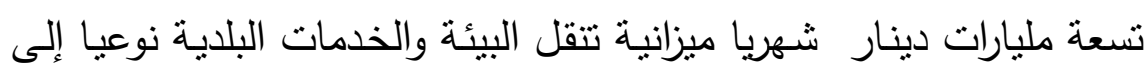

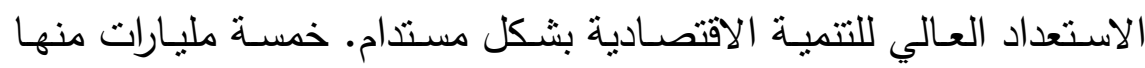

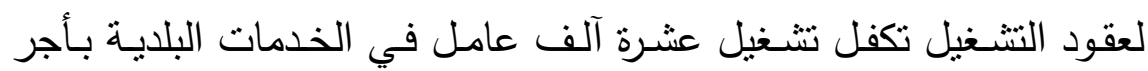

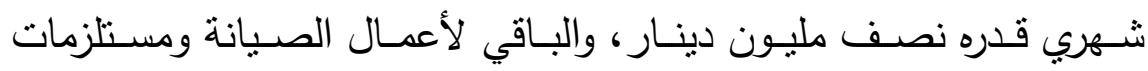

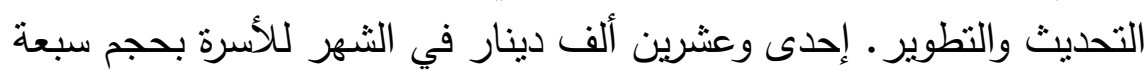

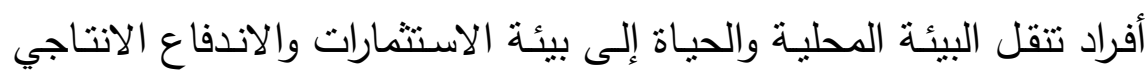
والمزيد من فرص العمل والتطوير . 


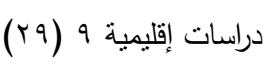

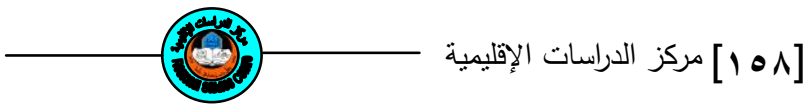

\title{
The Role of MunicipalServicesin Local Economic Development
}

\author{
Nawfal K. Ali Shahwan \\ Department of Economic \& Social Studies, The Centre for Regional \\ Studies, The University of Mosul
}

\begin{abstract}
This paper aimstoanalyse the role ofthe publicmunicipal servicesinlocal economic developmentof Nineveh Governorate,for 2003-2010andsought to identifythe points offailure, to raise theperformance of thesubsequent years. It isassumed that thetraditional mechanismsofthe prevailingsystemof workin the public sectorstillcausea lot ofshortcomings, as well as negative aspects oflocal governancesuch as corruption,red tape,manipulation ofpublic money, waste, lowsenseof responsibility andpubliccontrol and accountability.

Usingaquestionnairesurvey data,onthe comprehensivepublic servicesand facilitiesin Nineveh,analysis has stoodat

fundamentalturning pointson the lowefficiency of public servicesand their impactnegatively onthe local economy. It has suggested many urgent gates for prompt remedies.
\end{abstract}

Key words: Municipal services, Public Sector, Economic Development, Mosul Municipal, Nineveh Municipals. 
(1) Alnasrawi, Abbas (1994), The Economy of Iraq: Oil Wars Destruction of Development and Prospects 1950- 2010, Greenwood Press, London.

(2) Ministry of Planning and Development Cooperation MPDC (2008), The Iraqi Strategic Review Board, Iraq Development Strategy 2005-2007, on: http://www.export.gov/iraq/pdf/iraq_development_strategy 063005.pdf

(3) Auty, R. M. (ed. 2001), Resource Abundance and Economic Development, Oxford University Press the United Nations University.

(4) Bajo, Oscar et al. (1999), "Fiscal Policy and Growth, Revisited: The Case of Spanish Regions": www.uclm.es/organos/vic-Investigation/grupsweb/internationeconomics/pdf/pt2002-19.pdf

(5) Demetriades, Panicos O. and Khaled A. Hussein (1996), "Does financial development cause economic growth? Time-series evidence from 16 Countries", Journal of Development Economics, Vol. 51.

(6) Ashure, Ahmed Saqr (2005), "Improving Development Act through Reform of Governing Administration System At Arab Countries, " in: Good Administration Conference in Serve Arab States Development, Jordan, Dead See, 6-7 Feb. 2005.

(7) Dlamini, M.P. (1988), Development, Administrative Reform and the Civil Service: the Case of Swaziland, PhD Thesis, University of Manchester.

(8) World Bank (2011), Water Management Results in the Middle East and North Africa: www.worldbank.org/mna

(9) Ministry of Municipalities and Public work (2010), The General Directory of Sewage, Internal Report.

(10) Al-Khatib I. A. et al (2009). Quality of water and access to it in the Occupied Palestinian Territory. Eastern Mediterranean Health Journal. 
دراسات إقليمية و 9 (

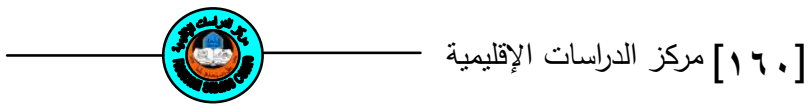

(11) Mulas, Andrés Sanz (2009), Public Policy Analysis in the Water and Sanitation Sector: Budgetary and Management Aspects", in: José Esteban Castro and Léo Heller-eds, (2009), Water and Sanitation Services: Public Policy and Management, Earthscan, London.

(12) Anderson, A. (1981), 'Growth and Stagnation of Economies with Public Goods: aNeoclassical Analysis', in: W.Buhr and P.Friedrich (eds), Lectureson Regiona1 Stagnation, Baden-Baden: Nomos.

(13) Nineveh Governorate (2010), Approve Letter of using the Questionnaire Data of Nineveh Governorate, Issued by Governor Office, Figured 3143, Dated Sept 11, 2010.

(14) Friedrich, Peter and Chang Woon Nam (2009), Economic Declineand Public Intervention: Do Special Economic Zones Matter? In: Roberta Capello and Peter Nijkamp, eds., Handbook of Regional Growth and Development Theories, Edward Elgar- Cheltenham, UK, NorthamptonMA, USA.

(15) Nineveh Governorate (2010), "Vision to Nineveh 2030", Annex of the Book of Round Cities, Mosul.

(16) Bartik, T.(1991), Who Benefits from State andLoca1 Economic Deve1opment Po1icies, Kalamazoo, M1: W.E. Upjohn 1nstitutefor Employment Research.

(17) Eichengreen, Barry (2002), "Institutions and Economic Growth: Europe after World War II", in: Nigholas Crafts and Gianni Toniolo (eds.), Economic Growth in Europe since 1945, Centre for Economic Policy Research, Cambridge University Press.

(1^) تعـد إمـدادات الطاقـة الكهربائيسة أكثر الخـدمات العامـة حيويـة وأهميـة للمجتمـع ولاقتصـاد،

$$
\text { ولخصوصيتها تتطلب دراسة خاصة ومستقلة. }
$$


(19) Al-Kahtani, M.M.S (1989), Regional Development Planning in Saudi Arabia: an Evaluation of Public Service Provision in Asia Region, PhD thesis,Southampton.

(20) Muradian, Roldan, Bishwa Nath Tiwari, Abu Jafar Shamsuddin and Laia Domènech (2009), "The South Asian Experience: Financial Arrangements for Facilitating Local Participation in Water and Sanitation Services (WSS) Interventions in Poor Urban Areas - Lessons from Bangladesh and Nepal", in: José Esteban Castro and Léo Hellereds, Water and Sanitation Services: Public Policy and Management, Earthscan, London.

(21) Gallagher, J. (2008), Baselining Access to Essential Local Public Service Infrastructure in Rural Areas - Rural Dwellers' Perspectives, PhD thesis, National University of Ireland Maynooth.

(r) للمزيد حول التعريف والنطبيق، ينظر: (Yhttp://egsc.usgs.gov/isb/pubs/gis_poster.

(23) Al-Wattar, Obey M. (2010), Population Growth, Urban Expansion and the Quantity of Residential and Commercial Solid Waste in Mosul City 1957-2006, Approved Paper for Publish, Review of Al Rafedain Development, Mosul University, Iraq.

(24) Kutan, Ali M., Thomas J. Douglas and William Q. Judge (2009), "Does Corruption Hurt Economic Development? Evidence from Middle Eastern-North African and Latin American countries", in: Serdar Sayan ed., EconomicPerformance in the Middle East and North Africa : Institutions, Corruption, and Reform, Routledge, New York, 2009.

(25) Maksymenko, Svitlana, and Mahbob Rabbani (June 2011), Economic Reforms, Human Capital, and Economic Growth in India and South Korea: A Co-integration Analysis, Journal of Economic Development, Volume 36, Number 2. 


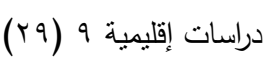

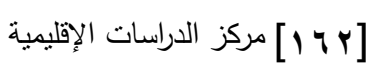

(26) Gleitsmann, B., M. Kroma and T. Steenhuis (2007) ‘Analysis of a Rural Water Supply Project in three Communities in Mali: Participation and Sustainability', Natural Resources Forum, Vol. 31, No 2.

(27) Pike, Andy, A. Rodríguez-Pose and J.Tomaney (2006), Localand Regiona1 Deve1opment, Routledge, Oxon, London.

وزعين في الموصل نحو 1,450مليون نسمة وفي الأقضية والنواحي والأرياف 1,788 مليون

(29) حصلت الأسرة على تجهيز حصنها من المنتجات النفطية مثلا مثل الكيروسين والبنزين والغاز

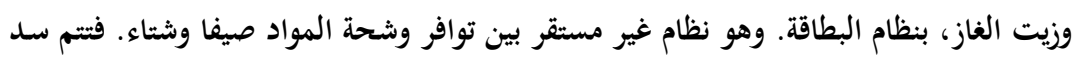

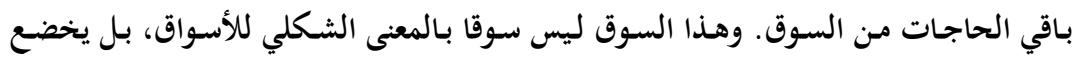

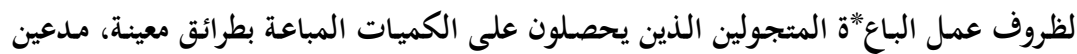

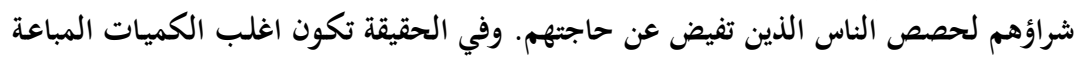

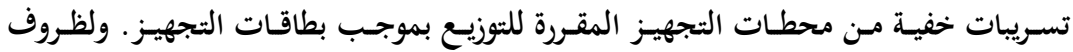

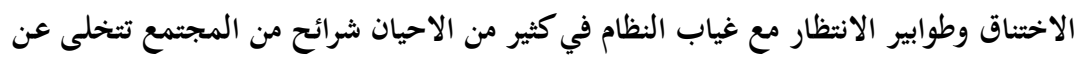

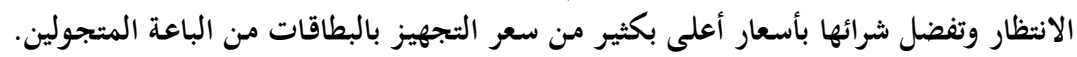

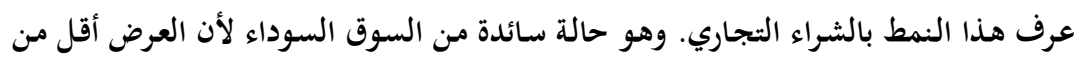

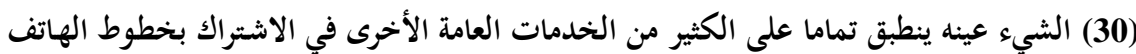

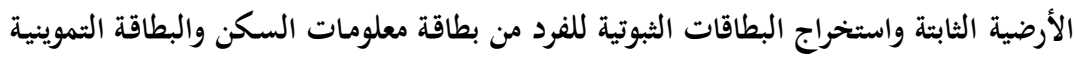

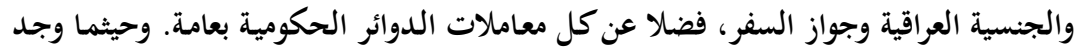

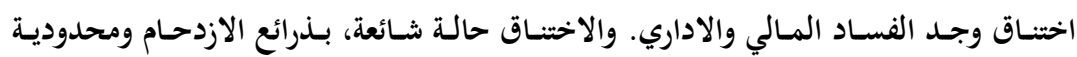

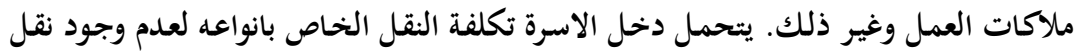

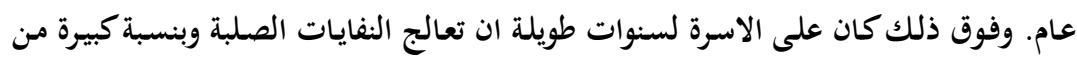

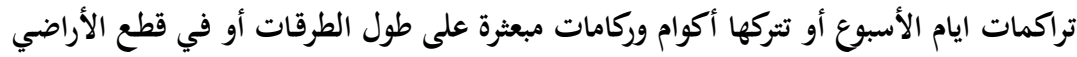

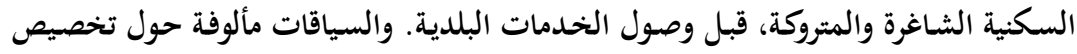

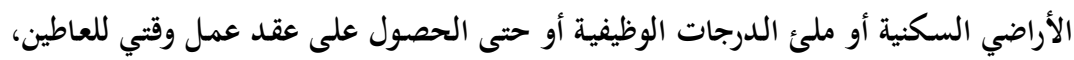

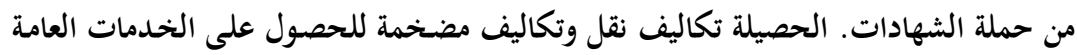

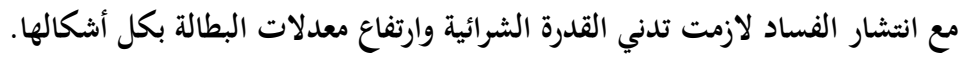


$17 \%]$

ــ د. نوفل قاسم علي الثهوان

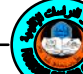

دور الخدمات البلدية في التتمية.

(31) ITAO Information Management Unit, Provincial Fact book, Ninawa, Mosul, June 2009.

(32) Wilson, Rodney (2002), Economic Development in the Middle East, Routledge , First published 1995 by Routledge, London.

(33) Sayan, Serdar (2009), "Institutions and Economic Performance in the MENA Region", in:Sayan, Serdar ed., Economic Performance in the Middle East and North Africa: Institutions, Corruption, and Reform, Routledge, New York.

(34) Etheredge, Laura S. ed. (2011), Iraq, Encyclopedia Britannica, Inc. Britannica Educational Publishing: Middle East- Region in Transition, Britannica in Association with Rosen Educational Services, New York, 15-28.

(35) World Bank, Op Cit. 